UNIVERSIDADE DE SÃO PAULO

ESCOLA DE ENFERMAGEM

MARIANA VIEIRA DE SOUZA

EFETIVIDADE DA INTERVENÇÃO COMPRESSAS MORNAS NA REDUÇÃO DA TEMPERATURA DE CRIANÇAS FEBRIS:

ENSAIO CLÍNICO RANDOMIZADO PILOTO

São Paulo

2020 


\section{EFETIVIDADE DA INTERVENÇÃO COMPRESSAS MORNAS NA REDUÇÃO DA TEMPERATURA DE CRIANÇAS FEBRIS: ENSAIO CLÍNICO RANDOMIZADO PILOTO}

Dissertação apresentada ao Programa de Pós- Graduação em Enfermagem da Escola de Enfermagem da Universidade de São Paulo para obtenção do título de Mestre em Ciências

Área de concentração: Cuidado em Saúde

Orientadora: Prof. ${ }^{a}$ Dr. ${ }^{a}$ Elaine Buchhorn Cintra Damião.

\section{São Paulo}


AUTORIZO A REPRODUÇÃO E DIVULGAÇÃO TOTAL OU PARCIAL DESTE TRABALHO, POR QUALQUER MEIO CONVENCIONAL OU ELETRÔNICO, PARA FINS DE ESTUDO E PESQUISA, DESDE QUE CITADA A FONTE.

Assinatura:

Data:

O presente trabalho foi realizado com apoio da Coordenação de Aperfeiçoamento de Pessoal de Nível Superior - Brasil (CAPES) - Código de Financiamento 001.

\section{Catalogação na Publicação (CIP)}

\section{Biblioteca "Wanda de Aguiar Horta"}

Escola de Enfermagem da Universidade de São Paulo

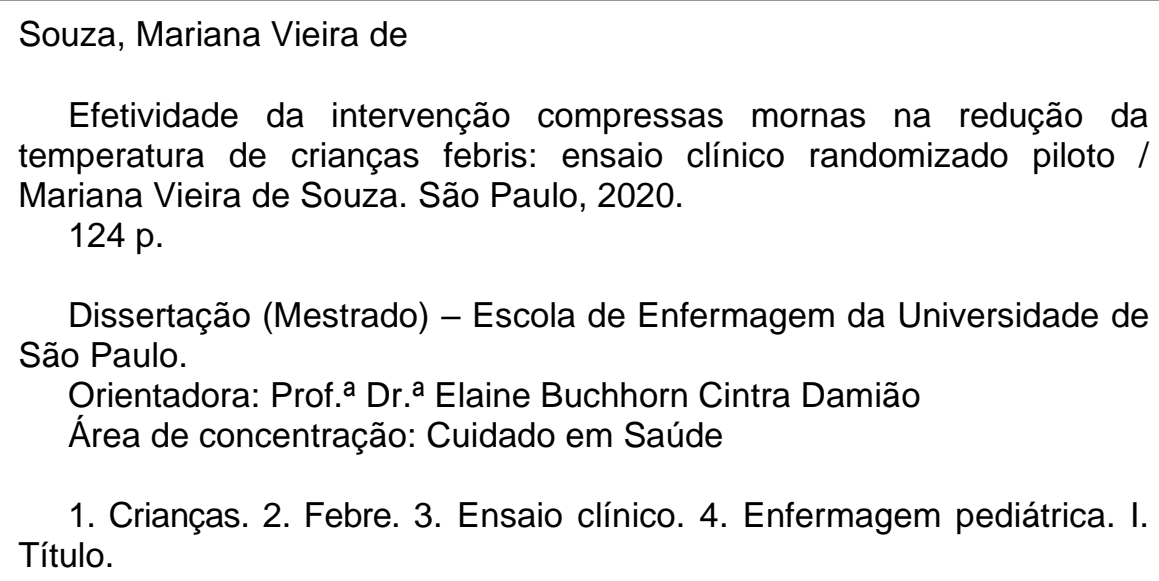

Ficha catalográfica elaborada por Fabiana Gulin Longhi (CRB-8: 7257) 
Nome: Mariana Vieira de Souza

Título: Efetividade da intervenção compressas mornas na redução da temperatura de crianças febris: ensaio clínico randomizado piloto.

Dissertação apresentada ao Programa de Pós-Graduação em Cuidado em Saúde em Enfermagem da Escola de Enfermagem da Universidade de São Paulo, para obtenção do título de Mestre em Ciências.

Aprovado em:

BANCA EXAMINADORA

Orientadora: Profa. Dra. Instituição:

Julgamento: Assinatura:

Profa. Dra. Instituição:

Julgamento: Assinatura

Profa. Dra. Instituição:

Julgamento: Assinatura:

Profa. Dra. Instituição:

Julgamento: Assinatura: 


\section{DEDICATÓRIA}

Aos meus amados pais, Maria e João, pelo amor, carinho e compreensão em todos os momentos da minha vida. Por todo incentivo, esforço e por proporcionarem todas as condições para que me tornasse a pessoa e profissional atual.

Ao meu grande amor, minha filha Isabella, que, em todos os momentos, esteve ao meu lado e, a cada dificuldade, tinha uma palavra de incentivo e conforto para que eu continuasse minha jornada. 


\section{AGRADECIMENTOS}

Primeiramente, agradeço a Deus por sua infinita bondade e misericórdia sobre minha vida, que me capacitou e permitiu que pudesse chegar até aqui.

Agradeço em especial à grande responsável, que me permitiu atingir essa conquista, que, desde o período da residência, têm contribuído para minha formação acadêmica e profissional e, sobretudo, acreditou no meu potencial. Além de professora, eu a considero como uma grande amiga, que soube me compreender nos momentos difíceis e, com muita paciência, me direcionou no caminho a ser percorrido, minha querida Professora Doutora Elaine Buchhorn Cintra Damião.

À Professora Doutora Soraia Marques Buchhorn por colaborar na condução deste trabalho.

À Mestra em Estatística Cíntia Yurie Yamachi por toda paciência em trabalhar com meus dados e pela dedicação em realizar as análises estatísticas para esta pesquisa.

À Chefe Técnica Enf. Dra. Nanci Cristiano dos Santos, responsável pela Divisão de Enfermagem Pediátrica, por me receber tão bem e abrir as portas do Hospital Universitário para condução deste trabalho.

À equipe de enfermagem da área Pediátrica do Hospital Universitário da USP (técnicas, enfermeiras e gestoras), por proporcionarem auxílio na coleta de dados e me acolherem com tanto carinho, em especial às enfermeiras que se engajaram na coleta de dados.

Aos residentes de enfermagem da área pediátrica que me apoiaram e auxiliaram na coleta de dados.

À minha querida equipe do Hospital Leforte (Andréa, Edneide, Gioconda e Patrícia), que me apoiou nos momentos de estresse e tensão, oferecendo um ombro amigo. 
Aos colegas que fiz no mestrado, que me deram suporte psicológico e apoio para enfrentar as dificuldades durante os estudos.

Em especial meu carinho e gratidão a todos as crianças e familiares que aceitaram participar deste estudo, sem os quais, não seria possível a concretização desta pesquisa.

Muito obrigada a todos! 
"Louvarei o nome de Deus com cânticos e proclamarei sua grandeza com ações de graças".

Salmos 69:30 
Souza MV. Efetividade da intervenção compressas mornas na redução da temperatura de crianças febris: ensaio clínico randomizado piloto [dissertação]. São Paulo: Escola de Enfermagem, Universidade de São Paulo; 2020.

\section{RESUMO}

Introdução: a febre é uma entidade clínica comum na infância, sendo responsável por grande parte da procura dos serviços de pronto atendimento e emergência em Pediatria. Objetivos: avaliar o efeito da intervenção "compressas mornas", em associação ao antitérmico prescrito, na redução da febre em crianças hospitalizadas e comparar a variação da temperatura corporal entre os Grupos Controle e Intervenção. Método: estudo piloto do tipo ensaio clínico controlado randomizado, desenvolvido em unidades pediátricas de um hospital de ensino, localizado na cidade de São Paulo, no período de junho de 2019 a janeiro de 2020. A amostra foi constituída por 33 pacientes que apresentaram temperatura corporal $\geq 37,8^{\circ} \mathrm{C}$, faixa etária entre 1 mês e 11 anos, 11 meses e 29 dias. As crianças foram alocadas aleatoriamente em dois grupos: 17 crianças receberam apenas o medicamento antitérmico (Grupo Controle) e 16 crianças receberam o medicamento antitérmico associado à intervenção "compressas mornas" (Grupo Intervenção). A temperatura axilar foi mensurada em quatro momentos durante 3 horas. Para a análise dos dados, foi utilizada estatística descritiva por meio de distribuições de frequências simples, medida de tendência central (média) e medidas de dispersão (variância e desvio-padrão), de acordo com a categorização da variável em estudo. Para a caracterização da amostra em relação a idade, sexo, inserção da criança na pesquisa (momento), local de internação, antitérmico administrado e diagnósticos frequentes, assim como testar a significância desses itens, foram utilizados os testes estatísticos: Mann Whitney, Exato de Fisher e Qui-quadrado. Na avaliação da efetividade da intervenção, utilizou-se a estatística inferencial por meio dos testes ANOVA e Modelo de Efeitos Mistos, considerando significância com $p<0,05$. Resultados: foram analisadas 33 crianças, a maioria pertencia ao sexo masculino, a idade variou entre 1 mês e 9 anos e 5 meses $(M=2$ a $5 \mathrm{~m}$ ). Em geral, as crianças inseridas na pesquisa estavam internadas em período inferior a 72 horas. Quanto ao diagnóstico médico, as patologias respiratórias (64\%) foram as mais frequentes. Em relação aos possíveis sinais adversos, duas crianças $(12,5 \%)$ apresentaram irritabilidade e choro, observados apenas no Grupo Intervenção. $\mathrm{Na}$ análise do efeito da intervenção, pode-se observar que a temperatura reduz conforme os momentos de aferição, embora não haja diferença na redução da temperatura entre os grupos, pois a intervenção não farmacológica "compressas mornas" não se mostrou significativa para explicar a diminuição da temperatura das crianças deste estudo. Conclusões: os desfechos sugerem que não há indicação da aplicação de compressas mornas como um método coadjuvante ao antitérmico ou qualquer intervenção não farmacológica em paciente pediátrico febril sem comorbidades, independentemente do contexto em que ele estiver inserido, pois indica que o procedimento apenas consome o tempo de assistência de enfermagem e pode não oferecer um resultado benéfico ao paciente.

PALAVRAS-CHAVE: Criança; Febre; Ensaio Clínico; Enfermagem pediátrica. 
Souza MV. Effectiveness of tepid sponging intervention in reducing temperature of children with fever: a pilot randomized clinical trial [dissertation]. São Paulo: School of Nursing, University of São Paulo; 2020.

\begin{abstract}
Introduction: The fever is a common clinical entity during childhood, being responsible for a large part of the demand of emergency services and emergency care in pediatrics. Objectives: Evaluating the effect of "tepid sponging", associated with the antipyretic prescribed, in fever reduction in hospitalized children and compare body temperature variation between the intervention and the control groups. Method: randomized controlled clinical trial pilot study, developed in pediatric units of a teaching hospital, located in São Paulo, from June 2019 to January 2020. The sample consisted of 33 patients who presented body temperature $\geq 37.8^{\circ} \mathrm{C}$, age group between 1 month and 11 years, 11 months and 29 days. Children were randomly allocated into two groups: Seventeen children received only the antipyretic medicine (Control Group) and sixteen children received the antipyretic medicine associated with "tepid sponging" intervention (Intervention Group). The axillary temperature was measured four times during three hours. Descriptive statistics was used to perform data analysis by means of simple frequency distributions, central tendency measure (mean) and dispersion measures (variance and standard deviations), in accordance with the study variable categorization. For the sample characterization in relation to age, sex, insertion of the child in research (time), place of hospitalization, antipyretic administered and frequent diagnoses, as well as testing the significance of these items, the following statistical tests were used: Mann Whitney test, Fisher's exact test and the Chi-square test. In order to evaluate the intervention effectiveness, inferential statistics by means of ANOVA tests and model of mixed effects were used, considering p <0.05 significance. Results: Overall 33 children were analyzed, being the majority the male gender, age ranged between 1 month and 9 years and 5 months $(M=2 \mathrm{a} 5 \mathrm{~m})$. In general, children included in the study were hospitalized in a period inferior than 72 hours. Regarding the medical diagnosis, respiratory pathologies $(64 \%)$ were the most frequent. In relation to possible adverse signs, two children (12.5\%) presented irritability and crying only in the Intervention Group. In the analysis of the intervention effect, it has been noticed that the temperature decreases depending on the moment of benchmarking, although there is no difference in temperature decrease between the groups, since the non-pharmacological intervention "tepid sponging" was not significant to explain temperature decrease of the children in this study. Conclusions: The outcomes suggest that there is no indication of tepid sponging application as an adjuvant method along with antipyretic or any nonpharmacological intervention in pediatric patients with fever and no comorbidities, regardless of the context in which they are inserted, it indicates that the procedure only consumes time of nursing care and may not offer a beneficial result for the patient.
\end{abstract}

KEYWORDS: Child; Fever; Clinical Trial; Pediatric nursing 


\section{LISTA DE FIGURAS}

Figura 1 - Fluxograma de artigos levantados na revisão integrativa sobre manejo não farmacológico da febre. São Paulo, 2020.

Figura 2 - Quadro explicativo: tempos de aferição da temperatura corporal e sequência da intervenção. São Paulo, 2020

Figura 3 - $\quad$ Pano Wiper Pro50®

Figura 4 - Termômetro clínico digital Termomed branco®

Figura 5- Termômetro digital temperatura interna e externa máx e mín. Incoterm ${ }^{\circledR}$

Figura 6 - Fluxograma da distribuição das crianças, conforme as etapas da pesquisa. São Paulo, 2020 .

Figura 7 - Temperatura média dos grupos controle e intervenção e média total conforme os momentos da coleta de dados. São Paulo, 2020

Figura 8 - Diferenças de temperatura entre os momentos de coleta de dados e diferença de temperatura final dos Grupos Intervenção e Controle. São Paulo, 2020 63

Figura 9 - Detalhamento do momento 4 classificado pelas temperaturas médias. São Paulo, 2020 64

Figura 10 - Gráfico da variação da temperatura nos quatro momentos de aferição. São Paulo, 2020 67 


\section{LISTA DE TABELAS}

Tabela 1 - Causas e tipos de hipertermia 22

Tabela 2 - Medicamentos antipiréticos, início de ação, duração da ação e via de administração 50

Tabela 3 - Caracterização dos pacientes de acordo com os grupos. São Paulo, 2020 59

Tabela 4 - Dados comparativos da média, desvio-padrão da variável idade. São Paulo, 2020

Tabela 5 - Frequência dos diagnósticos médicos das crianças entre os grupos controle e intervenção. São Paulo, 2020

Tabela 6 - Frequência dos sinais adversos nas crianças dos grupos controle e intervenção. São Paulo, 2020

Tabela 7 - Descritivas das temperaturas de acordo com os momentos de aferição e os grupos controle e intervenção. São Paulo, 2020

Tabela 8 - Análise estatística ANOVA com os dados da pesquisa. São Paulo, 2020........ 66

Tabela 9 - Temperatura média e desvio-padrão nos quatro momentos. São Paulo, 2020 . 68

Tabela 10 - Correções de Greenhouse-Geisser e Huynh-Feldt. São Paulo, 2020. 68

Tabela 11- Estimativas do modelo misto com intercepto aleatório. São Paulo, 2020 .70

Tabela 12 - Estimativas do modelo misto final com intercepto aleatório. São Paulo, 2020 


\section{SUMÁRIO}

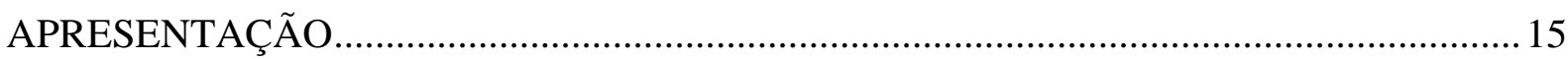

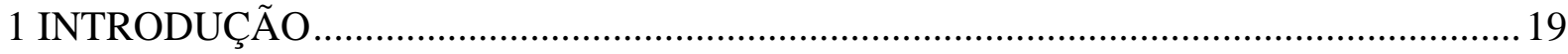

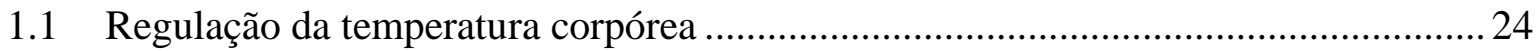

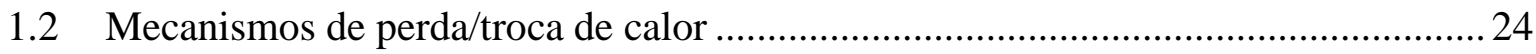

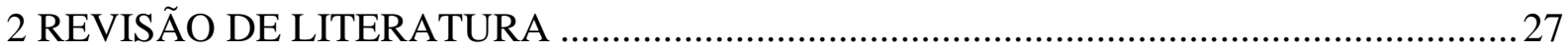

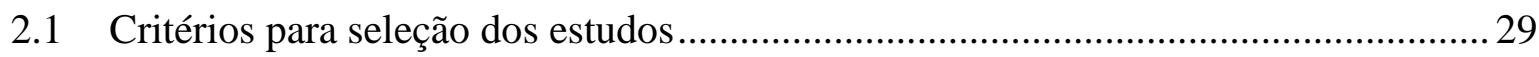

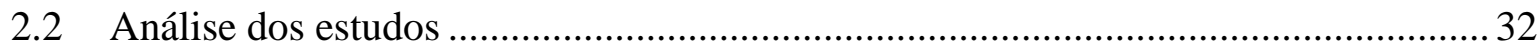

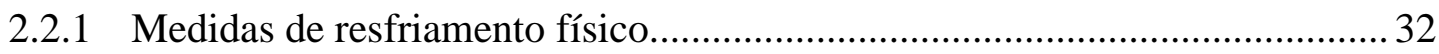

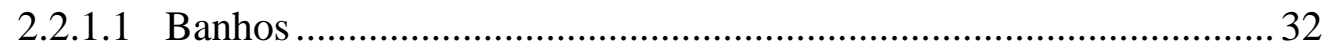

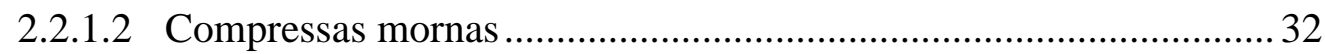

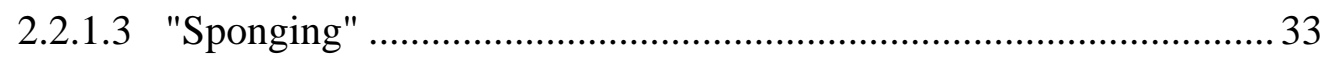

2.2.1.4 Incentivo à ingestão de líquidos ................................................. 34

2.2.1.5 Bolsas de gelo e cobertores refrigerados ........................................ 34

2.2.2 Medidas de resfriamento ambiental............................................................ 35

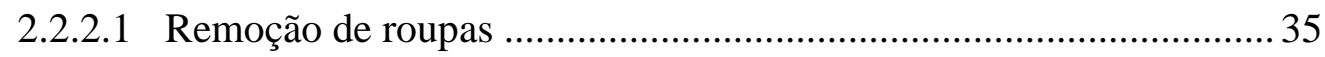

2.2.2.2 Ventilação do ambiente .............................................................. 35

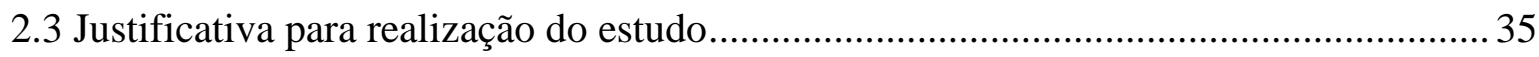

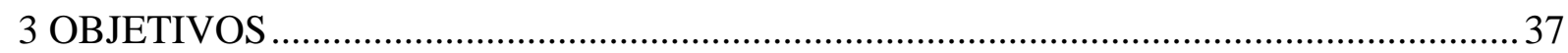

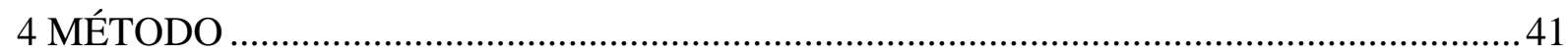

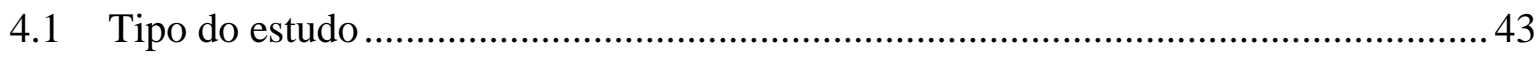

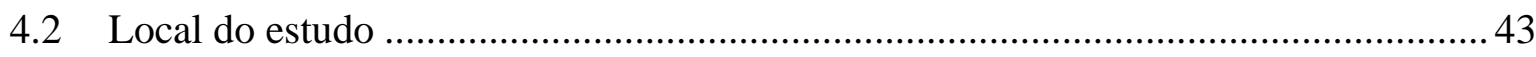

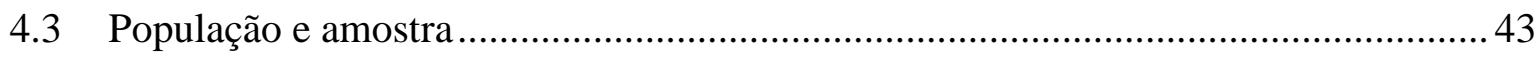

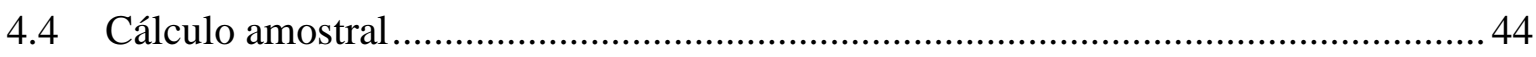

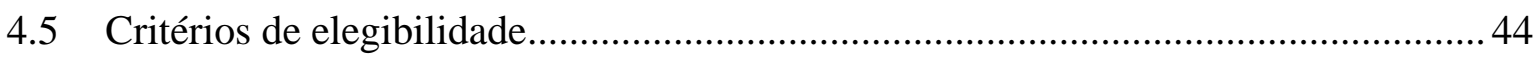

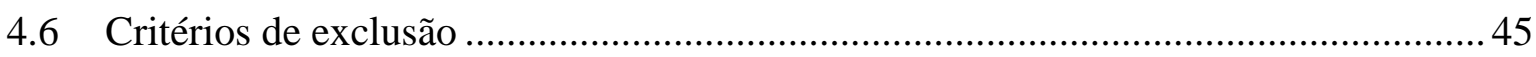

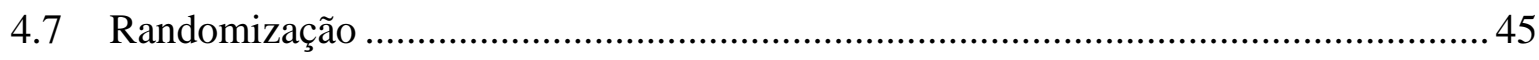

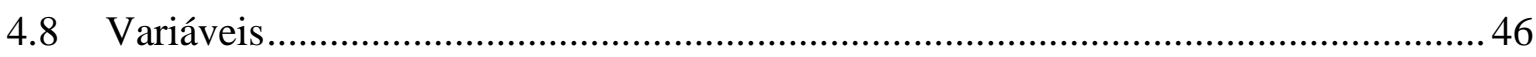

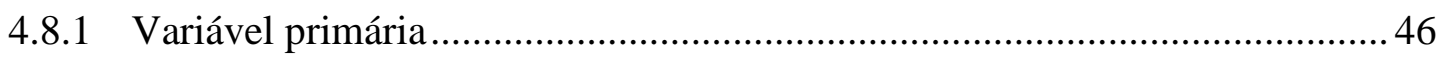

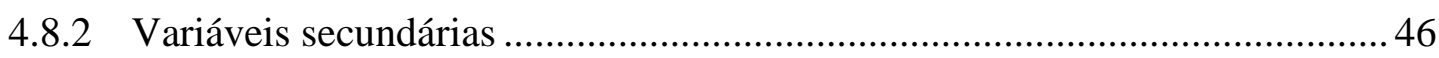

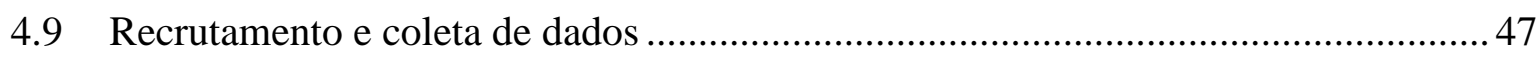

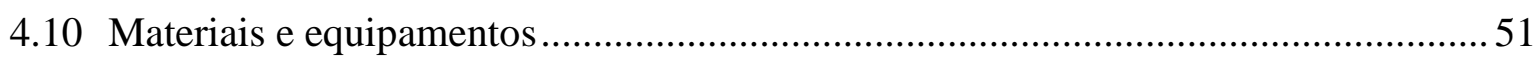

4.11 Procedimentos ético-legais e registro do ensaio clínico...........................................52 


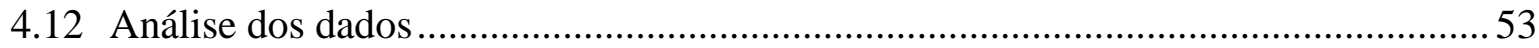

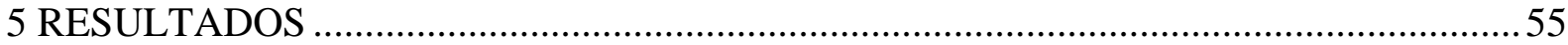

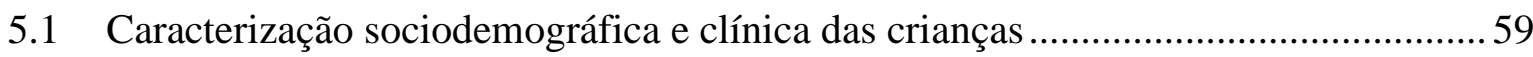

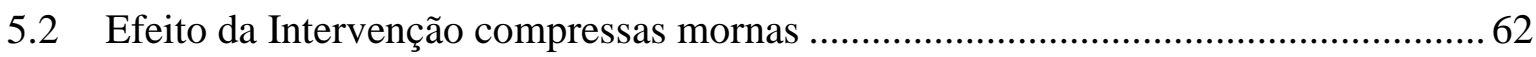

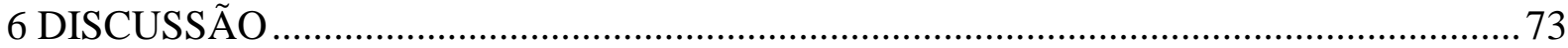

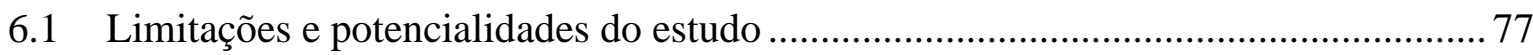

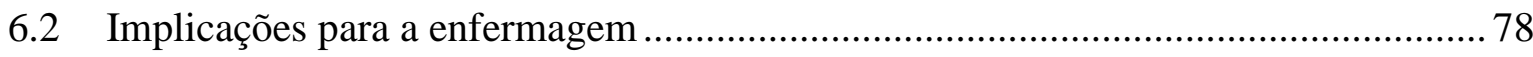

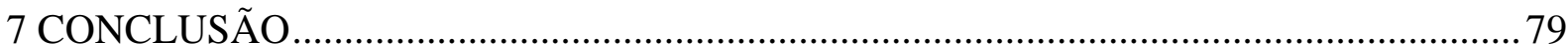

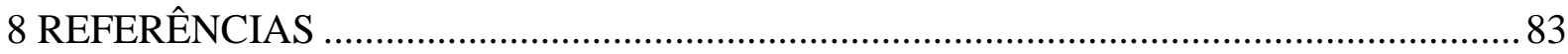

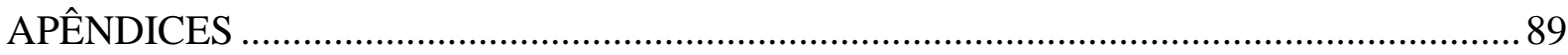

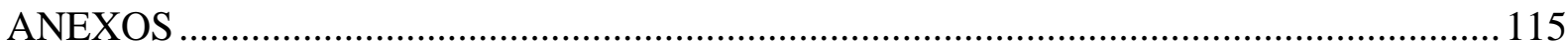


APRESENTAÇ̃̃O 



\section{APRESENTAÇÃO}

A Pediatria tornou-se minha área de interesse desde o período de estágio da graduação, assim, após o término desta, optei por uma especialização em Enfermagem Pediátrica e Neonatal pelo Instituto de Ensino e Pesquisa Albert Einstein e pude me aprofundar nos conteúdos de Saúde da Criança e Neonato. Nesse momento, tive a convicção de que havia feito a escolha certa.

A seguir, ingressei no programa de Residência em Enfermagem na Saúde da Criança e do Adolescente, pela Escola de Enfermagem da Universidade de São Paulo, tendo atuado por dois anos no Hospital Universitário da Universidade de São Paulo (HU-USP) nas unidades de Pronto Socorro Infantil (PSI), Unidade de Internação Pediátrica (UIped) e Unidade de Terapia Intensiva Pediátrica (UTIped). Naquele tempo, pude observar, que a implementação de medidas não farmacológicas para o resfriamento corpóreo em crianças febris tinha base na experiência empírica da prática cotidiana dos profissionais da enfermagem. Também não havia uma rotina assistencial preestabelecida ou um protocolo institucional que orientasse o manejo não farmacológico de febre em crianças baseado nas melhores evidências.

Nesse sentido, algumas situações me inquietavam, como, por exemplo, no PSI, onde as intervenções não farmacológicas em crianças febris se limitavam à faixa etária dos lactentes, que, em muitas situações, eram submetidos ao banho de imersão morno em banheira. Enquanto, na UTIped, a equipe utilizava compressas mornas nas regiões axilar, frontal, inguinal e tronco para resfriamento corpóreo em alguns pacientes e, em outras situações, também se fazia uso de compressas frias nas mesmas regiões. Desse modo, não havia uma medida padrão nas unidades pediátricas, havendo variadas condutas não farmacológicas aplicadas à criança febril.

A temática do manejo não farmacológico da febre já, há alguns anos, vinha sendo alvo de discussão do Grupo de Estudos sobre a Criança Doente (GECD). Assim, a partir da minha participação no Grupo e diante do observado no cenário de prática da residência, fui motivada a desenvolver meu Trabalho de Conclusão da Residência (TCR) sobre a matéria, tendo realizado um levantamento aprofundado da literatura científica com intuito de evidenciar a melhor prática para o cuidado à criança febril e com hipertermia. Foi realizada uma revisão integrativa da literatura, obtendo como resultados a utilização de diversas intervenções não farmacológicas pela enfermagem para tratamento de crianças febris hospitalizadas. Os estudos 
indicaram os benefícios e malefícios das várias práticas existentes, e pode-se observar a falta de consenso sobre a recomendação de algumas intervenções, como o banho morno e o uso de compressas. Atualmente, estas medidas não farmacológicas são utilizadas frequentemente pelo enfermeiro na prática assistencial. Entretanto, sabe-se que o cuidado fundamentado no conhecimento empírico pode acarretar danos à segurança do paciente.

Diante disso, era necessário realizar uma pesquisa de campo a fim de identificar os desfechos da intervenção não farmacológica no cuidado à criança febril. Sendo assim, tendo em vista o interesse de imersão na área da pesquisa e apoio de minha orientadora, optei por me inscrever e participar da seleção para o curso de mestrado da Escola de Enfermagem da USP, tendo sido aprovada.

Acreditava que, a partir do resultado da pesquisa, seria possível conhecer a eficácia da medida não farmacológica "compressa morna" no manejo da febre em crianças hospitalizadas. Tal conhecimento permitiria ao enfermeiro pediatra realizar o processo de cuidar baseado em evidências, contribuindo para o avanço da enfermagem brasileira. 



\section{INTRODUÇÃO}

A febre é uma entidade clínica comum na infância, sendo responsável por grande parte da procura dos serviços de pronto atendimento e emergência em Pediatria ${ }^{(1)}$. É definida como a elevação da temperatura corpórea acima do normal, desencadeada pelo hipotálamo, em resposta à liberação de proteínas reguladoras denominadas citocinas, produzidas durante as respostas inflamatórias e imunológicas a infecção ${ }^{(2)}$.

Apresenta quatro estágios sequenciais: 1) fase prodrômica: caracterizada por fadiga, indisposição e dores passageiras e não apresenta alteração da temperatura corporal; 2) fase de frio: o indivíduo sente frio, apresenta calafrios, tremores, precisando agasalhar-se; 3) fase de rubor: iniciada pela vasodilatação periférica, provocando rubor e sensação de calor e 4) fase de resfriamento: caracterizada por sudorese, que pode ser intensa, até que a temperatura atinja valores normais, seja pela diminuição da concentração de pirógenos na corrente sanguínea, seja pela ingestão de antipiréticos ${ }^{(2)}$. Geralmente, o paciente apresenta elevação da temperatura corpórea, extremidades frias, sudorese, sensação de frio, taquicardia, taquipneia e tremores ${ }^{(3)}$.

Ao contrário da febre, a hipertermia é o aumento da temperatura corpórea resultante de condições corporais ou externas que produzem mais calor do que o corpo pode eliminar, geralmente a temperatura se eleva acima de $40{ }^{\circ} \mathrm{C}$ e não responde ao uso de antitérmicos ${ }^{(2)}$. $\mathrm{O}$ excesso da produção de calor, excesso de calor do ambiente ou perda de calor prejudicada podem sobrecarregar os mecanismos regulatórios do organismo, resultando na hipertermia (2). Geralmente, o excesso da produção de calor pode ser observado em pessoas jovens durante alguma atividade ou exercício sob exposição do calor ${ }^{(2)}$.

Pode-se classificar os tipos de hipertermia, com relação à causa de origem, conforme tabela abaixo: 
Tabela 1 - Causas e tipos de hipertermia

\begin{tabular}{ll}
\hline Causas & Tipos \\
\hline Excesso da produção de calor & Hipertermia por esforço \\
& $\begin{array}{l}\text { Hipertermia medicamentosa (uso de anfetaminas, drogas, } \\
\text { hormônio tireoidiano exógeno. }\end{array}$ \\
Excesso de calor ambiental & Insolação \\
Perda de calor prejudicada & $\begin{array}{l}\text { Hipertermia medicamentos (uso de betabloqueadores, } \\
\text { diuréticos, anticolinérgicos) } \\
\text { Hipertermia maligna }\end{array}$ \\
\hline
\end{tabular}

Fonte: El-Radhi AS, Carrol J, Klein N. Clinical manual of fever in children.

A hipertermia pode resultar em algumas complicações, como: hipóxia, hipotensão, acidose metabólica, coagulação intravascular disseminada (CID), azotemia, hipoglicemia, insuficiência circulatória ou convulsões ${ }^{(4)}$. Ao contrário da febre, a hipertermia deve ser tratada de forma imediata, através de medidas de resfriamento externo e, quando estas não forem responsivas, a literatura refere que se pode recorrer a medidas de resfriamento corpóreo interno como a infusão peritoneal de solução salina gelada, hidratação intravenosa com solução fisiológica ${ }^{(2)}$.

Entre os tipos de hipertermia, destaca-se a hipertermia maligna com maior gravidade, considerada um distúrbio genético incomum e potencialmente fatal. Ocorre em indivíduos susceptíveis à exposição a anestésicos inalatórios halogenados e/ou relaxante muscular despolarizante, a succinilcolina ${ }^{(5,6)}$.

A medição da temperatura corporal é o método mais comum utilizado para detecção da febre e, a partir do valor obtido, são tomadas condutas em relação à investigação e ao tratamento das crianças ${ }^{(4)}$. Podem-se encontrar diferentes valores de referência da temperatura a partir dos quais são considerados como febre na literatura: $37,6-38^{\circ} \mathrm{C}$ (retal ou timpânica), 37,5-37, $6^{\circ} \mathrm{C}$ (oral) ou 37,2-38,5 ${ }^{\circ} \mathrm{C}$ (axilar), porém o conceito fisiopatológico da febre é universal ${ }^{(1,3,4)}$.

Para detecção da febre, podem-se utilizar diferentes termômetros: digital, retal, esofágico e timpânico. Na prática clínica, observa-se o uso frequente do termômetro digital e timpânico. De acordo com o tipo, podem-se observar algumas vantagens e desvantagens. O termômetro timpânico é um método confiável para monitorar a temperatura corporal e, por meio da temperatura infravermelha, irá refletir valores próximos ao da temperatura corporal central. Enquanto o termômetro eletrônico tem a vantagem de uso em diferentes locais, como 
retal, oral ou axilar; aferição rápida (em torno de 30 segundos, conforme a marca), além de ser um método confortável para uso em crianças. ${ }^{(7)}$.

Em contrapartida, o tratamento da febre ainda é uma questão controversa ${ }^{(4)}$. Muitos pais e profissionais da saúde consideram que a febre é um sinal perigoso e nocivo para as crianças, como uma doença e não um sinal de anormalidade ${ }^{(8-9)}$. Sabe-se que a febre é autolimitada e tem a função de estimular o sistema imunológico e as reações inflamatórias no combate à infecção ${ }^{(10)}$. Nos casos de crianças com doenças pulmonares, cardiovasculares, criticamente doentes, imunocomprometidas e com condições crônicas preexistentes, a febre deverá ser tratada, a fim de não sobrecarregar o organismo da criança com o aumento da demanda metabólica e de oxigênio ${ }^{(11)}$. Sabe-se que, a cada $1{ }^{\circ} \mathrm{C}$ de aumento da temperatura corporal, há o aumento de 11 a $13 \%$ da necessidade de oxigênio pelo organismo ${ }^{(2,12)}$.

A literatura relata diversas intervenções não farmacológicas para o tratamento da febre, como banhos de imersão ou chuveiro, sponging, compressas, bolsas de gelo e cobertores refrigerados, incentivo a ingestão de líquidos, remoção de roupas e ventilação do ambiente.

Apesar de os estudos não serem conclusivos sobre a eficácia de intervenções não farmacológicas à criança febril, observa-se com frequência, na prática clínica, o uso de banhos mornos, compressas mornas e frias na vigência de febre em crianças. Se as medidas forem ineficazes, o banho ou a aplicação de compressas podem trazer desconforto à criança, sem nenhum efeito na diminuição da temperatura corpórea, sendo, portanto, um cuidado iatrogênico. Além disso, há um mau uso do tempo tanto do enfermeiro que prescreve o cuidado como do profissional de enfermagem que o executa.

Diante da alta incidência de pacientes pediátricos febris nas instituições hospitalares e da falta de práticas baseadas em evidências, que subsidiem o cuidado de enfermagem, questiona-se se o uso da medida não farmacológica "compressa morna", associado ao antitérmico, seria mais eficaz em relação à administração isolada do medicamento antitérmico no manejo da febre em crianças hospitalizadas. Tal conhecimento poderia permitir ao enfermeiro pediatra realizar o processo de cuidar da criança febril baseado em evidências, bem como contribuir para o avanço da enfermagem pediátrica brasileira. 


\subsection{REGULAÇÃO DA TEMPERATURA CORPÓREA}

Para desenvolver funções vitais no organismo, tanto humanos quanto animais necessitam ter uma temperatura corporal padrão, que pode variar conforme as espécies, condições fisiológicas ou patológicas ${ }^{(13)}$. A composição corporal da infância até a terceira idade, assim como a proporção da área de superfície de peso, funções termossensoriais, isolamento corpóreo e mudanças frequentes na circulação da pele, e os mecanismos, formas e capacidade de perda de calor versus produção de calor ou processos de regulação central diferem conforme a faixa etária ${ }^{(13)}$.

Observa-se que as crianças são mais suscetíveis às mudanças de temperatura ambiente do que os adultos e sua capacidade de adaptação térmica é limitada. Isso pode ocorrer devido em parte à relação superfície/peso diferente; menor taxa metabólica, reservas termossensoriais, efetoras e funções regulatórias, que podem diferir dos adultos ${ }^{(13)}$.

O corpo humano ajusta a temperatura interna até aproximadamente $37^{\circ} \mathrm{C}$, por meio de um controle autonômico complexo do fluxo sanguíneo da pele e da transpiração, além da modulação local ${ }^{(14)}$. As vias aferentes dos termorreceptores centrais e periféricos (da pele) são encaminhadas para o centro de controle termorregulatório no hipotálamo anterior préóptico (POAH). As vias são integradas na POAH antes que os sinais simpáticos eferentes induzam ajustes sudomotores e vasomotores adequados para regular a temperatura corporal central $^{(14)}$.

\subsection{MECANISMOS DE PERDA/TROCA DE CALOR}

A literatura relata dois mecanismos de perda/troca de calor: a) mecanismo evaporativo: promove a dissipação do calor a partir da pele e superfícies respiratórias, por meio da sudorese ${ }^{(15)}$ e b) mecanismo não evaporativo, que é evidenciado por: condução (K), radiação (R) e convecção (C). As taxas de ganho e dissipação de calor devem ser equivalentes para manter o balanço térmico $(S=0)$ e uma temperatura central estável. Sob condições normotérmicas, os ajustes vasomotores cutâneos facilitam a perda ou ganho de calor por convecção na superfície da pele para combater pequenas flutuações na temperatura corporal $^{(14)}$. 
Os mecanismos de perda de calor não evaporativo são definidos, como se segue: a) Radiação: a perda de calor por meio da radiação ocorre na forma de raios de calor infravermelhos, tipo de onda eletromagnética. O corpo humano irradia os raios de calor em todas as direções, se a temperatura do corpo é maior do que a temperatura do ambiente, maior quantidade de calor é irradiada pelo corpo para o ambiente ${ }^{(15)}$; b) Condução: ocorre quando o calor flui de uma região de temperatura mais alta para outra de temperatura mais baixa, dentro de um meio sólido, líquido ou gasoso, ou entre meios diferentes de contato físico direto ${ }^{(16)}$. A perda de calor pela condução para o ar representa proporção considerável, aproximadamente $15 \%{ }^{(15)}$; c) Convecção: processo em que ocorre a troca de calor devido à movimentação do ar ou água próximos do corpo. A dispersão do calor pela convecção de correntes aéreas é denominada de perda de calor por convecção ${ }^{(15)}$.

A literatura destaca que, devido à imaturidade das glândulas sudoríparas dos bebês, a produção de suor pode ser limitada. Sendo assim, estão propensos à hipertermia, apesar da grande capacidade de vasodilatação da pele, o limiar de vasodilatação é mais alto, portanto, em um ambiente quente, a eficácia da perda de calor por radiação é limitada. A produção de suor pode ser visualizada principalmente na testa dos bebês e eles têm um limiar alto para induzir a transpiração, enquanto as crianças com idade entre 2-3 anos têm uma capacidade melhor para vasodilatação e sudorese ${ }^{(13)}$. 

2 REVISÃO DE LITERATURA 



\section{REVISÃO DE LITERATURA}

Realizou-se a revisão integrativa da literatura, que consiste na construção de uma análise ampla da literatura, contribuindo para discussões sobre métodos e resultados de pesquisas, assim como reflexões sobre a realização de futuros estudos ${ }^{(17)}$. Foram percorridas seis etapas: 1) Identificação do tema e seleção da hipótese ou questão de pesquisa para a elaboração da revisão integrativa; 2) Estabelecimento de critérios para inclusão e exclusão de estudos/amostragem ou busca na literatura; 3) Definição das informações a serem extraídas dos estudos selecionados/categorização dos estudos; 4) Avaliação dos estudos incluídos na revisão integrativa; 5) Interpretação dos resultados e 6) Apresentação da revisão/síntese do conhecimento $^{(17)}$.

A elaboração da questão norteadora foi estruturada a partir da estratégia PICO, a qual surge como um elemento fundamental proposto pela Prática Baseada em Evidências - PBE para formulação da questão de pesquisa e da construção da pergunta para a busca bibliográfica de evidências ${ }^{(18)}$. A PICO corresponde à abreviatura para Paciente, Intervenção, Comparação e "Outcomes” (desfecho) ${ }^{(18)}$. Atribuiu-se ao $\mathrm{P}$ - pacientes pediátricos com febre ou hipertermia, ao I - intervenções de enfermagem, ao C - medidas não farmacológicas utilizadas na febre e hipertermia e ao $\mathrm{O}$ - redução da temperatura corporal. Dessa forma, a questão norteadora constituiu-se em: "Quais são as intervenções de enfermagem utilizadas no manejo não farmacológico da febre e hipertermia?".

\subsection{CRITÉRIOS PARA SELEÇÃO DOS ESTUDOS}

A busca e a seleção dos estudos foram realizadas entre os meses de julho e setembro de 2014 e, posteriormente, em janeiro de 2017, sendo revisada em setembro e outubro de 2018, em três bases de dados indexadas: Literatura Latino-Americana em Ciências da Saúde (LILACS), PubMed, CINAHL e nas bibliotecas COCHRANE e Scientific Electronic Library Online (SciELO). Consideraram-se como critérios de inclusão dos artigos: idiomas português e inglês; artigos que abordassem a faixa etária de 29 dias a 18 anos, pesquisas publicadas no período de 2000 a 2018 e que contivessem os descritores e palavras-chave: "child" AND "fever" AND "nursing". Como critério de exclusão, os artigos repetidos. 
Foram identificadas 400 publicações, sendo 17 na base LILACS, 8 na base SciELO, 189 na CINAHL, 169 na PUBMED e 17 na COCHRANE. Paralelamente, realizou-se uma busca manual complementar, tendo sido incluídos nove artigos e acrescentados quatro estudos por meio de citações relacionadas. Ao término da primeira etapa, foram excluídos 40 estudos repetidos. Após a leitura do título e/ou do resumo, excluíram-se as produções científicas que não contemplavam o tema do trabalho, obtendo uma amostra de 46 artigos.

$\mathrm{Na}$ fase seguinte, procedeu-se à leitura de 46 estudos na íntegra e eliminaram-se os trabalhos que não relatavam as medidas não farmacológicas na febre e hipertermia na criança. A amostra final foi composta de 27 trabalhos, sendo organizados em um quadro com a sumarização dos estudos. Utilizou-se uma lista de checagem, na qual constou a identificação do artigo, método, objetivos, intervenções não farmacológicas e conclusões (Quadro 1 APÊNDICE 1).

Foi elaborado um fluxograma, conforme recomendado pelo método "Preferred Reporting Items for Systematic Reviews and Meta-Analyses" (PRISMA), demonstrando as etapas realizadas durante a busca bibliográfica e seleção dos estudos, constituído por: identificação, seleção, elegibilidade e inclusão ${ }^{(19)}$. 
Figura 1 - Fluxograma de artigos levantados na revisão integrativa sobre manejo não farmacológico da febre. São Paulo, SP, Brasil, 2020

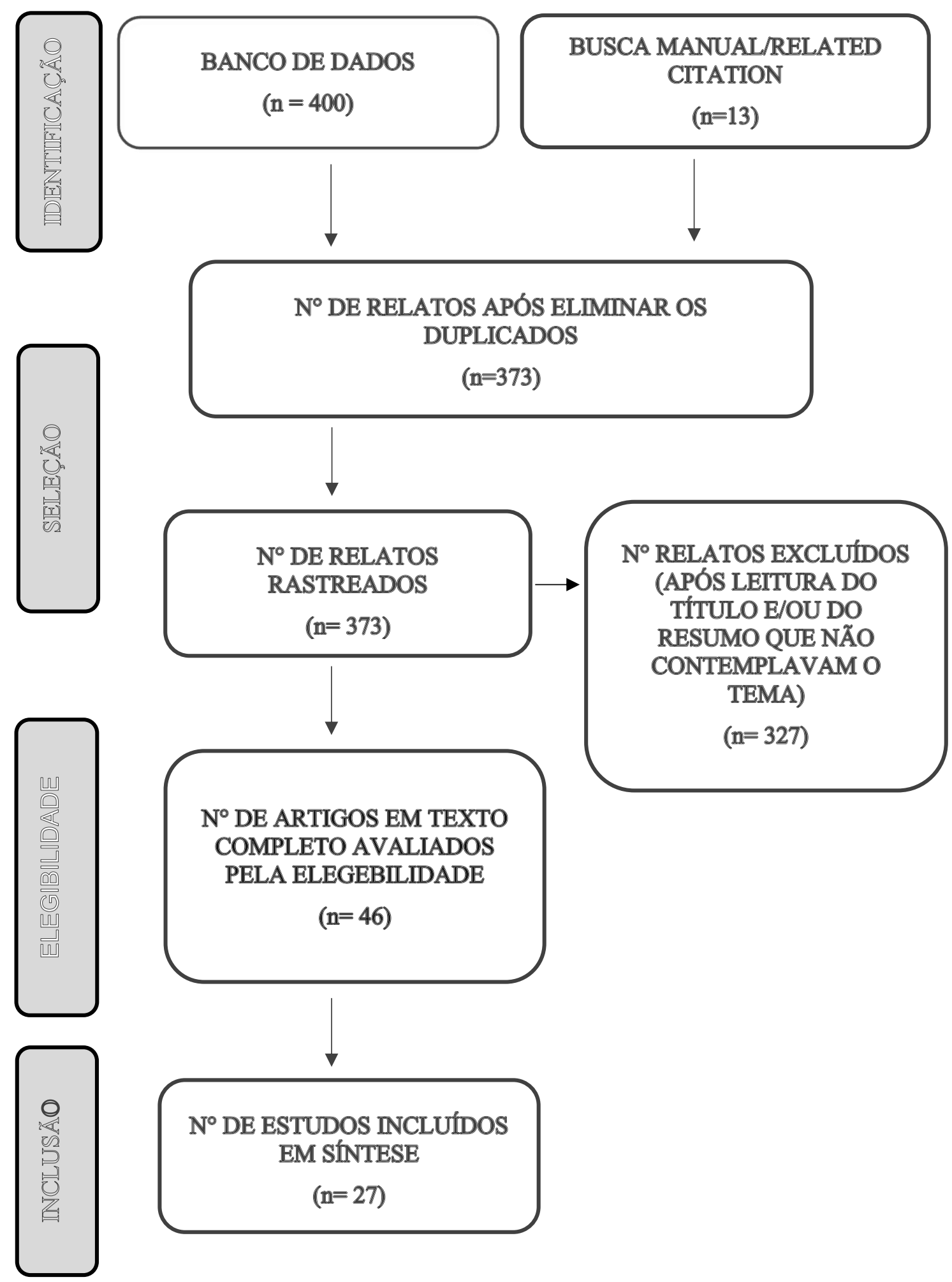

Fonte: Dados do estudo 


\subsection{ANÁLISE DOS ESTUDOS}

A análise dos artigos permitiu a organização dos resultados obtidos em categorias e subcategorias, após comparação entre os estudos e agrupamento por similaridade de conteúdo, sendo: Medidas de resfriamento físico e Medidas de resfriamento ambiental. Nesse sentido, elaborou-se um quadro com os artigos selecionados para a presente revisão integrativa, contendo os tópicos: identificação do estudo, objetivos, método, intervenções não farmacológicas e conclusões, conforme apêndice A.

\subsubsection{Medidas de resfriamento físico}

\subsubsection{Banhos}

Nessa categoria, cinco estudos mencionaram a aplicação do banho de imersão para redução da temperatura corpórea em crianças febris e a intervenção foi utilizada com água morna, fria e com álcool ${ }^{(20-25)}$. Entretanto, a eficácia do banho com água morna ou fria foi contestada devido à ineficiência na redução das prostaglandinas e ao desencadeamento de desconforto na criança, ao apresentar calafrios e tremores ${ }^{(22)}$. Além disso, a drástica redução da temperatura promovida pelo banho com água fria pode ocasionar um choque térmico ${ }^{(23)}$.

No manejo da febre e hipertermia em pacientes com injúrias neurológicas, o banho foi a medida não farmacológica escolhida em terceiro lugar por enfermeiros ${ }^{(22)}$.

\subsubsection{Compressas mornas}

A medida não farmacológica compressa morna, assim como outros métodos físicos, apresenta similar mecanismo de perda de calor por condução e convecção ${ }^{(26)}$. A técnica consiste no uso de compressas mornas, embebidas em água à temperatura entre $30-40^{\circ} \mathrm{C}$, e duração da intervenção de 15 minutos ${ }^{(27)}$.

Enquanto há escassez de pesquisas em território nacional com o uso de compressas mornas, observa-se um número elevado de publicações internacionais sobre sponging na literatura em relação às compressas mornas $\left.{ }^{3}, 11,20,23-26,28-39\right)$. Verifica-se, na literatura nacional, que os autores muitas vezes traduzem o termo sponging como compressa morna. Nesse sentido, parecem considerar a técnica de sponging e a de aplicação de compressas mornas como procedimentos análogos, entretanto elas diferem entre si, embora envolvam o mesmo mecanismo de perda de calor ${ }^{(20)}$. 
Os melhores desfechos encontrados relacionavam-se à intervenção compressa morna em associação ao antitérmico. Estudos comparativos entre pacientes medicados apenas com antitérmico versus aqueles que receberam antitérmico em uso combinado com compressa morna verificaram resfriamento corpóreo mais rápido nos primeiros 15 minutos na intervenção combinada ${ }^{(29)}$.

Entretanto, deve-se manter constante observação nos pacientes submetidos ao "uso da compressa morna", pois pode haver o desencadeamento de algumas reações adversas, tais como: tremores e vasoconstrição ${ }^{(20,33)}$.

\subsubsection{3 "Sponging" 1}

O "sponging" consiste em uma intervenção que tem sido amplamente empregada para redução da temperatura corpórea em crianças. Os mecanismos envolvidos na perda do calor são condução, convecção e evaporação ${ }^{(26)}$. Nas pesquisas, a intervenção com sponging foi utilizada com a adição de água fria, morna e com álcool ${ }^{(2,20-44)}$. A técnica sofre algumas variações, mas, em geral, a criança é mantida sem roupas e seu corpo, do pescoço aos pés, é gentilmente friccionado com a compressa embebida em água morna ${ }^{(25)}$. Outra técnica também realizada é a fricção com a compressa morna somente nos membros superiores e inferiores, mantendo-se coberto o tronco da criança. A principal recomendação para o tratamento da febre por meio de sponging consiste na utilização de água morna e tempo médio de 15 minutos ${ }^{(27,29,33)}$. A temperatura da água pode variar desde o valor abaixo da temperatura corpórea da criança até o limite de $33{ }^{\circ} \mathrm{C}^{(29,33,42)}$.

Em diversas pesquisas, a sponging morna tem sido utilizada em conjunto com um antitérmico $^{(20-21,23-27,29-35)}$. A intervenção conjugada, sponging morna e antitérmico, obtém parecer favorável apenas quando o uso tem como objetivo principal oferecer conforto à criança $^{(25,29)}$.

Em um ensaio clínico randomizado, sponging morna versus antitérmico, verificou-se que a sponging morna foi responsável pela redução mais rápida da temperatura nos primeiros 30 minutos, mas, após esse período, o antitérmico foi eficaz em longo prazo ${ }^{(20)}$. Em outra pesquisa, também um ensaio clínico randomizado, comparou-se a administração de dipirona com a aplicação de dipirona + sponging morna. Observou-se que a sponging morna não oferece efeitos adicionais em longo prazo, mesmo quando administrada juntamente com o antipirético $^{(29)}$.

\footnotetext{
${ }^{1}$ Manteve-se o termo em inglês por não haver termo equivalente em português, com o mesmo significado.
} 
Ainda que alguns artigos recomendem a utilização da sponging morna no tratamento de crianças febris, outras pesquisas questionam seu uso, destacando uma forte oposição ao método em razão dos efeitos adversos: toxicidade (banho e sponging com álcool), desconforto na criança, vasoconstrição, elevação da temperatura corpórea, rápida redução da temperatura, eficiência restrita aos primeiros 30 minutos após aplicação e falta de sinergismo no uso conjugado com antitérmico ${ }^{(11,21,23-28,31-33,37-38,42,44)}$.

As pesquisas indicam que não há evidências que comprovem que antitérmicos ou sponging morna impeçam convulsões febris ou as suas recorrências ${ }^{(29)}$. Contudo, crianças com hipertermia podem se beneficiar do uso da intervenção ${ }^{(43)}$.

\subsubsection{Incentivo à ingestão de líquidos}

A febre, em geral, causa importante perda hídrica na criança. Assim, quando o estado febril é prolongado, há o risco de a criança apresentar desidratação. Por isso as crianças devem ser estimuladas a aumentar a ingestão de líquidos $(2-3,11,20,24-25,30,35,37,39,44$,$) . Sobretudo$ às crianças sob aleitamento materno exclusivo, torna-se imprescindível a oferta do leite materno com maior frequência $(20,31,37)$. Estudos apontam que o aumento na ingesta de bebidas frias produz uma refrigeração interna na criança e auxilia as respostas fisiológicas do corpo diante da febre ${ }^{(37,44)}$.

\subsubsection{Bolsas de gelo e cobertores refrigerados}

O uso de bolsas de gelo e/ou cobertores refrigerados é aplicado para redução da temperatura corpórea em caso de febre e hipertermia ${ }^{(20,22,41,43)}$. As enfermeiras especialistas em Neurologia têm adotado essas intervenções como primeira escolha, por considerarem que essas medidas são efetivas no tratamento de pacientes com lesão neurológica ${ }^{(22)}$.

Os mecanismos de evaporação e convecção proporcionam a perda de calor e conferem ao cobertor refrigerado a efetividade no tratamento da hipertermia ${ }^{(21-22)}$. Entretanto, outro estudo relatou que o uso de bolsas de gelo, aplicadas nas regiões de axilas, pescoço e virilha, obteve resultado negativo, sendo inefetivo ${ }^{(32)}$.

Para o tratamento da febre, o uso de bolsas de gelo em associação ao antitérmico obteve sucesso ${ }^{(22)}$. Em estudo realizado com um grupo de pacientes febris com comprometimento neurológico, estes foram submetidos à utilização de cobertores refrigerados e antitérmico e observou-se uma redução rápida da temperatura corpórea, além da diminuição significativa do gasto energético diário ${ }^{(21)}$. Entretanto, a aplicação dessas intervenções não 
farmacológicas em pacientes febris pode desencadear vasoconstrição cutânea, tremores, ativação do sistema simpático e desconforto ${ }^{(21-22,43)}$.

Pode-se observar que essas medidas não farmacológicas foram vistas como úteis por alguns e consideradas problemáticas por outros pesquisadores, não havendo, portanto, um consenso entre eles $(21-22,41,43)$.

\subsubsection{Medidas de resfriamento ambiental}

\subsubsection{Remoção de roupas}

A remoção do excesso de roupas, lençóis e cobertores proporcionou conforto às crianças febris por permitir a perda de calor por irradiação ${ }^{(3,30,32,37,41,44)}$. É fundamental que se mantenham os bebês febris com a cabeça descoberta, pois, dessa forma, ocorre a perda do excesso de calor ${ }^{(44)}$. Enfermeiros mencionaram adotar essa medida como primeira opção no manejo de pacientes febris $(3,30,32)$.

\subsubsection{Ventilação do ambiente}

Nessa categoria, as técnicas utilizadas para ventilação do ambiente foram: abertura de janelas, promoção de ambiente arejado e uso de ventiladores $(24-26,30,32,38,41,43)$. O uso destes últimos no resfriamento do ambiente foi visto como benéfico, desde que o paciente não apresentasse tremores ${ }^{(35)}$. Entretanto, alguns estudos ressaltam a falta de evidência para indicar a abertura janelas ou ventilação do ambiente e até mesmo consideram tal prática como uma intervenção desnecessária ${ }^{(25-26,31)}$.

\subsection{JUSTIFICATIVA PARA REALIZAÇÃO DO ESTUDO}

Diversos estudos demonstraram que a implementação de medidas não farmacológicas isoladas não obteve resultados efetivos na redução da temperatura corpórea e promoção do conforto da criança. Observou-se maior índice de resultados benéficos nos estudos em que foram utilizadas medidas não farmacológicas em conjunto com terapia medicamentosa com antitérmicos $(2,20,27,29,34,36)$.

Tendo em vista o panorama da prática assistencial atual nacional e internacional, associado à revisão integrativa realizada, torna-se relevante avaliar o efeito da aplicação de 
medidas não farmacológicas em associação ao antitérmico prescrito na redução da febre em crianças hospitalizadas. Desse modo, justifica-se tanto a realização da pesquisa em si, isto é, o estudo clínico randomizado sobre a eficácia da utilização de medidas não farmacológicas em crianças febris hospitalizadas, quanto a escolha da medida não farmacológica "compressa morna", considerando que, no meio hospitalar brasileiro, os profissionais de enfermagem utilizam com maior frequência a compressa morna como medida não farmacológica no cuidado à criança febril. 
3 OBJETIVOS 



\section{OBJETIVOS}

$\checkmark$ Avaliar o efeito da aplicação da compressa morna em associação ao antitérmico prescrito na redução da febre em crianças hospitalizadas;

Comparar a variação da temperatura corporal entre os Grupos Controle e Intervenção. 

4 MÉTODO 



\section{MÉTODO}

\subsection{TIPO DO ESTUDO}

Trata-se de um estudo experimental piloto, do tipo ensaio clínico randomizado, sobre a aplicação da intervenção não farmacológica compressa morna associada à administração de antitérmico e somente a administração de antitérmico.

Destaca-se que esta pesquisa seguiu as recomendações do enunciado "Consolidated Standards of Reporting Trials" (CONSORT) para o relato de estudos clínicos controlados randomizados ${ }^{(45)}$.

\subsection{LOCAL DO ESTUDO}

O estudo foi realizado nas unidades pediátricas do Hospital Universitário da Universidade de São Paulo (HU - USP). O estudo foi desenvolvido nas seguintes unidades: Unidade de Internação Pediátrica (UIped), Unidade de Terapia Intensiva Pediátrica (UTIped) e Pronto Socorro Infantil (PSI). O HU é um hospital de atenção secundária, que integra o Sistema Único de Saúde (SUS). Optou-se por esse serviço por se tratar de uma instituição com filosofia de ensino e pesquisa, além do fato de a pesquisadora ter sido residente de enfermagem no serviço, o que facilitou a interação com a equipe assistencial.

A equipe de profissionais que prestam assistência aos pacientes nas unidades pediátricas é constituída por enfermeiros, fisioterapeutas, fonoaudiólogos, médicos, técnicos e auxiliares de enfermagem.

\subsection{POPULAÇÃO E AMOSTRA}

A população do estudo foi constituída por crianças com faixa etária de 1 mês a 11 anos, 11 meses e 29 dias, que atendessem aos critérios de inclusão, internadas nas Unidades Pediátricas, no período de junho de 2019 a janeiro de 2020, totalizando 33 pacientes. A delimitação da idade justifica-se, pois usualmente, em adolescentes febris, não são aplicadas 
técnicas não farmacológicas para o controle da febre, o que é confirmado pelos estudos encontrados na literatura, que referem a participação de indivíduos com idade até 12 anos, com ênfase em crianças abaixo de 5 anos $(1,3,24,29,31)$.

A amostra adotada foi de conveniência, pois foram selecionadas as crianças que estavam internadas nas unidades pediátricas durante o período de coleta de dados. Por se tratar de um estudo clínico, a amostra foi composta de dois grupos: 1. Grupo Controle: Crianças com febre submetidas ao tratamento farmacológico; 2. Grupo Intervenção: Crianças com febre submetidas ao tratamento farmacológico associado à aplicação de compressas mornas.

\subsection{CÁlCULO AMOSTRAL}

Em estudos longitudinais (experimentais), torna-se necessário calcular o número de sujeitos para garantir que um determinado efeito predefinido seja significativo ${ }^{(46)}$.

Embora este estudo seja piloto, a partir da amostra piloto de 33 pacientes, foi realizado o cálculo amostral, caso houvesse interesse futuro na reprodução do estudo, aplicando a fórmula de Twisk (2013), com nível de significância de 5\% e poder do teste de $80 \%$, verificou-se T=4, r=16/17, $\sigma=0,61451, \rho_{T}=0,28095, \mathrm{v}=0,0636$, obteve-se um tamanho amostral de 696 pacientes ${ }^{(46)}$.

\subsection{CRITÉRIOS DE ELEGIBILIDADE}

Foram incluídas no estudo crianças de 1 mês a 11 anos, 11 meses e 29 dias, que atendessem aos seguintes critérios:

- Temperatura axilar $\geq 37,8^{\circ} \mathrm{C}$;

- Intervalo entre a administração do antitérmico e o início da aplicação da intervenção, aplicação de compressas mornas de até 10 minutos;

- Permissão dos pais ou responsáveis e aceite em participar do estudo.

Além desses critérios, também foi permitida a inclusão da mesma criança, caso sua última inserção no estudo tivesse ocorrido em tempo superior a 12 horas e não estivesse sob efeito de antitérmico, estabelecendo um intervalo mínimo de 6 horas do último antitérmico. 
Optou-se por estabelecer o valor de temperatura axilar inicial de $37,8^{\circ} \mathrm{C}$ para inclusão da criança na pesquisa, pois, na prática clínica, tem se utilizado esse valor de referência, embora na literatura não haja um consenso, e pôde-se observar estudos que consideram a temperatura inicial entre 37,2 a $38,5^{\circ} \mathrm{C}^{(1,3,4)}$.

\subsection{CRITÉRIOS DE EXCLUSÃO}

Estabeleceram-se como critérios de exclusão: crianças com o diagnóstico de hipertermia maligna; disfunção neurológica; crianças a serem submetidas a algum procedimento durante o período de até 3 horas após administração do antitérmico.

\subsection{RANDOMIZAÇÃO}

O processo de randomização envolve a alocação aleatória dos participantes em grupo intervenção (GI) ou grupo controle (GC) e exige que os participantes tenham proporcional chance de ser alocados em qualquer um dos grupos. Quando realizada adequadamente, a randomização evita o viés de seleção e produz grupos de estudo comparáveis quanto a fatores de risco basais conhecidos e desconhecidos.

A randomização deste estudo foi realizada anteriormente ao início da coleta de dados, por meio do site www.randomizer.org, tendo sido confeccionados envelopes numerados em ordem sequencial. Ao incluir a criança no estudo, a coletadora abriu o envelope correspondente ao número de participação da criança inserida no estudo, indicando em que grupo a criança participaria de forma aleatória: grupo de intervenção ou grupo controle. 


\subsection{VARIÁVEIS}

\subsubsection{Variável primária}

Redução da temperatura axilar: variável quantitativa contínua. Dado coletado em todos os pacientes da amostra em graus Celsius por meio de termômetro digital.

\subsubsection{Variáveis secundárias}

Idade: variável quantitativa contínua. Estimada em meses e obtida através da identificação do paciente no formulário de coleta de dados.

Sexo: variável qualitativa categórica. Considerando-se sexo feminino e masculino, dado obtido da identificação do paciente no formulário de coleta de dados.

Unidade de Internação: variável qualitativa categórica. Sendo dividida em três setores em que ocorreu a coleta de dados: UTIped, UIped e PSI.

Tempo de internação: variável quantitativa contínua. Estimada em dias e obtida no formulário de coleta de dados.

Diagnóstico médico: variável qualitativa categórica. Obtida por meio do formulário de coleta de dados.

Medicamento em uso: variável qualitativa categórica. Obtida por meio do formulário de coleta de dados.

Via de administração: variável qualitativa categórica. Obtida por meio do formulário de coleta de dados, categorias: VO, EV, Enteral.

Irritabilidade: variável qualitativa categórica. O paciente foi classificado em: presença de irritabilidade ( $\operatorname{sim}$ ) ou (não), por meio de avaliação clínica realizada pelos coletadores.

Tremores: variável qualitativa categórica. O paciente foi classificado em: presença de tremores (sim) ou (não), por meio de avaliação clínica realizada pelos coletadores.

Choro: variável qualitativa categórica. O paciente foi classificado em: presença de choro (sim) ou (não), por meio de avaliação clínica realizada pelos coletadores. 


\subsection{RECRUTAMENTO E COLETA DE DADOS}

A coleta de dados foi realizada por enfermeiras e residentes de enfermagem da área pediátrica do Hospital Universitário da USP, com a participação da pesquisadora. Os coletadores (enfermeiras e residentes) foram devidamente treinados quanto à avaliação do paciente, ao uso dos equipamentos/materiais e ao registro dos dados durante a intervenção. $\mathrm{O}$ treinamento foi ministrado pela pesquisadora responsável antes do início da coleta, utilizando um manual de campo (APÊNDICE E). Esse procedimento teve o objetivo de uniformizar o significado de cada um dos itens do instrumento de coleta de dados e evitar vieses.

Em outro momento, foi realizada uma reunião de caráter informativo sobre a pesquisa, com as equipes assistenciais dos três setores. A finalidade desse encontro foi apresentar a pesquisa para a equipe e destacar a importância do envolvimento de todos. A equipe técnica atua diretamente no cuidado a crianças e, no presente estudo, desenvolveu um importante papel de facilitadora, indicando aos coletadores os possíveis pacientes elegíveis.

Após o início da coleta de dados, foi sugerida pelos coletadores a elaboração de um guia rápido para consulta, contendo informações resumidas (critérios de inclusão e exclusão, tempos de aferição da temperatura, temperatura da água para ser utilizada no grupo intervenção, locais e tempo de aplicação da compressa morna) para facilitar o processo de coleta de dados. Essas informações foram extraídas do manual de campo previamente confeccionado pela pesquisadora.

Posteriormente, as coletadoras da Unidade de Terapia Intensiva Pediátrica (UTIped) identificaram a necessidade de sinalizar na prancheta (prontuário de uso diário que contém: anotação de enfermagem, prescrição de enfermagem e médica e balanço hídrico) que a criança estava inserida na pesquisa, com o objetivo de facilitar a comunicação entre os diferentes plantões e auxiliar nas aferições de temperatura, pois a mensuração deveria ocorrer rigorosamente no horário estipulado. Esse impresso foi elaborado em conjunto com as enfermeiras (UTIped) e foi nomeado "Protocolo de febre" (APÊNDICE F) e posteriormente implementado em outras unidades (UIped e PSI).

$\mathrm{Na}$ condução da pesquisa, a criança e seu responsável foram convidados a participar do estudo conforme a randomização efetuada, tendo sido explicados os procedimentos a serem realizados. Os dados foram coletados por meio da aplicação do instrumento (APÊNDICE D) que se refere aos dados sociodemográficos das crianças do estudo. 
A operacionalização do estudo ocorreu da seguinte forma:

Grupo Controle (GC): a criança recebeu a terapia medicamentosa. A aferição da temperatura ocorreu nos seguintes momentos: $\mathrm{M}_{0}$ - Diagnóstico da febre pelo funcionário do hospital. $\mathrm{M}_{1}$ - Confirmação da febre pelo pesquisador com o termômetro digital padronizado, inserção da criança no estudo segundo os critérios de inclusão e administração do antitérmico prescrito pelo médico, $\mathbf{M}_{2}$ - Verificação da temperatura da criança 30 minutos após administração do antitérmico, $\mathrm{M}_{3}$ - Verificação da temperatura da criança 60 minutos após antitérmico e $\mathrm{M}_{4}$ - Verificação da temperatura da criança 3h após administração do antitérmico.

Grupo Intervenção (GI): a criança recebeu a terapia medicamentosa e em até 10 minutos, após administração do antitérmico, sendo aplicada a intervenção compressa morna por 15 minutos nas regiões frontal, axilar e inguinal. Em seguida, teve seu corpo seco. A aferição da temperatura ocorreu nos seguintes momentos: $\mathrm{M}_{0}$ - diagnóstico da febre pelo funcionário do hospital. $\mathrm{M}_{1}$ - Confirmação da febre pelo pesquisador com o termômetro digital padronizado, inserção da criança no estudo segundo os critérios de inclusão, administração do antitérmico prescrito pelo médico e aplicação de compressas mornas nas regiões frontal, axilar e inguinal por 15 minutos, $\mathrm{M}_{2}$ - Verificação da temperatura da criança 30 minutos após administração do antitérmico, $\mathrm{M}_{3}$ - Verificação da temperatura da criança 60 minutos após antitérmico e $\mathrm{M}_{4}$ - Verificação da temperatura da criança $3 \mathrm{~h}$ após administração do antitérmico (Figura 2). 
Figura 2 - Quadro explicativo: Tempos de aferição da temperatura corporal e sequência da intervenção. São Paulo, 2020

\begin{tabular}{|c|c|c|c|}
\hline $\mathbf{M}$ & Ações & Ator & Tempo \\
\hline $\mathrm{M}_{0}$ & Diagnóstico da febre com termômetro digital & Funcionário & \\
\hline $\mathrm{M}_{1}$ & $\begin{array}{l}\text { - Confirmação da febre com aferição da temperatura } \\
\text { com termômetro digital padronizado } \\
\text { - Administração do antitérmico segundo prescrição } \\
\text { médica } \\
\text { - Início das compressas mornas em fronte, axilas e } \\
\text { região inguinal na criança do GI }\end{array}$ & Coletador & Tempo 0 \\
\hline $\mathrm{M}_{2}$ & Verificação da temperatura com termômetro & Coletador & $\begin{array}{l}\text { Tempo } 1 \\
30 \text { min após } \\
\text { Tempo } 0\end{array}$ \\
\hline $\mathrm{M}_{3}$ & Verificação da temperatura com termômetro & Coletador & $\begin{array}{l}\text { Tempo } 2 \\
60 \text { min após } \\
\text { Tempo } 0\end{array}$ \\
\hline $\mathrm{M}_{4}$ & Verificação da temperatura com termômetro & Coletador & $\begin{array}{l}\text { Tempo } 3 \\
3 \text { h após } \\
\text { Tempo } 0\end{array}$ \\
\hline
\end{tabular}

Fonte: Dados do estudo

A aplicação da compressa morna foi realizada nas regiões frontal, axilar e inguinal por 15 minutos conforme a prática executada em nosso meio e exemplificada na literatura ${ }^{(33)}$.

Houve a opção metodológica por apenas um tipo de intervenção e que esta fosse “compressa morna”, pois é a intervenção não farmacológica de uso rotineiro na prática clínica utilizada por enfermeiros no Brasil. Não foi encontrada na literatura nacional a utilização da técnica do "sponging" como medida não farmacológica para o controle da febre em crianças. Além disso, observa-se, em alguns artigos nacionais, a utilização das expressões "compressas mornas" e "sponging" como técnicas equivalentes, entretanto a descrição da técnica na literatura internacional apresenta diferenças. Por outro lado, o mecanismo de perda de calor durante a aplicação de compressas mornas é semelhante ao da técnica "sponging", por meio do fenômeno de convecção. Não foi encontrada tradução para o termo sponging, porém, diante da leitura de diversos artigos, pode se observar que, fora do Brasil, a sponging é utilizada como intervenção equivalente a compressa morna $(20,25,27,33,34)$.

Em relação ao início da aplicação da compressa morna, estabeleceu-se o tempo de tolerância de até 10 minutos após a administração de antitérmico no Grupo Intervenção. 
Considerou-se que este seria o tempo de início de ação da medicação, não devendo ser ultrapassado, pois não seria mais possível determinar se a alteração da temperatura corporal da criança se deveu somente ao medicamento ou se houve interferência da aplicação de compressa morna.

Os momentos em que as temperaturas das crianças seriam aferidas foram determinados pela ação dos antitérmicos mais comuns utilizados em pediatria (Tabela 2).

Tabela 2 - Medicamentos antipiréticos, início de ação, duração da ação e via de administração

\begin{tabular}{cccc}
\hline MEDICAMENTO & INÍCIO DE AÇÃO & DURAÇÃO DA AÇÃO & VIA \\
\hline Paracetamol & $15-30$ minutos & $4-6$ horas & Oral \\
Dipirona & $30-60$ minutos & 4 horas & Via oral, enteral \\
& Imediata & $6-8$ horas & Via endovenosa \\
Ibuprofeno & 30 minutos & pico sérico de $1-2$ horas & Via oral \\
\hline
\end{tabular}

Fonte: ANVISA. Bulário eletrônico. Disponível em http://portal.anvisa.gov.br/bulario-eletronico1 ${ }^{(47)}$.

Os medicamentos antitérmicos foram administrados por via oral, enteral ou endovenosa. Para a intervenção usando compressa morna, a temperatura da água utilizada foi entre $34-37^{\circ} \mathrm{C}$, pois se considera um valor de temperatura aproximado, conforme referido em alguns estudos $(24,27,34)$.

Utilizou-se o termômetro clínico digital Termomed branco® (Figura 4) para aferição da temperatura axilar da criança, e a duração desse procedimento foi de 3-5minutos. Em relação à mensuração da temperatura da água, foi utilizado o termômetro digital de temperatura interna e externa máxima e mínima Incoterm (Figura 5). Esse procedimento foi realizado por uma vez previamente à intervenção, na tentativa de garantir a manutenção da temperatura, de característica morna, nas compressas utilizadas. 


\subsection{MATERIAIS E EQUIPAMENTOS}

Para a intervenção (compressas mornas), utilizou-se o pano multiuso Wiper Pro50®, tamanho $25 \mathrm{~cm}$ x $28 \mathrm{~cm}$ (Figura 3).

Figura 3 - Pano Wiper Pro50®

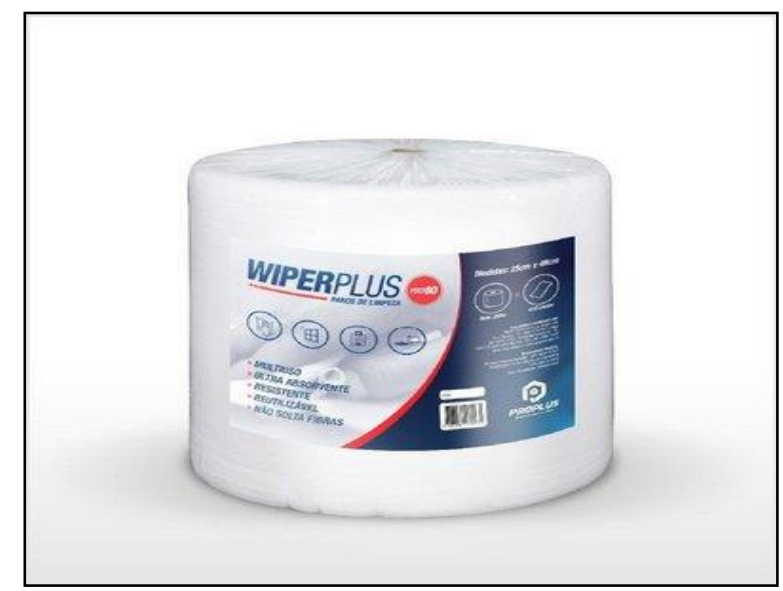

Fonte: Registro fotográfico obtido pela pesquisadora por meio do site: www.netsuprimentos.com.br.

Utilizou-se o termômetro clínico digital Termomed branco® para aferição da temperatura axilar (Figura 4).

Figura 4 - Termômetro clínico digital Termomed branco®

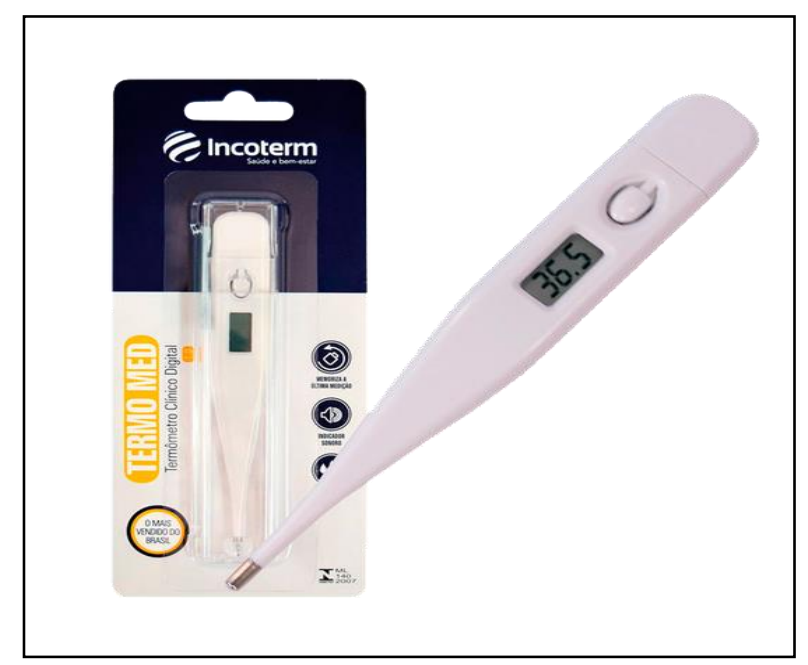

Fonte: Registro fotográfico obtido pela pesquisadora por meio do site: www.incoterm.com.br 
$\mathrm{Na}$ aferição da temperatura da água, utilizou-se o termômetro digital temperatura interno-externa máxima e mínima Incoterm® (Figura 5).

Figura 5 - Termômetro digital temperatura interna e externa máx e mín. Incoterm ${ }^{\circledR}$

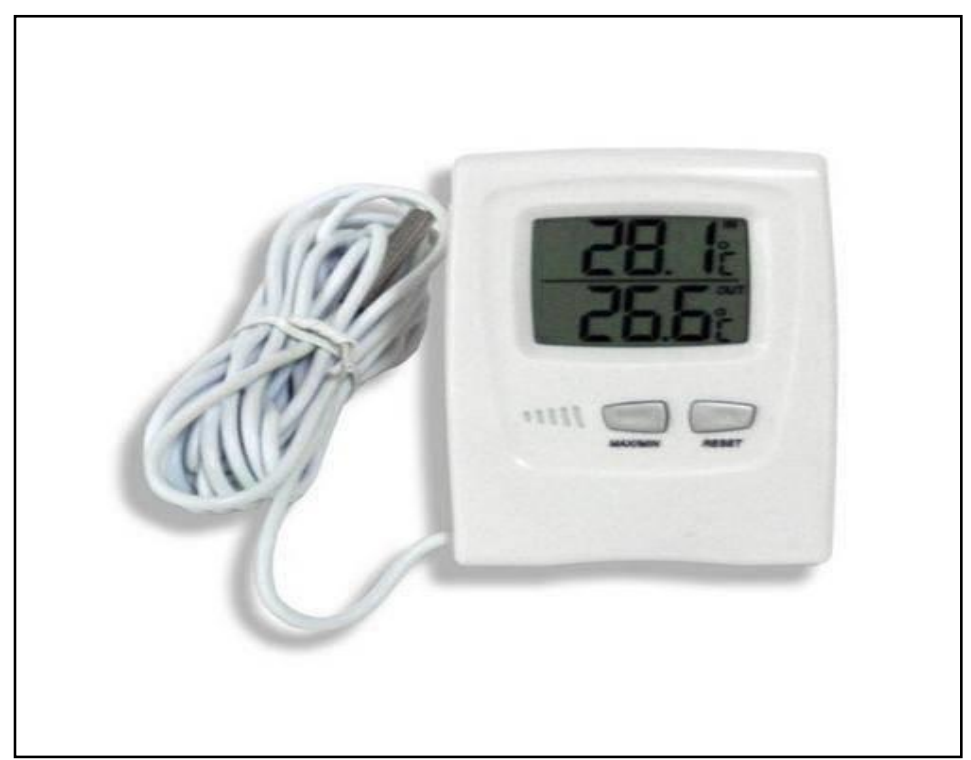

Fonte: Registro fotográfico obtido pela pesquisadora por meio do site: www.incoterm.com.br

Todos os materiais e equipamentos utilizados no estudo clínico foram providenciados pela pesquisadora com recursos próprios.

\subsection{PROCEDIMENTOS ÉTICO-LEGAIS E REGISTRO DO ENSAIO CLÍNICO}

O estudo obteve parecer favorável dos Comitês de Ética em Pesquisa (CEP) do Hospital Universitário da USP (CAAE $n^{\circ}$ 06472819.8.3001.0076/ Parecer do CEP: 3.604.872) e da Escola de Enfermagem da Universidade de São Paulo (CAAE $\mathrm{n}^{\circ}$ 06472819.8.0000.5392/ Parecer do CEP: 3.574.282). Seguiram-se as orientações determinadas nas diretrizes e normas regulamentadoras de pesquisa envolvendo seres humanos e na Resolução 466/2012 do Conselho Nacional de Saúde.

A pesquisa foi registrada no site do Registro Brasileiro de Ensaios Clínicos (ReBEC), obtendo o número de protocolo UTN- U1111-1229-1599. 


\subsection{ANÁLISE DOS DADOS}

Os dados foram armazenados e organizados em banco de dados, utilizando o programa Microsoft Office Excel $2007^{\circledR}$, o programa Statistica versão $13.5 .0 .17^{\circledR}$ e o programa R, pacotes $\mathrm{NLME}^{\circledR}, \mathrm{IME}^{\circledR}{ }^{\circledR}, \mathrm{HLM}^{\mathrm{Diag}}{ }^{\circledR}$, para a análise estatística da pesquisa. A análise descritiva dos dados foi realizada por meio da distribuição de frequência simples, medida de tendência central (média) e medidas de dispersão (variância e desvio-padrão), de acordo com a categorização da variável em estudo.

Para caracterizar a amostra em relação a idade, sexo, inserção da criança na pesquisa (momento), local de internação, antitérmico administrado e diagnósticos frequentes, assim como testar a significância desses itens, foram utilizados os testes estatísticos: Mann Whitney, Exato de Fisher e Qui-quadrado.

Utilizou-se a Análise da Variância (ANOVA) por tratar-se de um método paramétrico, que permite testar a igualdade de três ou mais médias populacionais, baseado na análise das variâncias amostrais. Os dados amostrais são separados em grupos segundo uma característica (fator). Fator (ou tratamento) é uma característica que permite distinguir diferentes populações umas das outras. Cada fator contém dois ou mais grupos (classificações) ${ }^{(48)}$.

Optou-se ainda por realizar um segundo tipo de modelagem, utilizado para análise de dados longitudinais: o Modelo de Regressão Linear Misto, também denominado popularmente como "Modelo de Efeitos Mistos".

O método Modelo de Efeitos Mistos é adequado para análise de dados biológicos e médicos, que exibem heterogeneidade de respostas a estímulos e tratamento. A ideia central desse teste é que os interceptos $\left\{\alpha_{\mathrm{i}}, \mathrm{i}=1, \ldots, N\right\}$ são randômicos e pertencem a uma população geral que pode ser expressa na segunda equação como $\alpha_{\mathrm{i}}=\alpha+b_{\mathrm{i}}$, onde $\alpha$ é a temperatura média da população (intercepto) e $b_{i}$ é o efeito aleatório. Os parâmetros $\alpha$ e $\beta$ são efeitos fixos (parâmetros de média populacional), enquanto $b_{i}$ é o efeito aleatório com zero $^{(49)}$.

Assim, foram hipóteses da pesquisa:

- $\mathrm{H}_{\text {nula }}$ ou $\mathrm{H}_{0}=$ a administração do medicamento antitérmico sozinho é tão eficaz para reduzir a temperatura corporal média da criança febril hospitalizada quanto a redução da temperatura ocorrida com as crianças que receberam antitérmico associado a intervenção compressas mornas; 
- $\mathrm{H}_{1}=\mathrm{A}$ intervenção da medida não farmacológica compressas mornas associada à administração do antitérmico é mais eficaz para reduzir a temperatura corporal média da criança febril hospitalizada. 
5 RESULTADOS 



\section{RESULTADOS}

Buscou-se, neste estudo, avaliar o efeito da aplicação da medida não farmacológica "compressa morna" em associação ao antitérmico prescrito, na redução da febre em crianças hospitalizadas, e comparar a variação da temperatura corporal entre os grupos Controle e Intervenção. No período de realização do estudo, a amostra foi composta por 37 crianças dez crianças no Pronto Socorro Infantil (PSI); 15 crianças na Unidade de Internação Pediátrica (UIped) e 12 crianças na Unidade de Terapia Intensiva Pediátrica (UTIped), que atenderam aos critérios de elegibilidade. Quatro crianças foram excluídas do estudo, pois, em três casos, houve falta do preenchimento de alguma medida da temperatura da criança e, no quarto caso, os dados sociodemográficos e clínicos da criança não foram devidamente preenchidos. Desse modo, a amostra da pesquisa foi de 33 crianças. Destas, 17 compuseram o Grupo Controle, tendo sido administrado somente o antitérmico e 16 crianças foram alocadas no Grupo Intervenção, tendo recebido o antitérmico e a aplicação da intervenção não farmacológica compressa morna. A distribuição dos participantes é apresentada na Figura 6, conforme fluxograma abaixo. 
Figura 6 - Fluxograma da distribuição das crianças, conforme as etapas da pesquisa. São Paulo, 2020

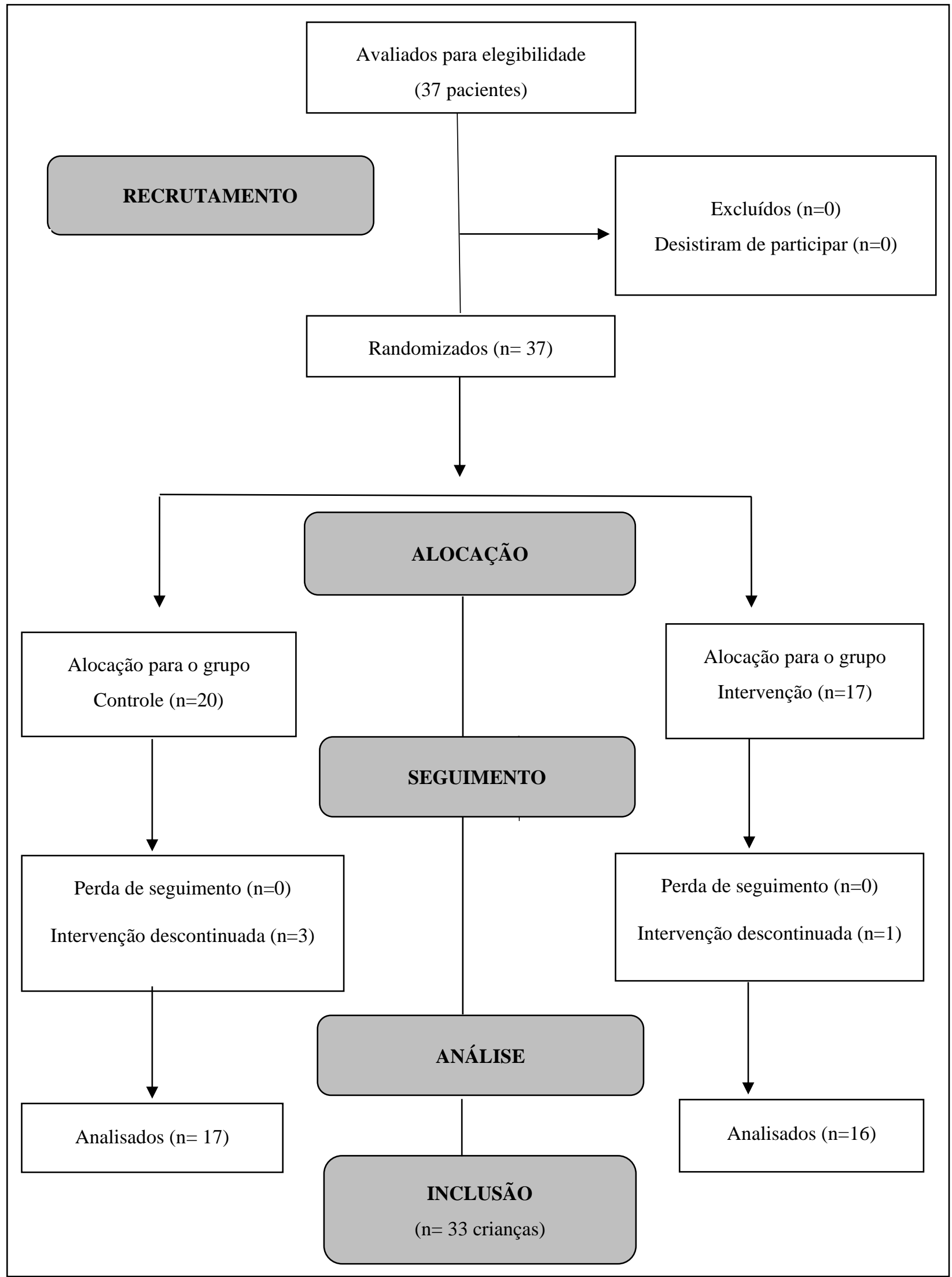

Fonte: Dados do estudo 


\subsection{CARACTERIZAÇÃO SOCIODEMOGRÁFICA E CLÍNICA DAS CRIANÇAS}

Em relação ao sexo, 17 crianças (52\%) eram do sexo masculino, enquanto 16 meninas representaram $48 \%$ da população do estudo. Quanto ao local de internação, sete crianças $(21,2 \%)$ estavam internadas no PSI, 15 (45,5\%) na UIped e $11(33,3 \%)$ na UTIped. Em relação ao medicamento antitérmico administrado: paracetamol $(\mathrm{GC}=6 ; 18 \% / \mathrm{GI}=4 ; 25 \%)$ e dipirona $(\mathrm{GC}=15 ; 88 \% / \mathrm{GI}=12 / 75 \%)$, não houve pacientes medicados com ibuprofeno. Quanto à variável "inserção da criança na pesquisa”, foi considerado o número de dias de internação, que precediam o momento da inserção da criança na pesquisa. Observou-se que 26 crianças haviam sido inseridas dentro do período de até 72 horas de internação, dado que se pode correlacionar com possível tempo de ação esperada dos antibióticos.

Tabela 3 - Caracterização dos pacientes de acordo com os grupos. São Paulo, 2020.

\begin{tabular}{|c|c|c|c|c|c|}
\hline \multirow{2}{*}{ Variáveis } & \multicolumn{2}{|c|}{ Grupo Controle $(n=17)$} & \multicolumn{2}{|c|}{ Grupo Intervenção $(\mathrm{n}=16)$} & \multirow{2}{*}{ p-valor* } \\
\hline & $\mathrm{N}$ & $\%$ & $\mathrm{~N}$ & $\%$ & \\
\hline \multicolumn{6}{|l|}{ Sexo } \\
\hline Feminino & 9 & $53 \%$ & 7 & $44 \%$ & \\
\hline Masculino & 8 & $47 \%$ & 9 & $56 \%$ & $0,5975^{*}$ \\
\hline \multicolumn{6}{|c|}{ Local da Internação } \\
\hline PSI & 6 & $35 \%$ & 1 & $6 \%$ & \\
\hline UIped & 7 & $41 \%$ & 8 & $50 \%$ & $0,1123 * *$ \\
\hline UTIped & 4 & $24 \%$ & 7 & $44 \%$ & \\
\hline \multicolumn{6}{|c|}{ Inserção da criança na pesquisa (horas) } \\
\hline$\leq 24$ horas & 10 & $59 \%$ & 3 & $19 \%$ & \\
\hline 24-72 horas & 4 & $23 \%$ & 9 & $56 \%$ & $0,084 * * *$ \\
\hline$>72$ horas & 3 & $18 \%$ & 4 & $25 \%$ & \\
\hline \multicolumn{6}{|l|}{ Medicamento } \\
\hline Paracetamol & 2 & $12 \%$ & 4 & $25 \%$ & \\
\hline Dipirona & 15 & $88 \%$ & 12 & $75 \%$ & $0,3983 * *$ \\
\hline Ibuprofeno & - & - & - & - & \\
\hline
\end{tabular}

Fonte: Coleta de dados no estudo.

Nota: *p-valor calculado com teste Qui-quadrado; **p-valor calculado com teste exato de Fisher; *** p-valor calculado com teste de Mann Whitney 
No que se refere à idade, as crianças pertenciam à faixa etária entre 1 mês e 9 anos e 5 meses $(M=30$ meses $=2$ anos e 5 meses; $D P=29$ meses $=2$ anos e 4 meses $)$, conforme a Tabela 4.

Tabela 4 - Dados comparativos da média e desvio-padrão da variável idade. São Paulo, 2020

\begin{tabular}{lccccc}
\hline \multirow{2}{*}{ Variáveis } & \multicolumn{2}{c}{ GRUPO CONTROLE } & \multicolumn{2}{c}{ GRUPO INTERVENÇÃo } \\
& \multicolumn{2}{c}{$(\mathbf{n}=\mathbf{1 7})$} & 16) & p-valor* \\
\cline { 2 - 5 } & Média & Desvio-Padrão & Média & Desvio-Padrão & \\
\hline Idade (meses) & 37 & 31 & 23 & 26 & 0,125 \\
\hline
\end{tabular}

Fonte: Coleta de dados no estudo

Nota: *p-valor calculado com o teste (Mann Whitney)

Em relação aos diagnósticos médicos dos participantes da pesquisa, as patologias respiratórias foram prevalentes, atingindo 21 (64\%) crianças, seguidas pelas patologias infecciosas cinco $(15 \%)$ crianças. O terceiro lugar foi ocupado pelas patologias diversas e gastrointestinais com três $(9 \%)$ crianças em cada grupo e, para uma criança, não havia a informação referente à causa da internação. A Tabela 5 apresenta esses dados.

Tabela 5 - Frequência dos diagnósticos médicos das crianças entre os grupos controle e intervenção. São Paulo, 2020

\begin{tabular}{|c|c|c|c|c|c|}
\hline \multirow[t]{2}{*}{ DIAGNÓSTICOS } & \multicolumn{2}{|c|}{$\begin{array}{c}\text { GRUPO CONTROLE } \\
n=17\end{array}$} & \multicolumn{2}{|c|}{$\begin{array}{c}\text { GRUPO INTERVENÇÃO } \\
n=16\end{array}$} & \multirow[t]{2}{*}{ p-valor* } \\
\hline & $\mathrm{n}$ & $\%$ & $\mathrm{n}$ & $\%$ & \\
\hline Patologias respiratórias & 12 & $70 \%$ & 9 & $56 \%$ & \multirow{4}{*}{$0,7279 *$} \\
\hline Patologias infecciosas & 2 & $12 \%$ & 3 & $19 \%$ & \\
\hline Patologias diversas & 1 & $6 \%$ & 2 & $12,5 \%$ & \\
\hline Patologias gastrointestinais & 1 & $6 \%$ & 2 & $12,5 \%$ & \\
\hline Patologia não identificada & 1 & $6 \%$ & - & - & \\
\hline
\end{tabular}

Fonte: Dados do estudo, São Paulo, 2020.

Nota: *p-valor calculado com o teste exato de Fisher. 
No que tange aos sinais adversos apresentados nas crianças no decorrer desta pesquisa, encontraram-se na amostra $(n=33)$ apenas duas crianças $(12,5 \%)$ que apresentaram irritabilidade e choro. Essa manifestação foi observada apenas no Grupo Intervenção. Em relato, as coletadoras mencionaram a dificuldade de realizar a intervenção (compressas mornas + antitérmico), em especial na Unidade de Internação Pediátrica. Esse fato se pode associar ao comportamento basal esperado em crianças de faixa etária abaixo de 3 anos (população predominante na amostra), que não estejam prostradas.

Tabela 6 - Frequência dos sinais adversos nas crianças dos grupos controle e intervenção. São Paulo, 2020

\begin{tabular}{|c|c|c|c|c|c|}
\hline \multirow{2}{*}{ Variáveis } & & \multicolumn{2}{|c|}{ GRUPO CONTROLE $(n=17)$} & \multicolumn{2}{|c|}{ GRUPO INTERVENÇÃO $(n=16)$} \\
\hline & & $\mathrm{n}$ & $\%$ & $\mathrm{~N}$ & $\%$ \\
\hline \multicolumn{6}{|l|}{ Irritabilidade } \\
\hline & Sim & - & - & 2 & 12,5 \\
\hline & Não & 17 & 100 & 14 & 87,5 \\
\hline \multicolumn{6}{|l|}{ Tremores } \\
\hline & Sim & - & - & - & - \\
\hline & Não & 17 & 100 & 16 & 100 \\
\hline \multicolumn{6}{|l|}{ Choro } \\
\hline & Sim & - & - & 2 & 12,5 \\
\hline & Não & 17 & 100 & 14 & 87,5 \\
\hline
\end{tabular}

Fonte: Dados do estudo. 


\subsection{EFEITO DA INTERVENÇÃO COMPRESSAS MORNAS}

O estudo propôs-se a demonstrar qual era a real eficácia da intervenção compressas mornas em crianças febris hospitalizadas medicadas com drogas antitérmicas. Assim, verificou-se que as temperaturas de todas as crianças febris diminuíram com o tempo, havendo atenuação progressiva, com as crianças tornando-se afebris somente em M4, 3h após o início da intervenção. Nota-se que, apesar de a média das temperaturas das crianças do GC estar mais elevada no M1 que a do GI, o GC obteve a média mais baixa no M4, apresentando um melhor desfecho, ainda que a diferença de temperatura tenha sido de $-0,5^{\circ} \mathrm{C}$, como demonstrado na Figura 7 e na Tabela 7 a seguir.

Figura 7 - Temperatura média dos grupos controle e intervenção e média total conforme os momentos da coleta de dados. São Paulo, 2020

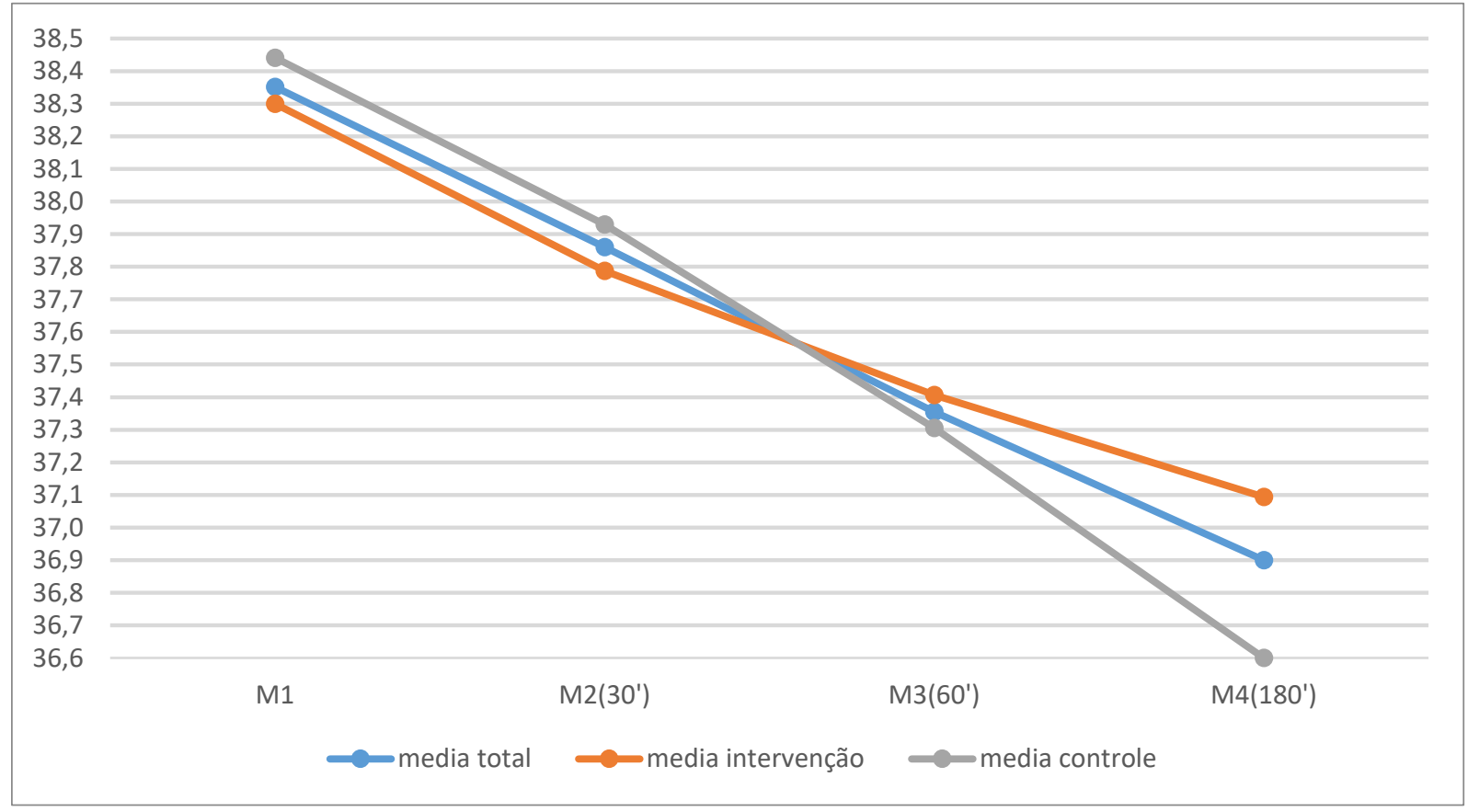

Fonte: Dados do estudo 
A seguir, na Figura 8, observa-se quanto cada grupo decresceu a temperatura entre os momentos de coleta de dados. Verifica-se que o Grupo Controle apresenta uma linha decrescente constante, enquanto que o Grupo Intervenção apresenta um decréscimo menor da temperatura em todos os momentos, culminando numa diferença de $0,5^{\circ} \mathrm{C}$ entre os dois grupos. Analisando-se as figuras 7 e 8, nota-se que, apesar de as crianças do GI apresentarem uma queda de temperatura maior no início da aplicação das compressas mornas, ao comparar com a Figura 8, vê-se que as do GC tiveram uma queda constante da temperatura e, após três horas, a média de temperatura é de $36,6^{\circ} \mathrm{C}$, enquanto a média do GI é de $37,1^{\circ} \mathrm{C}$.

Desse modo, apesar de não ser um dado estatisticamente significante, vide Tabela 8 , pode-se inferir que a intervenção compressas mornas não foi eficaz para ajudar a baixar a temperatura de crianças febris (GI) em comparação com o GC, que só foi medicado com antitérmico. Ressalta-se que a queda da temperatura no GI, em todos os momentos, foi inferior à queda apresentada pelo GC. Seria esperado que o GI tivesse o mesmo decréscimo de temperatura nos momentos que o GC ou mesmo maior se a intervenção fosse relevante.

Figura 8 - Diferenças de temperatura entre os momentos de coleta de dados e diferença de temperatura final dos Grupos Intervenção e Controle. São Paulo, 2020

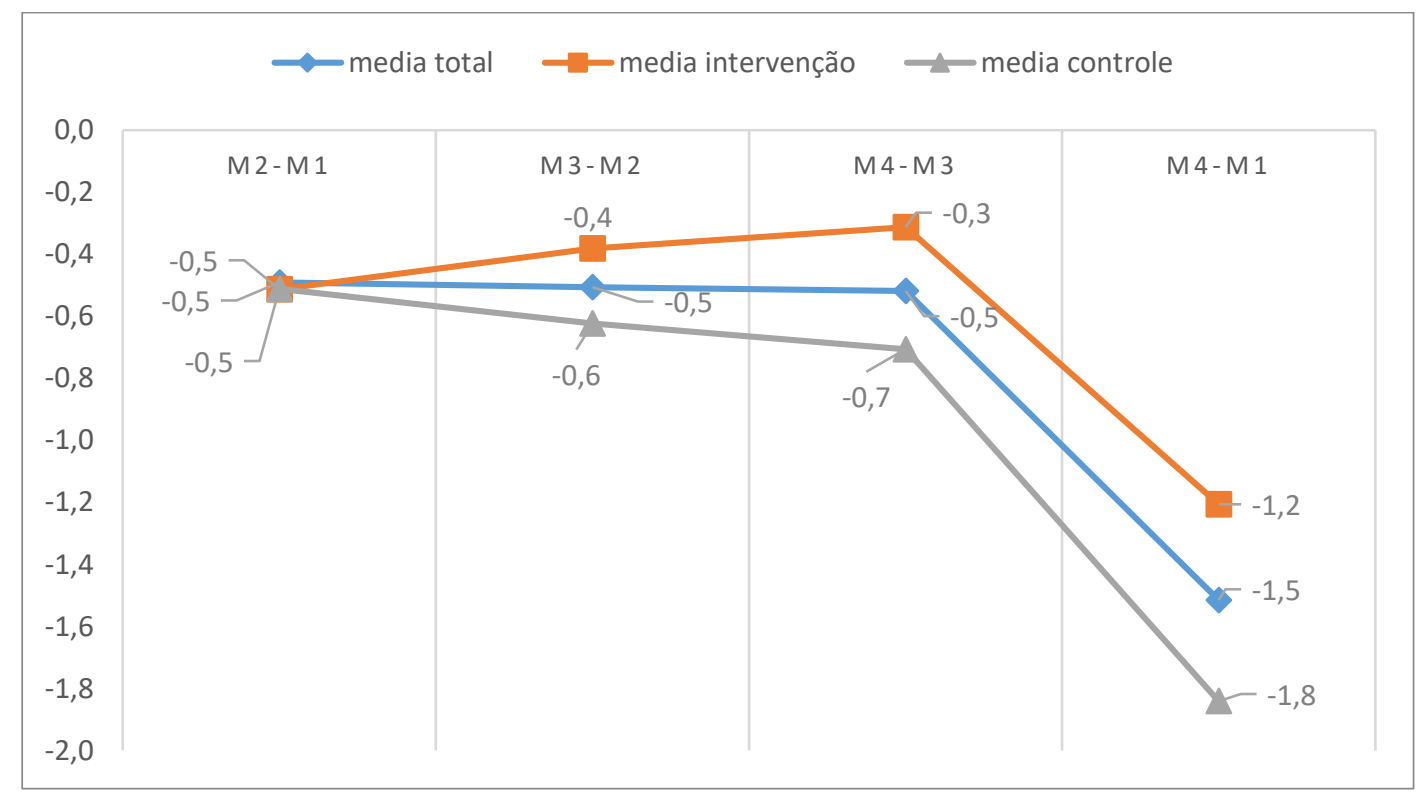

Fonte: Dados do estudo 
Na Figura 9, observa-se o momento 4 do estudo, onde se vê que a grande maioria das crianças terminou a intervenção afebril.

Figura 9 - Detalhamento do momento 4 classificado pelas temperaturas médias. São Paulo, 2020

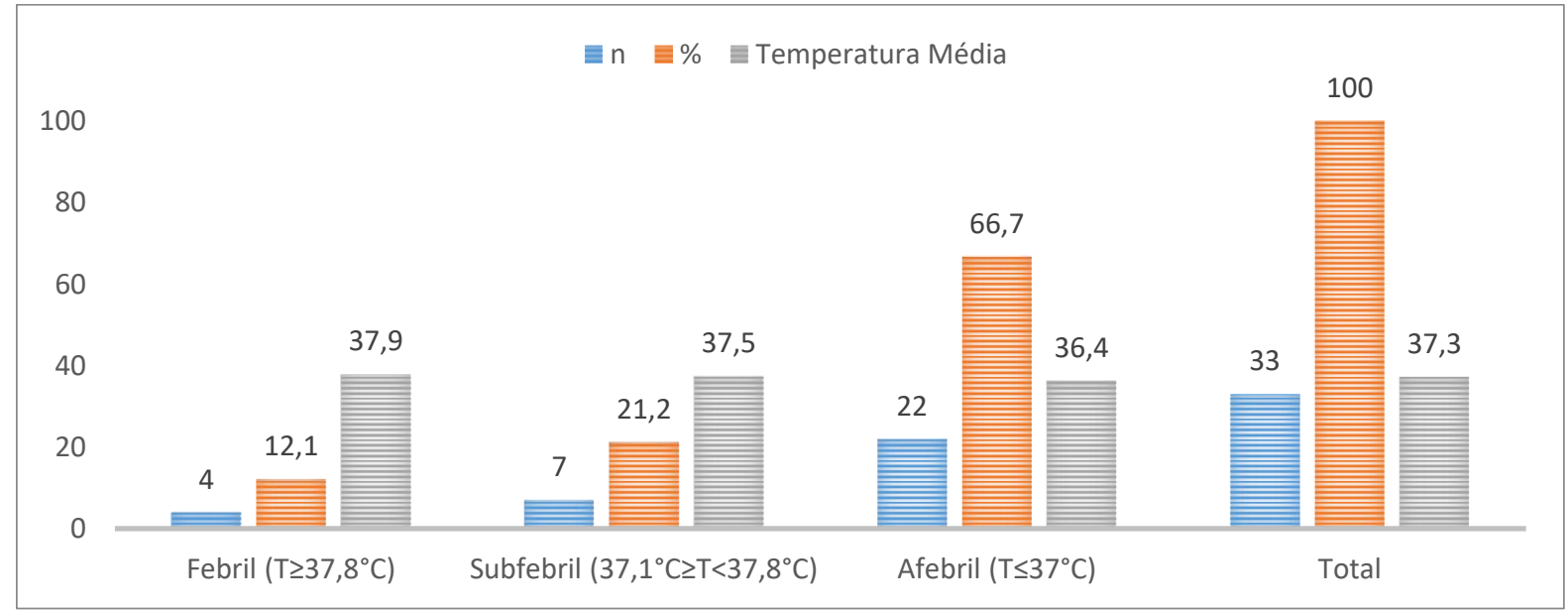

Fonte: Dados do estudo. 
Abaixo, na Tabela 7, podem-se analisar mais detalhadamente os valores de temperatura nos respectivos momentos de aferição nos grupos controle e intervenção.

Tabela 7 - Descritivas das temperaturas de acordo com os momentos de aferição e os grupos controle e intervenção. São Paulo, 2020

\begin{tabular}{lllcccc}
\hline \multicolumn{1}{c}{ Tempo (minutos) } & Grupo & n & Soma & Média & Variância & DP \\
\hline \multirow{2}{*}{ 0' - antitérmico } & Controle & 17 & 653,5 & $38,4(40-37,9)$ & 0,378 & $\pm 0,6$ \\
& Intervenção & 16 & 612,1 & $38,3(38,9-37,9)$ & 0,101 & $\pm 0,3$ \\
\multirow{2}{*}{ 30' após antitérmico } & Controle & 17 & 644,8 & $37,9(38,9-36,8)$ & 0,342 & $\pm 0,6$ \\
& Intervenção & 16 & 604,6 & $37,8(39,9-36,9)$ & 0,388 & $\pm 0,6$ \\
\multirow{2}{*}{ 60'após antitérmico } & Controle & 17 & 634,2 & $37,3(38-36,2)$ & 0,261 & $\pm 0,5$ \\
& Intervenção & 16 & 598,5 & $37,4(38,3-36,4)$ & 0,313 & $\pm 0,6$ \\
\multirow{2}{*}{ 180' após antitérmico } & Controle & 17 & 622,1 & $36,6(37,8-35,2)$ & 0,376 & $\pm 0,6$ \\
& Intervenção & 16 & 593,5 & $37,1(38,2-35,7)$ & 0,476 & $\pm 0,7$ \\
\hline
\end{tabular}

Fonte: Dados do estudo 
Utilizou-se o teste estatístico ANOVA para dados repetidos, por ser um teste adequado aos estudos longitudinais, que possuem várias medidas ao longo do tempo, representadas no presente estudo pelas quatro medidas de temperatura de cada criança participante. Desse modo, foram testadas todas as variáveis conforme apresentadas na Tabela 8.

Tabela 8 - Análise estatística ANOVA com os dados da pesquisa. São Paulo, 2020

\begin{tabular}{|c|c|c|c|c|c|}
\hline Efeito & $\begin{array}{c}\text { Soma de } \\
\text { quadrados }\end{array}$ & $\begin{array}{l}\text { Graus de } \\
\text { liberdade }\end{array}$ & $\begin{array}{l}\text { Quadrado } \\
\text { Médio }\end{array}$ & $\mathbf{F}$ & P-valor \\
\hline Grupo $^{1}$ & 0,24 & 1 & 0,240 & 0,32 & 0,574 \\
\hline Unidade de internação ${ }^{2}$ & 0,73 & 2 & 0,364 & 0,49 & 0,618 \\
\hline Grupo * Unidade de internação & 0,33 & 2 & 0,163 & 0,22 & 0,805 \\
\hline Momentos $^{3}$ & 23,62 & 3 & 7,875 & 39,83 & 0 \\
\hline Momentos * Grupo & 1,36 & 3 & 0,452 & 2,28 & 0,085 \\
\hline $\begin{array}{l}\text { Momentos * Unidade de } \\
\text { internação }\end{array}$ & 1,03 & 6 & 0,171 & 0,87 & 0,524 \\
\hline $\begin{array}{l}\text { Momentos * Grupo * Unidade de } \\
\text { internação }\end{array}$ & 0,88 & 6 & 0,146 & 0,74 & 0,618 \\
\hline
\end{tabular}

Fonte: Dados do estudo

Legenda: $\left({ }^{*}\right)$ - interação entre as variáveis; ${ }^{(1)} \mathrm{n}=33 ;{ }^{(2)}$ Unidade de internação; ${ }^{(3)}$ M1, M2, M3 e M4.

Observa-se, na Tabela 8, que a única variável estatisticamente significante foram momentos com $\mathrm{p}=0$. Desse modo, pode-se inferir que a aplicação de compressas mornas em crianças febris hospitalizadas pertencentes ao grupo de intervenção não foi eficaz, pois não foi estatisticamente significante. Também não fez diferença qual unidade de internação em que a criança estava alocada no momento da coleta de dados $(\mathrm{p}=0,618)$, bem como se a criança pertencia ao GC ou GI $(\mathrm{p}=0,574)$. Observa-se ainda, que a interação entre a variável momentos e as demais variáveis não foi significativa, indicando que somente o decréscimo da temperatura no período de três horas da coleta de dados foi significante, devido à administração do medicamento antitérmico. 
Na Figura 10, verifica-se a queda da temperatura das crianças ao longo do tempo.

Figura 10 - Gráfico da variação da temperatura nos quatro momentos de aferição. São Paulo, 2020

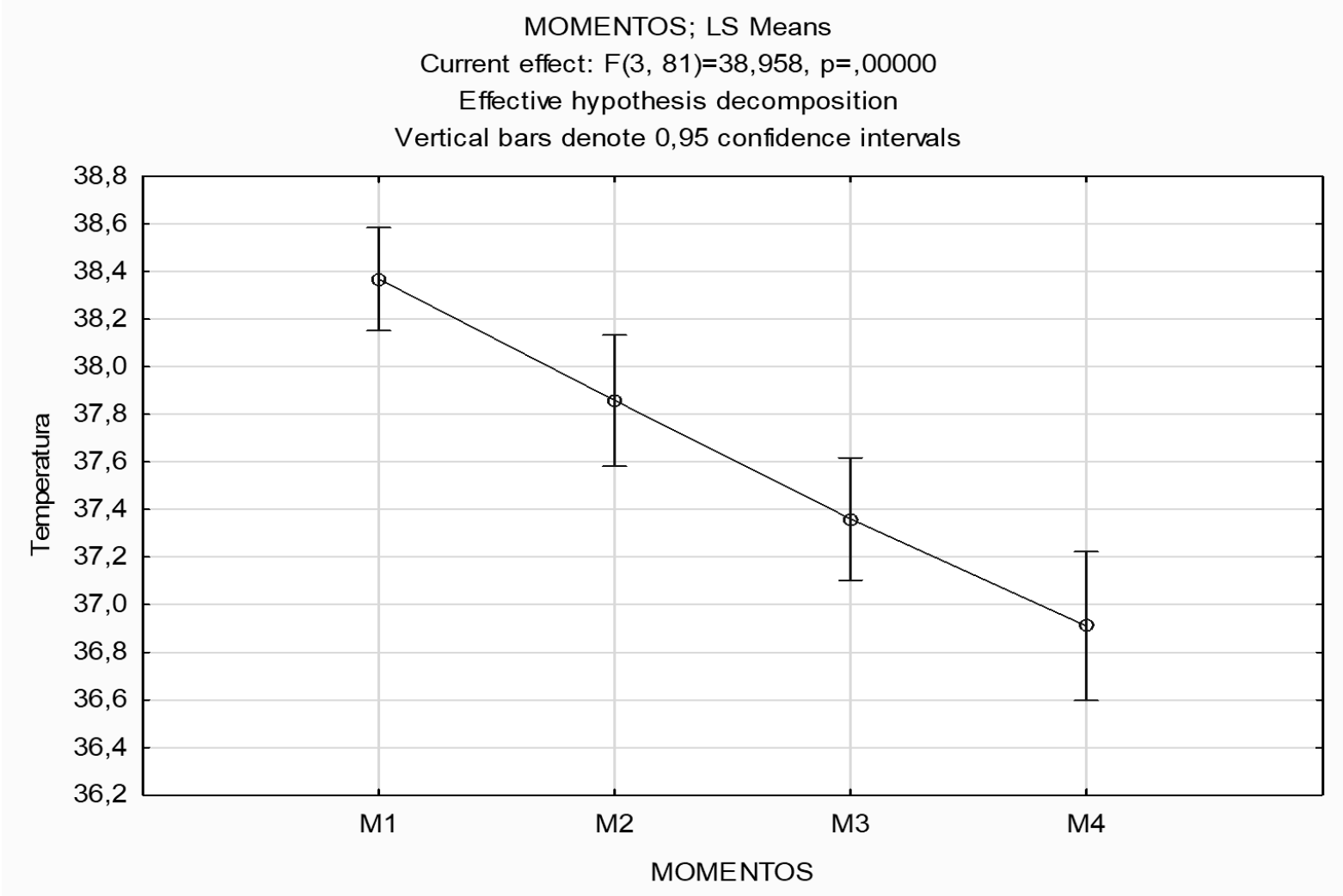

Fonte: Dados do estudo 
A partir da Tabela 8 , construiu-se a Tabela 9 com as variáveis significativas a $5 \%$.

Tabela 9 - Temperatura média e desvio-padrão nos quatro momentos. São Paulo, 2020

\begin{tabular}{cccc}
\hline Momentos & Temperatura Média & Desvio- padrão & IC de 95\% \\
\hline M1 & 38,4 & 0,104 & {$[38,2 ; 38,6]$} \\
M2 & 37,9 & 0,134 & {$[37,6 ; 38,1]$} \\
M3 & 37,4 & 0,125 & {$[37,1 ; 37,6]$} \\
M4 & 36,9 & 0,153 & {$[36,6 ; 37,2]$} \\
\hline
\end{tabular}

Fonte: Dados do estudo.

Foi ainda realizado o Teste de Esfericidade de Mauchly, verificando-se que a hipótese da esfericidade foi violada com $p=0,011881(\mathrm{p} \leq 0,05)$. Desse modo, foi necessário calcular as correções de Greenhouse-Geisser e de Huynh-Feldt para contornar a violação de esfericidade. A fim de escolher entre o teste de Greenhouse-Geisser ou Huynh-Feldt, deve-se observar o valor de Epsilon. Para valores de Epsilon $\leq$ 0,75, deve-se utilizar Greenhouse-Geisser e >0,75, o teste de Huynh-Feldt ${ }^{(50-51)}$.

Tabela 10 - Correções de Greenhouse-Geisser e Huynh-Feldt. São Paulo, 2020

\begin{tabular}{|c|c|c|c|c|}
\hline Efeitos & $\begin{array}{c}\text { G-G } \\
\text { Epsilon }\end{array}$ & $\begin{array}{l}\text { G-G Adj } \\
\text { P-valor }\end{array}$ & $\begin{array}{c}\text { H-F } \\
\text { Epsilon }\end{array}$ & $\begin{array}{c}\text { H-F Adj, } \\
\text { P-valor }\end{array}$ \\
\hline Momentos $^{3}$ & 0,771 & 0 & 1 & 0 \\
\hline Momentos $^{3 * \text { grupo }^{1}}$ & 0,771 & 0,102 & 1 & 0,085 \\
\hline Momentos $^{3 *}$ unidade de internação ${ }^{2}$ & 0,771 & 0,503 & 1 & 0,524 \\
\hline Momentos $^{3 *}$ Grupo $^{1 *}$ Unidade de internação ${ }^{2}$ & 0,771 & 0,586 & 1 & 0,618 \\
\hline
\end{tabular}

Legenda: $(*)$ - Interação entre as variáveis $/{ }^{(1)}=$ grupo - 33 pacientes/ ${ }^{(2)}$ Enfermaria de Pediatria/ ${ }^{(3)}$ M1, M2, M3 e M4. Fonte: Dados do estudo

Portanto, pela análise ANOVA para dados repetidos, pode-se observar que a temperatura reduz conforme os "Momentos" (tempos de aferição: 0, 30 minutos, 1 hora e 3 horas), não sendo importante o "Grupo" (controle ou intervenção) no qual a criança está alocada. Assim como se torna indiferente o local em que a criança está internada. Os dados sugerem que a redução da temperatura está relacionada ao uso do antitérmico e que a aplicação das compressas mornas como intervenção complementar não teve significância na redução da temperatura para o grupo de crianças participantes deste estudo. 
De forma complementar, a fim de embasar os resultados e atribuir maior fidelidade à análise, foi realizado o teste estatístico Modelo de Efeitos Mistos, utilizando a variação da temperatura corporal de crianças febris que receberam o medicamento antitérmico em associação com a intervenção não farmacológica "compressa morna" em comparação com aquelas que receberam somente o antitérmico. Nessa análise, foi ajustado um modelo misto com intercepto aleatório seguindo normalidade.

A variável resposta do modelo misto foi a temperatura, que segue distribuição normal e como covariáveis: indicadora do Momento 2, indicadora do Momento 3, indicadora do Momento 4, indicadora do grupo intervenção, indicadora da Unidade de Internação Pediátrica (UIped), indicadora da Unidade de Terapia Intensiva Pediátrica (UTIped), indicadora do sexo masculino, idade em meses, tempo de internação em dias, indicadora do medicamento dipirona, indicadora da via de administração intravenosa, indicadora da via de administração enteral, indicadora de choro, indicadora de irritabilidade, indicadora do diagnóstico 1 (patologias respiratórias), indicadora do diagnóstico 2 (patologias infecciosas), indicadora do diagnóstico 3 (patologias diversas), indicadora do diagnóstico 4 (patologias gastrointestinais), conforme Tabela 11. 
Tabela 11 - Estimativas do modelo misto com intercepto aleatório. São Paulo, 2020.

\begin{tabular}{lcccc}
\hline & Estimativa & Desvio-padrão & IC de 95\% & P-valor \\
\hline Intercepto & 37,712 & 0,703 & {$[36,3 ; 39,1]$} & 0,000 \\
\hline Indicadora do Momento 2 & $-0,482$ & 0,117 & {$[-0,713 ;-0,250]$} & $<0,001$ \\
\hline Indicadora do Momento 3 & $-0,988$ & 0,117 & {$[-1,219 ;-0,756]$} & 0,000 \\
\hline Indicadora do Momento 4 & $-1,506$ & 0,117 & {$[-1,737 ;-1,274]$} & 0,000 \\
\hline $\begin{array}{l}\text { Indicadora do grupo } \\
\text { Intervenção }\end{array}$ & 0,082 & 0,200 & {$[-0,339 ; 0,504]$} & 0,685 \\
\hline $\begin{array}{l}\text { Indicadora da Unidade de } \\
\text { Internação- UIped }\end{array}$ & $-0,023$ & 0,377 & {$[-0,818 ; 0,772]$} & 0,952 \\
\hline $\begin{array}{l}\text { Indicadora da Unidade de } \\
\text { Terapia Intensiva - UTIped }\end{array}$ & 0,081 & 0,574 & {$[-1,130 ; 1,293]$} & 0,889 \\
\hline $\begin{array}{l}\text { Indicadora do sexo masculino } \\
\text { Idade em meses }\end{array}$ & $-0,053$ & 0,207 & {$[-0,489 ; 0,384]$} & 0,802 \\
\hline $\begin{array}{l}\text { Tempo de internação em dias } \\
\text { Indicadora do medicamento } \\
\text { dipirona }\end{array}$ & 0,001 & 0,004 & {$[-0,006 ; 0,009]$} & 0,70 \\
\hline $\begin{array}{l}\text { Indicadora da via de } \\
\text { administração intravenosa }\end{array}$ & $-0,035$ & 0,029 & {$[-0,096 ; 0,027]$} & 0,249 \\
\hline $\begin{array}{l}\text { Indicadora da via de } \\
\text { administração enteral }\end{array}$ & 0,419 & 0,306 & {$[-0,227 ; 1,066]$} & 0,189 \\
\hline $\begin{array}{l}\text { Indicadora de choro } \\
\text { Indicadora de irritabilidade }\end{array}$ & $-0,517$ & 0,415 & {$[-1,392 ; 0,357]$} & 0,229 \\
\hline $\begin{array}{l}\text { Indicadora diagnóstico 1 } \\
\text { (patologias respiratórias) }\end{array}$ & 0,119 & 0,534 & {$[-1,006 ; 1,245]$} & 0,826 \\
\hline $\begin{array}{l}\text { Indicadora diagnóstico 2 } \\
\text { (patologias infecciosas) }\end{array}$ & 0,609 & 0,473 & {$[-0,388 ; 1,607]$} & 0,215 \\
\hline $\begin{array}{l}\text { Indicadora diagnóstico 3 } \\
\text { (patologias diversas) }\end{array}$ & 0,634 & 0,683 & {$[-1,645 ; 1,237]$} & 0,769 \\
\hline $\begin{array}{l}\text { Indicadora diagnóstico 4 } \\
\text { patologias gastrointestinais) }\end{array}$ & 0,271 & 0,564 & {$[-0,607 ; 1,771]$} & 0,316 \\
\hline & & 0,578 & {$[-0,766 ; 1,671]$} & 0,444 \\
\hline
\end{tabular}

Fonte: Dados do estudo 
Conforme a Tabela 11, observa-se que apenas as variáveis relacionadas com a temperatura: indicadora do momento 2 , indicadora do momento 3 , indicadora do momento 4 , foram significativas a 5\%. Dessa maneira, pode-se elaborar uma nova tabela com modelo reajustado, contendo as estimativas do modelo misto final com intercepto aleatório (Tabela 12).

Tabela 12 - Estimativas do modelo misto final com intercepto aleatório. São Paulo, 2020

\begin{tabular}{ccccc}
\hline & Estimativa & Desvio-padrão & IC de 95\% & P-valor \\
\hline Intercepto & 38,342 & 0,102 & {$[38,140 ; 38,545]$} & 0 \\
\hline $\begin{array}{c}\text { Indicadora do } \\
\text { momento 2 }\end{array}$ & $-0,482$ & 0,117 & {$[-0,713 ;-0,250]$} & $<0,001$ \\
$\begin{array}{c}\text { Indicadora do } \\
\text { momento 3 }\end{array}$ & $-0,988$ & 0,117 & {$[-1,219 ;-0,756]$} & 0 \\
\hline $\begin{array}{c}\text { Indicadora do } \\
\text { momento 4 }\end{array}$ & $-1,506$ & 0,117 & {$[-1,737 ;-1,274]$} & 0 \\
\hline
\end{tabular}

Fonte: Dados do estudo.

Dessa forma, constata-se que, para os indivíduos com a mesma estimativa do termo aleatório, estar no momento 2 reduz a temperatura em 0,482, mantendo as outras variáveis constantes. Para os indivíduos com a mesma estimativa do termo aleatório, estar no momento 3 diminui a temperatura em 0,988, mantendo as outras variáveis constantes. Enquanto, para os indivíduos com a mesma estimativa do termo aleatório, estar no momento 4 diminui a temperatura em 1,506, mantendo as outras variáveis constantes.

Observa-se nas crianças avaliadas neste estudo que a intervenção aplicação de “compressas mornas" como método coadjuvante não apresentou evidências do auxílio na redução da temperatura dessas crianças. $\mathrm{Na}$ análise dados, não se observou significância em relação ao grupo de que a criança participasse. A variável "Unidade de internação" também não se mostrou importante para explicar as alterações de temperatura sofridas pelas crianças.

Portanto, tanto a partir da análise ANOVA quanto da análise de Modelo de Efeitos Mistos, podem-se concluir os seguintes fatos: a temperatura reduz conforme os momentos considerados (Tabela 9), não há diferença na redução da temperatura das crianças entre os grupos, pois a intervenção não farmacológica "compressa morna" não se mostrou significativa para explicar a diminuição da temperatura das crianças deste estudo. 

6 DISCUSSÃO 



\section{DISCUSSÃO}

Algumas práticas assistenciais da enfermagem têm sido executadas com base no conhecimento empírico. Esse cenário pode ser evidenciado na literatura, em que se observou que as principais fontes de evidências utilizadas pelos enfermeiros hospitalares foram: experiência pessoal e protocolos assistenciais locais ${ }^{(50)}$. O uso da intervenção compressas mornas é uma dessas práticas empíricas amplamente empregadas pela enfermagem para manejo de crianças febris hospitalizadas, concentrando-se para crianças na faixa etária de 1 mês a 5 anos de idade ${ }^{(29)}$.

Entretanto, até o momento, não houve um consenso sobre a eficácia do uso de compressas mornas. Os estudos realizados são contraditórios, pois alguns demonstraram que a intervenção compressas mornas ou sponging tem um efeito sinérgico com o antitérmico, sendo mais rápida e duradoura a diminuição da temperatura corporal da criança febril, do que somente a administração do antitérmico. Enquanto outros estudos mostram que a intervenção compressas mornas ou sponging não faz diferença, sendo o medicamento o único responsável pela queda da temperatura da criança $(20,29,33-34,37)$.

Nesse sentido, há um movimento mundial crescente na área da saúde para melhoria da qualidade dos serviços, que integra a segurança do paciente, o controle dos custos e a qualidade assistencial. Desse modo, Práticas Baseadas em Evidências surgem como uma ferramenta para solucionar um determinado problema, para prestar o cuidado de enfermagem baseado na melhor evidência, proveniente de estudos bem delineados e adaptado às preferências e valores do paciente, bem como à expertise do profissional de saúde ${ }^{(50)}$.

Este estudo objetivou contribuir com evidências fidedignas sobre o uso de compressas mornas como uma intervenção não farmacológica à criança febril hospitalizada, a fím de que os enfermeiros pudessem prestar uma assistência de qualidade. Assim, o presente estudo se propôs a investigar o efeito dessa intervenção associada ao antitérmico prescrito à criança. Foram testados dois métodos de tratamento da febre em crianças hospitalizadas: a um grupo foi administrado somente do medicamento antitérmico e o outro grupo foi tratado com o medicamento antitérmico acrescido da intervenção não farmacológica compressas mornas.

Em relação aos dados demográficos e clínicos do estudo, pode-se constatar que o maior número de pacientes pertencia à faixa etária de 1 mês a 3 anos de idade, com média 
aproximada de 2 anos e 5 meses de idade. A maior queixa clínica e principal causa de hospitalização foram as doenças respiratórias (64\%), corroborando os dados da literatura tanto nacional como internacional ${ }^{(51-52)}$.

Diferentemente do que aponta a literatura internacional, nacional e também no HUUSP, a droga antitérmica de escolha foi a dipirona, porém sem significância estatística, em relação ao ibuprofeno e paracetamol. Existem outros estudos internacionais sobre os três medicamentos mais usados na prática clínica da pediatria, porém também não há um consenso definitivo sobre o uso preferencial de algum deles ${ }^{(53-54)}$.

Quanto à terapia combinada de antitérmico e métodos físicos para auxiliar na redução da temperatura corporal em crianças, há alguns estudos que comparam a aplicação de compressa morna associada a antitérmico versus apenas a administração de antitérmico ${ }^{(29,34)}$. Os resultados são controversos: há estudos em que a aplicação de método físico compressas mornas ou sponging atua sinergicamente com o antitérmico administrado à criança ${ }^{(29)}$; já a revisão Cochrane (2003) não encontrou evidências suficientes que comprovassem que métodos físicos são eficazes, porém afirmou que a aplicação de método físico em conjunto com antitérmico é melhor que de antitérmico sozinho. Outro estudo afirma que, apesar de não ter resultados estatisticamente significantes, o uso de método físico e antitérmico é melhor que o antitérmico sozinho, a equipe de saúde acredita que, ainda assim, há indicação clínica da aplicação de métodos não farmacológicos em adição a antitérmico ${ }^{(20)}$. Há um estudo que demonstrou que, apesar de o método físico ter contribuído para a diminuição da temperatura corporal no início no grupo intervenção, os dois grupos terminaram praticamente com a mesma temperatura no final ${ }^{(29,33)}$.

Outra questão interessante refere-se ao valor da temperatura corporal para ser considerada febre. Na prática clínica pediátrica, considera-se febre em crianças a temperatura corporal $\geq 37,8{ }^{\circ} \mathrm{C}$ na maioria dos casos. Entretanto, estudos nacionais e internacionais relatam como critério de elegibilidade crianças com temperatura corporal acima de $38^{\circ} \mathrm{C}$ ou até acima de $38,3^{\circ} \mathrm{C}^{(20,29,33)}$. Apesar de este estudo ter partido de uma temperatura mais baixa, ao final de três horas, a média de temperatura corporal das crianças era, em sua maioria, abaixo de $37^{\circ} \mathrm{C}$.

O nível de desconforto observado na pesquisa foi bastante pequeno, uma vez que apenas duas crianças $(12,5 \%)$ do Grupo Intervenção apresentaram irritabilidade $(p=0,215)$ e choro ( $\mathrm{p}=0,769)$. Diferentemente, em outros estudos, o nível de desconforto foi maior no Grupo Intervenção, sendo estatisticamente significante $(\mathrm{p}<0.001)^{(29,33,34,37)}$. Talvez, devido à 
amostra pequena desta pesquisa ou talvez por ser o Brasil um país tropical e os dados terem sido colhidos no período de verão, não se tenha observado uma grande incidência de desconforto nas crianças participantes do estudo.

Entretanto, houve relatos das enfermeiras coletadoras sobre a dificuldade em manter as crianças em repouso durante os 15 minutos da aplicação das compressas mornas. Esse fato não foi mencionado na literatura pesquisada, porém é um dado que deve ser levado em consideração, pois as crianças, em geral, são bastante ativas, em especial, até os três anos de idade, mesmo doentes.

Diante desse cenário, a partir dos resultados obtidos com esse estudo piloto, nessa população, confirmou-se a Hnula: a administração do medicamento antitérmico sozinho é tão eficaz para reduzir a temperatura corporal média da criança febril hospitalizada quanto à redução da temperatura corporal média apresentada pelas crianças que receberam antitérmico associado à intervenção da medida não farmacológica compressas mornas.

\subsection{LIMITAÇÕES E POTENCIALIDADES DO ESTUDO}

Entre as limitações do estudo, podem-se citar a coleta de dados, pois era necessário aguardar os pacientes elegíveis apresentarem pico febril para participarem da pesquisa, e a disponibilidade do coletador naquele momento para coletar os dados, diante da dinâmica da unidade e escala de colaboradores vigente. Outro fator que interferiu no estudo foi a baixa taxa de ocupação hospitalar, no período da coleta de dados, bem como os dados terem sido colhidos em somente uma instituição. É importante salientar que este estudo foi realizado com uma amostra de 33 pacientes, formato piloto, não podendo ser aplicado a qualquer população.

Como potencialidades desta pesquisa, destaca-se o tipo de estudo, pois se trata de um ensaio clínico randomizado, que confere um alto nível de evidência científica à pesquisa, tornando-se um estudo relevante para a prática de enfermagem pediátrica. Embora não tenha ocorrido o mascaramento de pacientes, coletadores e pesquisadora, o desfecho do estudo é um dado mensurado que segue os critérios exigidos para estudos dessa categoria, isento de vieses que pudessem comprometer a pesquisa. 


\subsection{IMPLICAÇÕES PARA A ENFERMAGEM}

O estudo traz para o enfermeiro a possibilidade de questionar se as práticas da enfermagem pediátrica que fazem parte da rotina da assistência são realmente necessárias e eficazes. A aplicação de compressas mornas, nesta e em outras pesquisas, não se mostrou eficaz como coadjuvante do tratamento da febre da criança hospitalizada. Nesse sentido, novos estudos são necessários com um maior número de crianças e em diferentes cenários a fim de o resultado a favor da aplicação de compressas mornas ou contra possa ser generalizado para todas as populações pediátricas. 



\section{CONCLUSÃO}

Avaliou-se o efeito da aplicação da compressa morna em associação ao antitérmico prescrito na redução de febre em crianças hospitalizadas. Os desfechos sugerem que não há indicação de aplicação de compressas mornas como um método coadjuvante ao antitérmico ou qualquer intervenção não farmacológica em paciente pediátrico febril sem comorbidades, independentemente do contexto em que ele estiver inserido, pois indica que o procedimento apenas consome o tempo de assistência de enfermagem e pode não oferecer um resultado benéfico ao paciente. 



\section{REFERENCIAS}





\section{REFERÊNCIAS}

1. Pereira GL, Tavares NU, Mengue SS, Pizzol T da S. Therapeutic procedures and use of alternating antipyretic drugs for fever management in children. J Pediatr. 2013;89(1):25-32.

2. Beard RM, Day MW. Fever and hyperthermia: learn to beat the heat. Nursing. 2008;38(6):28-31.

3. McDougall P, Harrison M. Fever and feverish illness in children under five years. Nurs Stand. 2014;28(30):49-59.

4. El-Radhi AS, Carrol J, Klein N. Clinical manual of fever in children. New York: Springer; 2009.

5. Ramanujan M, Gulati S, Tyagi A. Malignant hyperthermia: an Indian perspective. J Anaesthesiol Clin Pharmacol. 2019;35(4):557-8.

6. Silva HCA, Ferreira G, Rodrigues G, Santos JM, Andrade PM, Hortense A, et al. Profile of malignant hyperthermia susceptibility reports confirmed with muscular contracture test in Brazil. Rev Bras Anestesiol. 2019;69(2)152-9.

7. El-Radhi AS. Determining fever in children: the search for an ideal thermometer. Br J Nurs. 2014;23(2):91-4.

8. Olympia RP. School nurses on the front lines of medicine: A student with fever and sore throat. NASN Sch Nurse. 2016;31(3):150-2.

9. Martins M, Abecasis F. Healthcare professionals approach paediatric fever in significantly different ways and fever phobia is not just limited to parents. Acta Paediatr. 2016;105(7):829-33.

10. El-Radhy AS. Why is the evidence not affecting the practice of fever management? Arch Dis Child. 2008;93(11):918-20.

11, Clarke P. Evidence-based management of childhood fever: What pediatric nurses need to now. J Pediatr Nurs. 2014;29(4),372-5.

12. Cannon JG. Perspective on fever: The basic science and conventional medicine. Complement Ther Med. 2013;21(1):54-60.

13. Székely M, Garai J. Thermoregulation and age. In: Romanovsky AA, editor. Thermoregulation: from Basic Neuroscience to Clinical Neurology, Part I. New York: Elsevier; 2018. p. 377-95. 
14. Smith CJ. Pediatric Thermoregulation: Considerations in the Face of Global Climate Change. Nutrients. 2019;11(9).

15. Hall JE, Guyton AC. Tratado de Fisiologia Médica Etradução Alcides Marinho Junior et al]. 12a ed. Rio de Janeiro: Elsevier; 2011. Temperatura corporal, regulação da temperatura e febre; p. 915-6.

16. Kreith F, Bohn MS. Principios de transferência de calor. São Paulo: Edgard Blucher; 1977; p.1-21.

17. Mendes KDS, Silveira RCCP, Galvão CM. Revisão integrativa: Método de Pesquisa para a incorporação de evidências na Saúde e na Enfermagem. Texto Contexto Enferm. 2008;17(4):758-64.

18. Santos CMC, Pimenta CAM, Nobre MRC. A estratégia PICO para a construção da pergunta de pesquisa e busca de evidências. Rev Latino-Am Enfermagem. 2007;15(3):508-11.

19. Moher D, Liberati A, Tetzlaff J, Altman DG. The PRISMA Group. Principais itens para relatar revisões sistemáticas e meta-análises: A recomendação PRISMA [Tradução para o idioma português]. Epidemiol Serv Saúde. 2015;24(2):335-42.

20. Salgado PO, Silva LCR, Silva PMA, Paiva IRA, Macieira TGR, Chianca TCM. Cuidados de enfermagem a pacientes com temperatura corporal elevada: revisão integrativa. Rev Min Enferm. 2015;19(1):212-19.

21. Axelrod P. External cooling in the management of fever. Clin Infect Dis. 2000;31(5):224-9.

22. Thompson HJ, Kirkness CJ, Mitchell PH, Webb DJ. Fever management practices of neuroscience nurses: national and regional perspectives. J Neurosci Nurs. 2007;39(3):151-62.

23. Casey G. Fever management in children. Nurs Stand. 2000;14(40):36-40.

24. Joanna Briggs Institute for Evidence Based Nursing and Midwifery. Management of the child with fever. Best Practice Evidence Based Practice Information Sheets for Health Professionals. Blackwell Science-Asia, Australia. 2001;5(5):1.

25. Watts R, Robertson J. Non-pharmacological management of fever in otherwise healthy children. JBI Libr Syst Rev. 2012;10(28):1634-87.

26. Purssel E. Physical treatment of fever. Arch Dis Child. 2000;82(23):238-9.

27. Pavithra C. Effect of Tepid vs Warm sponging on body temperature and comfort among children with Pyrexia at Sri Ramakrishna hospital, Coimbatore. IJSAR. 2018;5(6):2530. 
28. Lava SAG, Simonetti GD, Ramelli GP, Tschumi S, Bianchetti MG. Symptomatic management of fever by Swiss board-certified Pediatricians: results from a cross-sectional, web-based survey. Clin Ther. 2012;34(1):250-6.

29. Alves JG, Almeida NDCM; Almeida CDCM. Tepid sponging plus dipyrone versus dipyrone alone for reducing body temperature in febrile children. Sao Paulo Med J. 2008; 126(2):107-11.

30. Watts R, Robertson J, Thomas G. Nursing management of fever in children: A systematic review. Int J Nurs Pract. 2003;9(1)1-8.

31. Moran P, Nicholson A. Management of fever in young children. WIN. 2012;20(9):404.

32. Christie J. Managing febrile children: when and how to treat. Nurs N Z. 2002;8(1):157.

33. Thomas S, Vijaykumar C, Naik R, Antonisamy B. Comparative effectiveness of tepid sponging and antipyretic drug versus only antipyretic drug in the management of fever among children: a randomized controlled trial. Indian Pediatr. 2009;46(2):133-6.

34. Meremikwu MM, Oyo-Ita A. Physical methods versus drug placebo or no treatment for managing fever in children. Cochrane Database Syst Rev. 2003; (2):1-23.

35. Robertson J. Management of the child with fever. Collegian. 2002;9(2):40-2.

36. Bernath VF, Anderson JN, Silagy CA. Tepid sponging and paracetamol for reduction of body temperature in febrile children. Med J Aust. 2002;176(3):130.

37. National Institute for Health and Care Excellence: Clinical Guidelines. Feverish illness in children assessment and initial management in children younger than 5 years. NICE, Reino Unido. 2013 May:1-43.

38. Roberts S. The feverish child: knowing what to do. British Journal of School Nursing. 2008;3(6):290-2.

39. Edwards H, Walsh A, Courtney M, Monaghan S, Wilson J, Young J. Improving paediatric nurses knowledge and attitudes in childhood fever management. J Adv Nurs. 2007;57(3):257-69.

41. Thompson HJ, Kagan SH. Clinical management of fever by nurses: doing what works. J Adv Nurs J. 2011;67(2):359-70.

42. Aluka TM, Gyuse AN, Udonwa NE, Asibong UE, Meremikwu MM, Oyo-Ita A. Comparison of cold water sponging and acetaminophen in control of Fever among children 
attending a tertiary hospital in South Nigeria. 2013. J Family Med Prim Care. 2013;2(2):1538.

43. Chiappini E, Principi N, Longhi R, Tovo PA, Becherucci P, Bonsignori F, et al. Management of fever in children: Summary of the Italian Pediatric Society Guidelines. ClinTher. 2009;31(8):1826-43.

44. Bridgwater K, Fletcher M, Hatter E, Houghton J, Mason C, Monaghan J. Managing fever. Paediatr Nurs. 2008;20(8):27.

45. Schulz KF, Altman DG, Moher D; CONSORT Group. CONSORT 2010 statement: updated guidelines for reporting parallel group randomized trials. Obstet Gynecol. 2010;115(5):1063-70.

46. Twisk JWR. Applied longitudinal data analysis for epidemiology: a pratical guide. Vrije Universiteit, Amsterdam: Cambridge University Press; 2013. Sample size calculations; p. 237-42.

47. Brasil. Agência Nacional de Vigilância Sanitária. Bulário eletrônico [Internet]. [citado 2020 fev. 5]. Disponível em: http:// http://www.anvisa.gov.br/datavisa/fila_bula/index.asp.

48. Rocha KR, Júnior AJB. ANOVA Medidas repetidas e seus pressupostos: Análise passo a passo de um experimento. Perspectivas da Ciência e Tecnologia. 2018;10:29-51.

49. Demidenko E. Mixed models theory and applications with R. New Jersey: Hoboken, Wiley; 2013. Why Mixed Models; p.3-4.

50. Camargo FC, Iwamoto HH, Galvão CM, Pereira GA, Andrade RB, Masso GC. Competences and barriers for the evidence-based practice in nursing: an integrative review. Rev Bras Enferm. 2018;71(4):2030-8.

51. Passos SD, Maziero FF, Antoniassi DQ, Souza LT, Felix AF, Dottab E, et al. Acute respiratory diseases in Brazilian children: are caregivers able to detect early warning signs? Rev Paul Pediatr. 2018;36(1):3-9.

52. Houda BA, Sourour Y, Maissa BJ, Jihene J, Mariem BH, Maroua T, et al. Pediatric respiratory tract diseases: chronological trends and perspectives. Pediatr Int. 2017;60(1):7682.

53. Magni AM, Scheffer DK, Bruniera P. Antipyretic effect of ibuprofen and dipyrone in febrile children. J Pediatr. 2011;87(1):36-42.

54. Sá ACMGN, Silva RM, Capanema FD, Gonçalves LAO, Rocha RL. Febre infantil e seu manejo pelos pais: análise quantitativa. R Bras Cien Saúde. 2018;22(2):117-24. 
APENNDICES 



\section{APÊNDICE A}

Quadro 1 - Estudos incluídos na revisão integrativa, classificação e categorização. São Paulo, 2020

(continua)

\begin{tabular}{|c|c|c|c|c|c|}
\hline $\begin{array}{l}\text { Número de } \\
\text { ordem }\end{array}$ & Identificação & Objetivo(s) & Método & $\begin{array}{l}\text { Intervenções não } \\
\text { farmacológicas }\end{array}$ & Conclusões \\
\hline 1 & $\begin{array}{l}\text { Beard RM, Day MW. Fever } \\
\text { and hyperthermia: learn to } \\
\text { beat the heat. Nursing. } 2008 \text {. }\end{array}$ & $\begin{array}{l}\text { Distinguir entre febre e } \\
\text { hipertermia, avaliar e intervir } \\
\text { de forma adequada }\end{array}$ & Estudo de reflexão & $\begin{array}{l}\text { - Incentivo à ingestão } \\
\text { de líquidos } \\
\text { - Sponging fria } \\
\text { - Uso de bolsas de } \\
\text { gelo. }\end{array}$ & $\begin{array}{l}\text { Métodos recomendados na vigência } \\
\text { do antitérmico: sponging fria sobre } \\
\text { a testa, uso de bolsas de gelo sobre } \\
\text { a virilha e axilas e incentivo à } \\
\text { ingestão de líquidos. }\end{array}$ \\
\hline 2 & $\begin{array}{l}\text { McDougall P, Harrison M. } \\
\text { Fever and feverish illness in } \\
\text { children under five years. } \\
\text { Nursing Standard. } 2014 .\end{array}$ & $\begin{array}{l}\text { Aumentar a compreensão do } \\
\text { leitor da fisiopatologia da } \\
\text { febre em crianças e } \\
\text { identificação de doença grave }\end{array}$ & Revisão de literatura & $\begin{array}{l}\text { - } \text { Remoção do excesso } \\
\text { de roupas } \\
\text { - Incentivo à ingestão } \\
\text { de líquidos } \\
\text { - Banho morno } \\
\text { - Banho frio } \\
\text { - Sponging }\end{array}$ & $\begin{array}{l}\text { Não deve ser dado banho frio ou } \\
\text { morno. Intervenções } \\
\text { recomendadas: sponging ou banho } \\
\text { em temperatura ambiente, } \\
\text { incentivo à ingestão de fluídos e } \\
\text { remoção do excesso de roupas. }\end{array}$ \\
\hline
\end{tabular}


Quadro 1 - Estudos incluídos na revisão integrativa, classificação e categorização. São Paulo, 2020

(continuação)

\begin{tabular}{|c|c|c|c|c|c|}
\hline $\begin{array}{l}\text { Número } \\
\text { de ordem }\end{array}$ & Identificação & Objetivo(s) & Método & $\begin{array}{l}\text { Intervenções não } \\
\text { farmacológicas }\end{array}$ & Conclusões \\
\hline 3 & $\begin{array}{l}\text { Clarke P. Evidence Based } \\
\text { Management of Childhood } \\
\text { Fever: What Pediatric Nurses } \\
\text { Need to Know. Journal of } \\
\text { Pediatric Nursing: Nursing Care } \\
\text { of Children and Families. } 2014 \text {. }\end{array}$ & $\begin{array}{l}\text { Analisar a base de conhecimento } \\
\text { dos enfermeiros pediatras em } \\
\text { relação a febre em crianças }\end{array}$ & $\begin{array}{l}\text { Revisão de } \\
\text { literatura }\end{array}$ & $\begin{array}{l}\text { - Sponging com álcool } \\
\text { - Sponging fria }\end{array}$ & $\begin{array}{l}\text { Sponging com álcool é contraindicado } \\
\text { no tratamento de febre. Orientar os } \\
\text { pais sobre o incentivo à oferta de } \\
\text { líquidos, a remoção do excesso de } \\
\text { roupas e a observação para sinais de } \\
\text { gravidade. }\end{array}$ \\
\hline 4 & $\begin{array}{l}\text { Thompson HJ, Kirkness CJ, } \\
\text { Mitchell PH, Webb DJ. Fever } \\
\text { Management practices of } \\
\text { neuroscience nurses: national } \\
\text { and regional perspectives. } \\
\text { JNeurosciNurs. } 2007 \text {. }\end{array}$ & $\begin{array}{l}\text { Determinar se existem } \\
\text { tendências nas práticas nacionais } \\
\text { na gestão de febre e hipertermia } \\
\text { em pacientes neurologicamente } \\
\text { vulneráveis }\end{array}$ & $\begin{array}{l}\text { Estudo } \\
\text { quantitativo/ } \\
\text { método tipo Survey }\end{array}$ & $\begin{array}{l}\text { - Bolsas de gelo } \\
\text { - Cobertores } \\
\text { refrigerados } \\
\text { - Banhos }\end{array}$ & $\begin{array}{l}\text { Intervenções recomendadas na gestão } \\
\text { da febre e hipertermia: uso de } \\
\text { compressas de gelo, cobertores } \\
\text { refrigerados e banhos. }\end{array}$ \\
\hline
\end{tabular}


Quadro 1 - Estudos incluídos na revisão integrativa, classificação e categorização. São Paulo, 2020

(continuação)

\begin{tabular}{|c|c|c|c|c|c|}
\hline $\begin{array}{l}\text { Número } \\
\text { de ordem }\end{array}$ & Identificação & Objetivo(s) & Método & $\begin{array}{l}\text { Intervenções não } \\
\text { farmacológicas }\end{array}$ & Conclusões \\
\hline 5 & $\begin{array}{l}\text { Casey G. Fever management in } \\
\text { children. Nursing Standard. } \\
2000 .\end{array}$ & $\begin{array}{l}\text { Fornecer uma explicação sobre } \\
\text { os mecanismos fisiológicos no } \\
\text { controle da temperatura } \\
\text { corporal das crianças e a } \\
\text { maneira como se alteram na } \\
\text { febre }\end{array}$ & Estudo de reflexão & $\begin{array}{l}\text { - } \text { Banho frio } \\
\text { - Sponging morna } \\
\text { - } \text { Terapia combinada } \\
\text { (Sponging morna }+ \\
\text { antitérmico) }\end{array}$ & $\begin{array}{l}\text { Não se recomenda o uso do sponging } \\
\text { morna e banho com água fria, pois } \\
\text { podem aumentar o desconforto, além } \\
\text { de reduzir rapidamente a temperatura } \\
\text { corporal e ocasionar um choque } \\
\text { térmico. }\end{array}$ \\
\hline 6 & $\begin{array}{l}\text { Axelrod P. External } \\
\text { cooling in the } \\
\text { management of fever. } \\
\text { Clin Infect Dis. } 2000 .\end{array}$ & $\begin{array}{l}\text { Avaliar medidas de } \\
\text { resfriamento externo para o } \\
\text { tratamento da febre }\end{array}$ & $\begin{array}{l}\text { Revisão de } \\
\text { literatura }\end{array}$ & $\begin{array}{ll}\text { - } & \text { Banho com álcool } \\
\text { - } & \text { Sponging } \\
\text { - } & \text { Terapia combinada } \\
\text { (Sponging morna + } \\
\text { antitérmico) } \\
\text { - Sponging com álcool } \\
\text { - Sponging gelada } \\
\text { - Cobertores } \\
\text { refrigerados. }\end{array}$ & $\begin{array}{l}\text { As crianças tratadas com sponging } \\
\text { morna e antitérmicos geralmente } \\
\text { apresentam maior desconforto do que } \\
\text { aquelas tratadas apenas com } \\
\text { antitérmico. Orienta-se que métodos } \\
\text { físicos são indicados somente no } \\
\text { tratamento da hipertermia. }\end{array}$ \\
\hline
\end{tabular}


Quadro 1 - Estudos incluídos na revisão integrativa, classificação e categorização. São Paulo, 2020

(continuação)

\begin{tabular}{|c|c|c|c|c|c|}
\hline $\begin{array}{l}\text { Número } \\
\text { de } \\
\text { ordem }\end{array}$ & Identificação & Objetivo(s) & Método & $\begin{array}{l}\text { Intervenções não } \\
\text { farmacológicas }\end{array}$ & Conclusões \\
\hline 7 & $\begin{array}{l}\text { Thompson HJ, } \\
\text { Kagan SH. Clinical } \\
\text { management of } \\
\text { fever by nurses: } \\
\text { doing what works. } \\
\text { J AdvNurs J. } 2011 \text {. }\end{array}$ & $\begin{array}{l}\text { Definir a febre na perspectiva dos } \\
\text { enfermeiros, relatar a tomada de } \\
\text { decisão dos enfermeiros quanto ao } \\
\text { gerenciamento da febre e relatar as } \\
\text { barreiras para a prática baseada em } \\
\text { evidências }\end{array}$ & $\begin{array}{l}\text { Estudo de caso/ } \\
\text { qualitativo }\end{array}$ & $\begin{array}{l}\text { - Remoção de cobertores } \\
\text { - } \text { Abertura de janelas } \\
\text { - Uso de ventiladores } \\
\text { - Bolsas de gelo } \\
\text { - Cobertores refrigerados } \\
\text { - Banhos }\end{array}$ & $\begin{array}{l}\text { Falta da criação de protocolos } \\
\text { multiprofissionais. Enfermeiras } \\
\text { utilizam intervenções baseadas na } \\
\text { experiência empírica, não há a } \\
\text { recomendação baseada em } \\
\text { evidências sobre o melhor método. }\end{array}$ \\
\hline 8 & $\begin{array}{l}\text { Joanna Briggs } \\
\text { Institute for } \\
\text { Evidence Based } \\
\text { Nursing and } \\
\text { Midwifery. Best } \\
\text { Practice Evidence } \\
\text { Based Practice } \\
\text { Information Sheets } \\
\text { for Health } \\
\text { Professionals. } \\
\text { Management of } \\
\text { the Child with } \\
\text { Fever. Blackwell } \\
\text { Science-Asia, } \\
\text { Australia. 2001. }\end{array}$ & $\begin{array}{l}\text { Determinar se a evidência } \\
\text { disponível apoia os tipos e } \\
\text { temporização das diversas } \\
\text { intervenções de enfermagem } \\
\text { comumente usadas para reduzir a } \\
\text { febre em crianças }\end{array}$ & $\begin{array}{l}\text { Guia de boas práticas no } \\
\text { cuidado a criança febril, } \\
\text { proposto pela The Joanna } \\
\text { Briggs Institute for } \\
\text { Evidence } \\
\text { Based Nursing and } \\
\text { Midwifery }\end{array}$ & $\begin{array}{ll}\text { - } & \text { Sponging morna } \\
\text { - } & \text { Terapia combinada } \\
& \text { (Sponging + antitérmico) } \\
\text { - } & \text { Banho frio } \\
\text { - } & \text { Aplicação de compressas } \\
\text { frias } \\
\text { - } \\
\text { - } \text { Uemoção de roupas } \\
\text { - Incentivo à ingestão de } \\
\text { líquidos }\end{array}$ & $\begin{array}{l}\text { Sponging morna não é indicada } \\
\text { para o tratamento de febre. } \\
\text { Recomenda-se o incentivo à } \\
\text { ingestão de líquidos, a remoção do } \\
\text { excesso de roupas ou lençóis. }\end{array}$ \\
\hline
\end{tabular}


Quadro 1 - Estudos incluídos na revisão integrativa, classificação e categorização. São Paulo, 2020

(continuação)

\begin{tabular}{|c|c|c|c|c|c|}
\hline $\begin{array}{l}\text { Número } \\
\text { de } \\
\text { ordem }\end{array}$ & Identificação & Objetivo(s) & Método & $\begin{array}{l}\text { Intervenções não } \\
\text { farmacológicas }\end{array}$ & Conclusões \\
\hline 9 & $\begin{array}{l}\text { Lava SAG, Simonetti GD, } \\
\text { Ramelli GP, Tschumi S, } \\
\text { Bianchetti MG. Symptomatic } \\
\text { management of fever by Swiss } \\
\text { board-certified Pediatricians: } \\
\text { results from a cross-sectional, } \\
\text { web-based survey. ClinTher. } \\
2012 \text {. }\end{array}$ & $\begin{array}{l}\text { Descrever o gerenciamento de } \\
\text { febre em crianças }\end{array}$ & Estudo quantitativo & - Sponging morna & $\begin{array}{l}\text { Métodos físicos não são } \\
\text { recomendados devido a } \\
\text { vantagens clínicas insuficientes. }\end{array}$ \\
\hline 10 & $\begin{array}{l}\text { Alves JG, Almeida NDCM; } \\
\text { Almeida CDCM. Tepid sponging } \\
\text { plus dipyrone versus dipyrone } \\
\text { alone for reducing body } \\
\text { temperature in febrile children. } \\
\text { Sao Paulo Med. J. } 2008 \text {. }\end{array}$ & $\begin{array}{l}\text { Comparar os efeitos da } \\
\text { sponging morna e dipirona } \\
\text { com apenas dipirona no } \\
\text { tratamento de febre }\end{array}$ & $\begin{array}{l}\text { Ensaio Clínico } \\
\text { Randomizado }\end{array}$ & $\begin{array}{l}\text { - Terapia combinada } \\
\text { (sponging morna } \\
\text { +antitérmico) }\end{array}$ & $\begin{array}{l}\text { A aplicação de esponja embebida } \\
\text { em água morna conjuntamente } \\
\text { com administração de dipirona } \\
\text { promove uma refrigeração mais } \\
\text { rápida durante os primeiros } 15 \\
\text { minutos, porém o uso isolado de } \\
\text { dipirona leva ao melhor controle } \\
\text { de temperatura em longo do } \\
\text { prazo. }\end{array}$ \\
\hline 11 & $\begin{array}{l}\text { Purssel Edward. Physical } \\
\text { treatment of fever. Arch Dis } \\
\text { Child. } 2000 .\end{array}$ & $\begin{array}{l}\text { Avaliar a eficácia de métodos } \\
\text { físicos no tratamento de febre } \\
\text { em crianças }\end{array}$ & Estudo de reflexão & 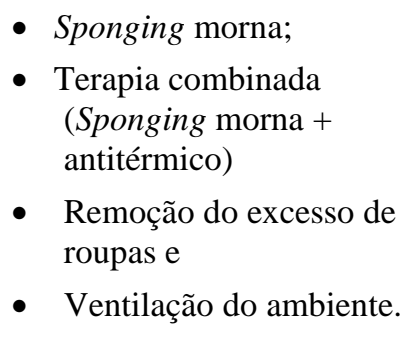 & $\begin{array}{l}\text { O uso da terapia combinada } \\
\text { oferece pouca vantagem em } \\
\text { relação à administração isolada } \\
\text { de antitérmico no tratamento de } \\
\text { crianças febris. }\end{array}$ \\
\hline
\end{tabular}


Quadro 1 - Estudos incluídos na revisão integrativa, classificação e categorização. São Paulo, 2020

(continuação)

\begin{tabular}{|c|c|c|c|c|c|}
\hline $\begin{array}{l}\text { Número } \\
\text { de ordem }\end{array}$ & Identificação & Objetivo(s) & Método & $\begin{array}{l}\text { Intervenções não } \\
\text { farmacológicas }\end{array}$ & Conclusões \\
\hline 12 & $\begin{array}{l}\text { Watts R, Robertson J, Gail } \\
\text { T. Nursing management } \\
\text { of fever in children: A } \\
\text { systematic review. } \\
\text { International Journal of } \\
\text { Nursing Practice. } 2003 \text {. }\end{array}$ & $\begin{array}{l}\text { Determinar a melhor } \\
\text { evidência disponível que } \\
\text { suporta os tipos e timing das } \\
\text { intervenções de enfermagem } \\
\text { diferentes que são comumente } \\
\text { usados para reduzir febre em } \\
\text { crianças não críticas tratadas, } \\
\text { bem como avaliar em que } \\
\text { medida os resultados são } \\
\text { influenciados por essas ações } \\
\text { de enfermagem }\end{array}$ & $\begin{array}{l}\text { Revisão } \\
\text { sistemática }\end{array}$ & $\begin{array}{l}\text { - Incentivo à ingestão de } \\
\text { - } \text { líquidos } \\
\text { - Remoção do excesso de } \\
\text { - Venpas } \\
\text { - } \\
\text { - } \text { Sponginilação do ambiente } \\
\text { (Sponging morna } \\
\text { +antitérmico) }\end{array}$ & $\begin{array}{l}\text { Recomenda-se o incentivo à ingestão de líquidos, } \\
\text { a remoção do excesso de roupas ou ventilação do } \\
\text { ambiente. }\end{array}$ \\
\hline 13 & $\begin{array}{l}\text { Salgado PA, Silva LCR, } \\
\text { Silva PMA, Paiva IRA, } \\
\text { Macieira TGR, Chianca } \\
\text { TCM. Nursing care to } \\
\text { patients with high body } \\
\text { temperature: an } \\
\text { integrative review. } \\
\text { REME rev. min. enferm. } \\
2015 \text {. }\end{array}$ & $\begin{array}{l}\text { Identificar as evidências } \\
\text { disponíveis na literatura sobre } \\
\text { os melhores cuidados de } \\
\text { enfermagem para o paciente } \\
\text { com temperatura corporal } \\
\text { elevada }\end{array}$ & $\begin{array}{l}\text { Revisão } \\
\text { Integrativa }\end{array}$ & $\begin{array}{l}\text { - } \text { Banho morno } \\
\text { - } \text { Compressas mornas } \\
\text { - } \text { Bolsas de gelo } \\
\text { - } \quad \text { Ventilação do ambiente }\end{array}$ & $\begin{array}{l}\text { Para tratamento de crianças com febre: incentivar } \\
\text { a ingesta hídrica, remover o excesso de roupas, } \\
\text { garantir a circulação de ar no ambiente e a } \\
\text { educação dos pais. Embora alguns estudos em } \\
\text { pediatria demonstrem que o uso da terapia } \\
\text { combinada é mais eficaz na redução da } \\
\text { temperatura corporal do que a administração de } \\
\text { apenas antitérmico. }\end{array}$ \\
\hline
\end{tabular}


Quadro 1 - Estudos incluídos na revisão integrativa, classificação e categorização. São Paulo, 2020

(continuação)

\begin{tabular}{|c|c|c|c|c|c|}
\hline $\begin{array}{l}\text { Número } \\
\text { de } \\
\text { ordem }\end{array}$ & Identificação & Objetivo(s) & Método & $\begin{array}{l}\text { Intervenções não } \\
\text { farmacológicas }\end{array}$ & Conclusões \\
\hline 14 & $\begin{array}{l}\text { Watts R, Robertson J. } \\
\text { Non- } \\
\text { pharmacological } \\
\text { Management of } \\
\text { Fever in Otherwise } \\
\text { Healthy Children. } \\
\text { JBI Library of } \\
\text { Systematic Reviews. } \\
2012 \text {. }\end{array}$ & $\begin{array}{l}\text { Estabelecer quais medidas não } \\
\text { farmacológicas são efetivas no } \\
\text { gerenciamento de febre em } \\
\text { crianças saudáveis de } 3 \text { meses a } \\
12 \text { anos de idade }\end{array}$ & Revisão sistemática & $\begin{array}{ll}\text { - } & \text { Sponging morna } \\
\text { - } & \text { Terapia combinada - } \\
\text { (Sponging } \\
\text { +antitérmico) } \\
\text { - Uso de ventiladores } \\
\text { - } \\
\text { - } \\
\text { - Incepouso } \\
\text { de líquido à ingestão }\end{array}$ & $\begin{array}{l}\text { Sponging morna não tem efeito } \\
\text { benéfico. Recomenda-se o incentivo à } \\
\text { ingestão de líquidos, remoção do } \\
\text { excesso de roupas. }\end{array}$ \\
\hline 15 & $\begin{array}{l}\text { Moran P, Nicholson } \\
\text { A. Management of } \\
\text { fever in young } \\
\text { children. WIN. } 2012 \text {. }\end{array}$ & $\begin{array}{l}\text { Identificar febre e sinais de } \\
\text { gravidade e fornecer orientações } \\
\text { sobre o gerenciamento da febre }\end{array}$ & Revisão de literatura & $\begin{array}{l}\text { - Abertura de janelas e } \\
\text { ventilação do } \\
\text { ambiente } \\
\text { - Sponging morna } \\
\text { - Terapia combinada } \\
\text { (Sponging morna } \\
\text { +antipirético) }\end{array}$ & $\begin{array}{l}\text { Falta de evidência para indicar a } \\
\text { abertura de janelas ou ventilação do } \\
\text { ambiente. O uso de sponging morna não } \\
\text { oferece vantagens significativas sobre o } \\
\text { uso isolado de antitérmicos. }\end{array}$ \\
\hline
\end{tabular}


Quadro 1 - Estudos incluídos na revisão integrativa, classificação e categorização. São Paulo, 2020

(continuação)

\begin{tabular}{|c|c|c|c|c|c|}
\hline $\begin{array}{l}\text { Número } \\
\text { de } \\
\text { ordem }\end{array}$ & Identificação & Objetivo(s) & Método & $\begin{array}{l}\text { Intervenções não } \\
\text { farmacológicas }\end{array}$ & Conclusões \\
\hline 16 & $\begin{array}{l}\text { Christie J. Managing } \\
\text { febrile children: when } \\
\text { and how to treat. Nurs N } \\
\text { Z. } 2002 \text {. }\end{array}$ & $\begin{array}{l}\text { Comparar e avaliar a eficácia de } \\
\text { métodos de resfriamento e } \\
\text { determinar as melhores práticas } \\
\text { fundamentadas em diretrizes } \\
\text { baseadas em evidências }\end{array}$ & Revisão de literatura & 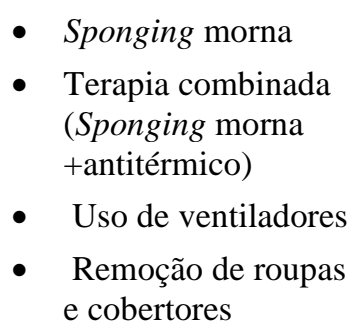 & $\begin{array}{l}\text { Não é recomendado o uso de sponging } \\
\text { morna, assim como o uso de } \\
\text { ventiladores e a remoção de roupas são } \\
\text { intervenções desnecessárias. }\end{array}$ \\
\hline 17 & $\begin{array}{l}\text { Thomas S, Vijaykumar C, } \\
\text { Naik R, Antonisamy B. } \\
\text { Comparative } \\
\text { Effectiveness of Tepid } \\
\text { Sponging and Antipyretic } \\
\text { Drug Versus Only } \\
\text { Antipyretic Drug in the } \\
\text { Management of Fever } \\
\text { Among Children: A } \\
\text { Randomized Controlled } \\
\text { Trial. Indian Pediatr. } 2009 .\end{array}$ & $\begin{array}{l}\text { Comparar a efetividade da } \\
\text { esponja embebida em água } \\
\text { morna e medicamentos } \\
\text { antipiréticos versus apenas } \\
\text { medicamentos antipiréticos no } \\
\text { tratamento de crianças febris }\end{array}$ & $\begin{array}{l}\text { Ensaio Clínico } \\
\text { Randomizado }\end{array}$ & $\begin{array}{l}\text { - Terapia combinada } \\
\text { (sponging morna } \\
\text { +antitérmico) }\end{array}$ & $\begin{array}{l}\text { A aplicação de esponja embebida em } \\
\text { água morna conjuntamente com } \\
\text { administração de antitérmico não } \\
\text { oferece qualquer vantagem na redução } \\
\text { da temperatura e pode resultar em } \\
\text { desconforto. }\end{array}$ \\
\hline
\end{tabular}


Quadro 1 - Estudos incluídos na revisão integrativa, classificação e categorização. São Paulo, 2020

(continuação)

\begin{tabular}{|c|c|c|c|c|c|}
\hline $\begin{array}{l}\text { Número de } \\
\text { ordem }\end{array}$ & Identificação & Objetivo(s) & Método & $\begin{array}{l}\text { Intervenções não } \\
\text { farmacológicas }\end{array}$ & Conclusões \\
\hline 18 & $\begin{array}{l}\text { Meremikwu MM, Oyo-Ita A. } \\
\text { Physical methods versus } \\
\text { drug placebo or no } \\
\text { treatment for managing } \\
\text { fever in children. Cochrane } \\
\text { Database Syst Rev. } 2003\end{array}$ & $\begin{array}{l}\text { Avaliar os benefícios e } \\
\text { prejuízos da utilização de } \\
\text { métodos físicos de } \\
\text { resfriamento na gestão de } \\
\text { febre em crianças }\end{array}$ & $\begin{array}{l}\text { Revisão } \\
\text { sistemática }\end{array}$ & $\begin{array}{l}\text { - Sponging morna } \\
\text { - } \quad \text { Terapia combinada } \\
\text { (sponging morna } \\
\text { +antitérmico) }\end{array}$ & $\begin{array}{l}\text { Sponging morna associada a paracetamol } \\
\text { alcança melhor efeito antipirético do que } \\
\text { apenas o antitérmico. Porém, a falta de } \\
\text { evidências dificulta a conclusão de possíveis } \\
\text { benefícios e malefícios associados a essa } \\
\text { prática comum. }\end{array}$ \\
\hline 19 & $\begin{array}{l}\text { Robertson J. Management } \\
\text { of the child with fever. } \\
\text { Collegian. } 2002 \text {. }\end{array}$ & $\begin{array}{l}\text { Identificar os fatores que } \\
\text { devem ser considerados } \\
\text { antes de iniciar o } \\
\text { tratamento de febre; } \\
\text { avaliar o valor das } \\
\text { intervenções utilizadas } \\
\text { pelos enfermeiros para } \\
\text { tratar febre na infância e } \\
\text { fornecer informações aos } \\
\text { pais que lhes permitam } \\
\text { gerir com segurança o } \\
\text { cuidado à criança febril } \\
\text { em casa }\end{array}$ & $\begin{array}{l}\text { Estudo de } \\
\text { reflexão }\end{array}$ & $\begin{array}{ll}\text { - } & \text { Sponging morna } \\
\text { - } & \text { Terapia combinada } \\
\text { (sponging morna } \\
\text { +antitérmico) } \\
\text { - Incentivo à ingestão } \\
\text { de líquidos } \\
\text { - Remoção do excesso } \\
\text { de roupas. }\end{array}$ & $\begin{array}{l}\text { Recomenda-se o incentivo à ingestão de } \\
\text { líquidos e a remoção do excesso de roupas. }\end{array}$ \\
\hline
\end{tabular}


Quadro 1 - Estudos incluídos na revisão integrativa, classificação e categorização. São Paulo, 2020

(continuação)

\begin{tabular}{|c|c|c|c|c|c|}
\hline $\begin{array}{l}\text { Número de } \\
\text { ordem }\end{array}$ & Identificação & Objetivo(s) & Método & $\begin{array}{l}\text { Intervenções não } \\
\text { farmacológicas }\end{array}$ & Conclusões \\
\hline 20 & $\begin{array}{l}\text { Bernath VF, Anderson JN, Silagy } \\
\text { CA. Tepid sponging and } \\
\text { paracetamol for reduction of body } \\
\text { temperature in febrile children. } \\
\text { Med J Aust. } 2002 .\end{array}$ & $\begin{array}{l}\text { Avaliar a eficácia da sponging } \\
\text { morna na redução da temperatura } \\
\text { corporal e se o paracetamol pode } \\
\text { ser mais eficaz quando } \\
\text { combinado com sponging morna }\end{array}$ & $\begin{array}{l}\text { Revisão de } \\
\text { literatura }\end{array}$ & $\begin{array}{l}\text { - Sponging morna } \\
\text { - Terapia } \\
\text { combinada } \\
\text { (sponging morna } \\
\text { +antitérmico) }\end{array}$ & $\begin{array}{l}\text { Sponging morna é eficaz no } \\
\text { tratamento de crianças febris nos } \\
\text { primeiros } 30 \text { minutos e tem um } \\
\text { efeito aditivo quando combinada } \\
\text { com paracetamol. }\end{array}$ \\
\hline 21 & $\begin{array}{l}\text { Aluka TM, Gyuse AN, Udonwa } \\
\text { NE, Asibong UE, Meremikwu } \\
\text { MM, Oyo-Ita A. Comparison of cold } \\
\text { water sponging and acetaminophen } \\
\text { in control of Fever among children } \\
\text { attending a tertiary hospital in } \\
\text { South Nigeria. J Family Med Prim } \\
\text { Care. } 2013 \text {. }\end{array}$ & $\begin{array}{l}\text { Investigar a eficácia da sponging } \\
\text { fria comparada ao uso oral de } \\
\text { paracetamol no tratamento da } \\
\text { criança febril atendida no } \\
\text { Hospital Universitário de Calabar }\end{array}$ & $\begin{array}{l}\text { Ensaio Clínico } \\
\text { Randomizado }\end{array}$ & - Sponging fria & $\begin{array}{l}\text { O desconforto desencadeado pela } \\
\text { utilização da sponging fria não } \\
\text { deve limitar o uso dessa } \\
\text { intervenção, considerada uma } \\
\text { técnica segura, deve ser } \\
\text { incentivada, inclusive a fim de } \\
\text { evitar convulsões. }\end{array}$ \\
\hline
\end{tabular}


Quadro 1 - Estudos incluídos na revisão integrativa, classificação e categorização. São Paulo, 2020

\begin{tabular}{|c|c|c|c|c|c|}
\hline $\begin{array}{l}\text { Número de } \\
\text { ordem }\end{array}$ & Identificação & Objetivo(s) & Método & $\begin{array}{l}\text { Intervenções não } \\
\text { farmacológicas }\end{array}$ & Conclusões \\
\hline 22 & $\begin{array}{l}\text { National Institute for Health and } \\
\text { Care Excellence: Clinical } \\
\text { Guidelines. Feverish illness in } \\
\text { children assessment and initial } \\
\text { management in children younger } \\
\text { than } 5 \text { years. NICE, Reino Unido. } \\
2013 \text {. }\end{array}$ & $\begin{array}{l}\text { Apresentar a recente } \\
\text { diretriz clínica sobre o } \\
\text { gerenciamento da criança } \\
\text { febril }\end{array}$ & $\begin{array}{l}\text { Guia de boas } \\
\text { práticas no } \\
\text { cuidado à } \\
\text { criança febril, } \\
\text { proposto pela } \\
\text { NICE }\end{array}$ & $\begin{array}{l}\text { - Sponging morna } \\
\text { - Remoção do excesso } \\
\text { de roupas }\end{array}$ & $\begin{array}{l}\text { Não é recomendado o uso de } \\
\text { sponging morna para o tratamento } \\
\text { de febre. Recomenda-se a remoção } \\
\text { do excesso de roupas e cobertores, o } \\
\text { incentivo à ingestão de líquidos e o } \\
\text { aleitamento materno para os bebês. }\end{array}$ \\
\hline 23 & $\begin{array}{l}\text { Chiappini E, Principi N, Longhi R, } \\
\text { Tovo PA, Becherucci P, Bonsignori } \\
\text { F, et al. Management of fever in } \\
\text { children: Summary of the Italian } \\
\text { Pediatric Society Guidelines. } \\
\text { ClinTher. } 2009 .\end{array}$ & $\begin{array}{l}\text { Fornecer a orientação sobre } \\
\text { gestão dos sinais e } \\
\text { sintomas de febre em } \\
\text { crianças, preparada como } \\
\text { parte } \\
\text { do programa de orientação } \\
\text { (NGLP) }\end{array}$ & $\begin{array}{l}\text { Revisão de } \\
\text { literatura }\end{array}$ & $\begin{array}{l}\text { - Sponging morna } \\
\text { - Exposição ao ar frio } \\
\text { - Cobertores } \\
\text { refrigerados } \\
\text { - Bolsas de gelo } \\
\text { - Sponging com álcool. }\end{array}$ & $\begin{array}{l}\text { Métodos físicos não são } \\
\text { recomendados para redução de } \\
\text { febre, apenas no tratamento da } \\
\text { hipertermia. }\end{array}$ \\
\hline 24 & $\begin{array}{l}\text { Roberts S. The feverish child: } \\
\text { knowing what to do. British Journal } \\
\text { of School Nursing. } 2008 \text {. }\end{array}$ & $\begin{array}{l}\text { Explorar as questões } \\
\text { relacionadas a febre em } \\
\text { crianças pequenas, como } \\
\text { reconhecê-la e discutir } \\
\text { diferentes formas de } \\
\text { tratamento }\end{array}$ & $\begin{array}{l}\text { Estudo de } \\
\text { reflexão }\end{array}$ & $\begin{array}{l}\text { - Sponging morna } \\
\text { - Uso de ventilador }\end{array}$ & $\begin{array}{l}\text { Não é recomendado o uso de } \\
\text { sponging morna. Deve-se indicar o } \\
\text { uso do ventilador para resfriar o } \\
\text { ambiente desde que a criança febril } \\
\text { não apresente tremores. }\end{array}$ \\
\hline
\end{tabular}


Quadro 1 - Estudos incluídos na revisão integrativa, classificação e categorização. São Paulo, 2020

\begin{tabular}{|c|c|c|c|c|c|}
\hline $\begin{array}{l}\text { Número de } \\
\text { ordem }\end{array}$ & Identificação & Objetivo(s) & Método & $\begin{array}{l}\text { Intervenções não } \\
\text { farmacológicas }\end{array}$ & Conclusões \\
\hline 25 & $\begin{array}{l}\text { Pavithra C. Effect of Tepid Vs } \\
\text { Warm sponging on body } \\
\text { temperature and comfort among } \\
\text { children with Pyrexia at Sri } \\
\text { Ramakrishna hospital, } \\
\text { Coimbatore. IJSAR. } 2018 \text {. }\end{array}$ & $\begin{array}{l}\text { Avaliar o efeito do sponging } \\
\text { morna em crianças com febre; } \\
\text { avaliar o efeito do sponging } \\
\text { quente em crianças com febre; } \\
\text { comparar o efeito da sponging } \\
\text { morna com a sponging quente } \\
\text { em crianças com febre }\end{array}$ & Estudo clínico & $\begin{array}{l}\text { - Sponging morna } \\
\text { - Sponging quente }\end{array}$ & $\begin{array}{l}\text { Redução substancial no valor da } \\
\text { temperatura corpórea com o uso } \\
\text { do sponging morna e quente. } \\
\text { Sponging morna causa leve } \\
\text { desconforto quando comparado a } \\
\text { sponging quente. Recomenda-se o } \\
\text { uso de sponging quente na redução } \\
\text { da temperatura corpórea e } \\
\text { promoção do conforto entre } \\
\text { crianças com febre. }\end{array}$ \\
\hline 26 & $\begin{array}{l}\text { Bridgwater K, Fletcher M, Hatter E, } \\
\text { Houghton J, Mason C, Monaghan J. } \\
\text { Managing Fever. Paediatric Nursing. } \\
2008 .\end{array}$ & $\begin{array}{l}\text { Orientar sobre as melhores } \\
\text { práticas para auxiliar o } \\
\text { enfermeiro a prestar um } \\
\text { cuidado com base na } \\
\text { evidência de crianças e jovens } \\
\text { com febre }\end{array}$ & $\begin{array}{l}\text { Guia de boas } \\
\text { práticas no } \\
\text { cuidado à criança } \\
\text { febril, proposto } \\
\text { pela RCN }\end{array}$ & $\begin{array}{l}\text { - Sponging morna } \\
\text { - Remoção do excesso } \\
\text { de roupas, lençóis e } \\
\text { cobertores } \\
\text { - Incentivo à ingestão } \\
\text { de líquidos. }\end{array}$ & $\begin{array}{l}\text { Não é recomendado o uso de tepid } \\
\text { sponging para gestão de febre. } \\
\text { Recomenda-se a remoção do } \\
\text { excesso de roupas e o incentivo à } \\
\text { ingestão de líquidos. }\end{array}$ \\
\hline 27 & $\begin{array}{l}\text { Edwards H, Walsh A, Courtney M, } \\
\text { Monaghan S, Wilson J, Young J. } \\
\text { Improving paediatric nurses } \\
\text { knowledge and attitudes in } \\
\text { childhood fever management. } \\
\text { Journal of Advanced Nursing. } 2007 \text {. }\end{array}$ & $\begin{array}{l}\text { Apresentar a avaliação da } \\
\text { eficácia de um programa de } \\
\text { educação para o } \\
\text { desenvolvimento do } \\
\text { conhecimento baseado em } \\
\text { evidências voltado para a o } \\
\text { gerenciamento de febre }\end{array}$ & $\begin{array}{l}\text { Estudo } \\
\text { quantitativo }\end{array}$ & $\begin{array}{l}\text { - Incentivo à ingestão } \\
\text { de líquidos } \\
\text { - Sponging morna }\end{array}$ & $\begin{array}{l}\text { Recomenda-se o incentivo à } \\
\text { ingestão de líquidos e o uso de } \\
\text { sponging morna } 30 \text { minutos após a } \\
\text { administração do antitérmico. }\end{array}$ \\
\hline
\end{tabular}




\section{APÊNDICE B \\ TERMO DE CONSENTIMENTO LIVRE E ESCLARECIDO HOSPITAL UNIVERSITÁRIO DA USP - Grupo Controle}

Gostaríamos de convidar seu(sua) filho(a) a participar de livre e espontânea vontade do estudo chamado de "Manejo não farmacológico de crianças febris: ensaio clínico randomizado", que será realizado pela pesquisadora responsável Mariana Vieira de Souza. O objetivo do estudo é avaliar se a aplicação do tratamento não medicamentoso - compressas mornas - é melhor para ajudar a diminuir a febre da criança que está internada no hospital. Caso concorde em permitir a participação de seu (sua) filho (a), ele(a) receberá a medicação prescrita pelo médico contra febre. O procedimento relativo à verificação da temperatura poderá trazer algum desconforto, mas serão tomadas providências para minimizá-lo.

Este estudo pode não trazer benefícios imediatos a seu (sua) filho(a), mas ajudará a área da enfermagem pediátrica a cuidar melhor de crianças internadas com febre. O resultado do estudo será somente do meu conhecimento e de minha orientadora, sendo mantido sigilo e respeito a sua privacidade. O relatório final será publicado, sem que seu nome ou de seu (sua) filho(a) seja mencionado. $\mathrm{O}$ (a) senhor(a) poderá desistir de colaborar com a pesquisa em qualquer momento, sem que o(a) senhor(a), seu (sua) filho (a) ou sua família tenha qualquer gasto ou prejuízo de qualquer ordem, e não haverá prejuízo na assistência recebida na instituição de saúde. $O(a)$ senhor(a) também não será pago, bem como o seu (sua) filho (a) ou sua família ou receberão qualquer benefício, no entanto, se houver despesas extras decorrentes da pesquisa, o(a) senhor(a) será ressarcido(a). Se em algum momento de sua colaboração com o estudo, houver algum desconforto ou constrangimento, o(a) senhor(a) poderá interromper imediatamente a participação de seu (sua) filho (a) sem qualquer ônus. E, se for necessário, procuraremos ajuda especializada. Embora nenhum dano físico, decorrente da participação neste estudo, seja esperado durante ou após a participação no estudo de seu (sua) filho (a), caso ocorra, o(a) senhor(a) poderá pedir indenização. Em caso de dúvidas, o(a) senhor(a) poderá entrar em contato com a Profa. Elaine Buchhorn Cintra Damião, no endereço: Av. Dr. Enéas de Carvalho Aguiar, 419, CEP 05403-000, São Paulo, SP e pelo telefone (11) 3061-7602 em horário comercial e, durante 24h, comigo pelo e-mail: mariana.ee@usp.br/ou com o Comitê de Ética do Hospital Universitário da USP: Av. Prof. Lineu Prestes, 2965 - Cidade Universitária - CEP: 05508-000 - São Paulo - Tel.: 11 3091-9457- e-mail: cep@ hu.usp.br.

Este documento será assinado e rubricado em todas as páginas, em duas vias, ficando uma via com o(a) senhor(a) e a outra comigo. Esta pesquisa atende todas as especificações da Resolução n. 466, de 12 de dezembro de 2012, que aprova as diretrizes e normas regulamentadoras de pesquisas envolvendo seres humanos.

Caso o(a) senhor(a) tenha alguma consideração ou dúvida sobre a ética da pesquisa, entre em contato com o Comitê de Ética em Pesquisa (CEP) - Endereço - Av. Dr. Enéas de Carvalho Aguiar, 419 - Cerqueira César - São Paulo/SP CEP - 05403-000 Telefone- (11) 30618858 e-mail cepee@usp.br.

\section{Nome do responsável legal:}

\section{Grau de parentesco:}

\section{Assinatura do responsável legal:}

Assinatura do Pesquisador: 


\section{TERMO DE CONSENTIMENTO LIVRE E ESCLARECIDO HOSPITAL UNIVERSITÁRIO DA USP - Grupo Intervenção}

Gostaríamos de convidar seu(sua) filho(a) a participar de livre e espontânea vontade do estudo chamado de "Manejo não farmacológico de crianças febris: ensaio clínico randomizado", que será realizado pela pesquisadora responsável Mariana Vieira de Souza. O objetivo do estudo é avaliar se a aplicação do tratamento não medicamentoso - compressas mornas - é melhor para ajudar a diminuir a febre de criança internada no hospital. Caso concorde em permitir a participação de seu(sua) filho(a), este(a) irá receber a aplicação das compressas mornas no corpo e a medicação prescrita pelo médico contra febre. O procedimento relativo à verificação da temperatura poderá trazer algum desconforto, mas serão tomadas providências para minimizá-lo.

Este estudo pode não trazer benefícios imediatos a seu(sua) filho(a), mas ajudará a área da enfermagem pediátrica a cuidar melhor de crianças internadas com febre. O resultado do estudo será somente do meu conhecimento e de minha orientadora, sendo mantido sigilo e respeito a sua privacidade. O relatório final será publicado, sem que seu nome ou de seu(sua) filho(a) seja mencionado. $\mathrm{O}$ (a) senhor(a) poderá desistir de colaborar com a pesquisa em qualquer momento, sem que o(a) senhor(a), seu (sua) filho (a) ou sua família tenha qualquer gasto ou prejuízo de qualquer ordem, e não haverá prejuízo na assistência recebida na instituição de saúde. $O(a)$ senhor(a) também não será pago, bem como o seu (sua) filho (a) ou sua família ou receberão qualquer benefício, no entanto, se houver despesas extras decorrentes da pesquisa, o(a) senhor(a) será ressarcido(a). Se em algum momento de sua colaboração com o estudo, houver algum desconforto ou constrangimento, o(a) senhor(a) poderá interromper imediatamente a participação do seu (sua) filho (a) sem qualquer ônus. Caso ocorra algum desconforto decorrente da aplicação das compressas, serão tomadas providências devidas. E, se for necessário, procuraremos ajuda especializada. Embora nenhum dano físico, decorrente da participação neste estudo, seja esperado durante ou após a participação no estudo de seu (sua) filho (a), caso ocorra, o(a) senhor(a) poderá pedir indenização. Em caso de dúvidas, o(a) senhor(a) poderá entrar em contato com a Profa. Elaine Buchhorn Cintra Damião, no endereço: Av. Dr. Enéas de Carvalho Aguiar, 419, CEP 05403-000, São Paulo, SP e pelo telefone (11) 3061-7602 em horário comercial e, durante 24h, comigo pelo e-mail: mariana.ee@ usp.br/ou com o Comitê de Ética do Hospital Universitário da USP: Av. Prof. Lineu Prestes, 2965 - Cidade Universitária - CEP: 05508-000 - São Paulo - Tel.: 11 3091-9457- e-mail: cep@ hu.usp.br.

Este documento será assinado e rubricado em todas as páginas, em duas vias, ficando uma via com o(a) senhor(a) e a outra comigo. Esta pesquisa atende todas as especificações da Resolução n. 466, de 12 de dezembro de 2012, que aprova as diretrizes e normas regulamentadoras de pesquisas envolvendo seres humanos.

Caso o(a) senhor(a) tenha alguma consideração ou dúvida sobre a ética da pesquisa, entre em contato com o Comitê de Ética em Pesquisa (CEP)- Endereço - Av. Dr. Enéas de Carvalho Aguiar, 419 - Cerqueira Cesar - São Paulo/SP CEP - 05403-000 Telefone- (11) 30618858 e-mail cepee@usp.br.

Nome do responsável legal:

Grau de parentesco:

Assinatura do responsável legal:

Assinatura do Pesquisador:

Data: 


\section{APÊNDICE C}

\section{TERMO DE ASSENTIMENTO}

\section{HOSPITAL UNIVERSITÁRIO DA USP}

Meu nome é Mariana Vieira de Souza. Eu estou fazendo um trabalho sobre febre em crianças que estão internadas no Hospital. Convido você a participar do estudo e vou te contar o que irá acontecer se você quiser me ajudar:

Primeiro, vou te dar um remédio e também vou colocar um pano com água morna na sua testa, nas axilas (suvaco) e nas virilhas.

A sua participação será muito importante, pois me ajudará a escrever um trabalho, que poderá ajudar outras crianças internadas. Mas, se você quiser desistir a qualquer momento, não haverá problema. É só me falar.

Você não é obrigado (a) a participar, se não quiser. Você pode me fazer perguntas caso não esteja entendendo alguma coisa.

O seu nome não aparecerá no trabalho quando eu for escrevê-lo. Vou guardar essa carta comigo e entregar outra via dela para você.

Obrigada por você me ajudar.

Mariana Vieira

Data:

Assinatura da criança:

Assinatura da Pesquisadora 


\section{APÊNDICE D}

INSTRUMENTO DE COLETA DE DADOS

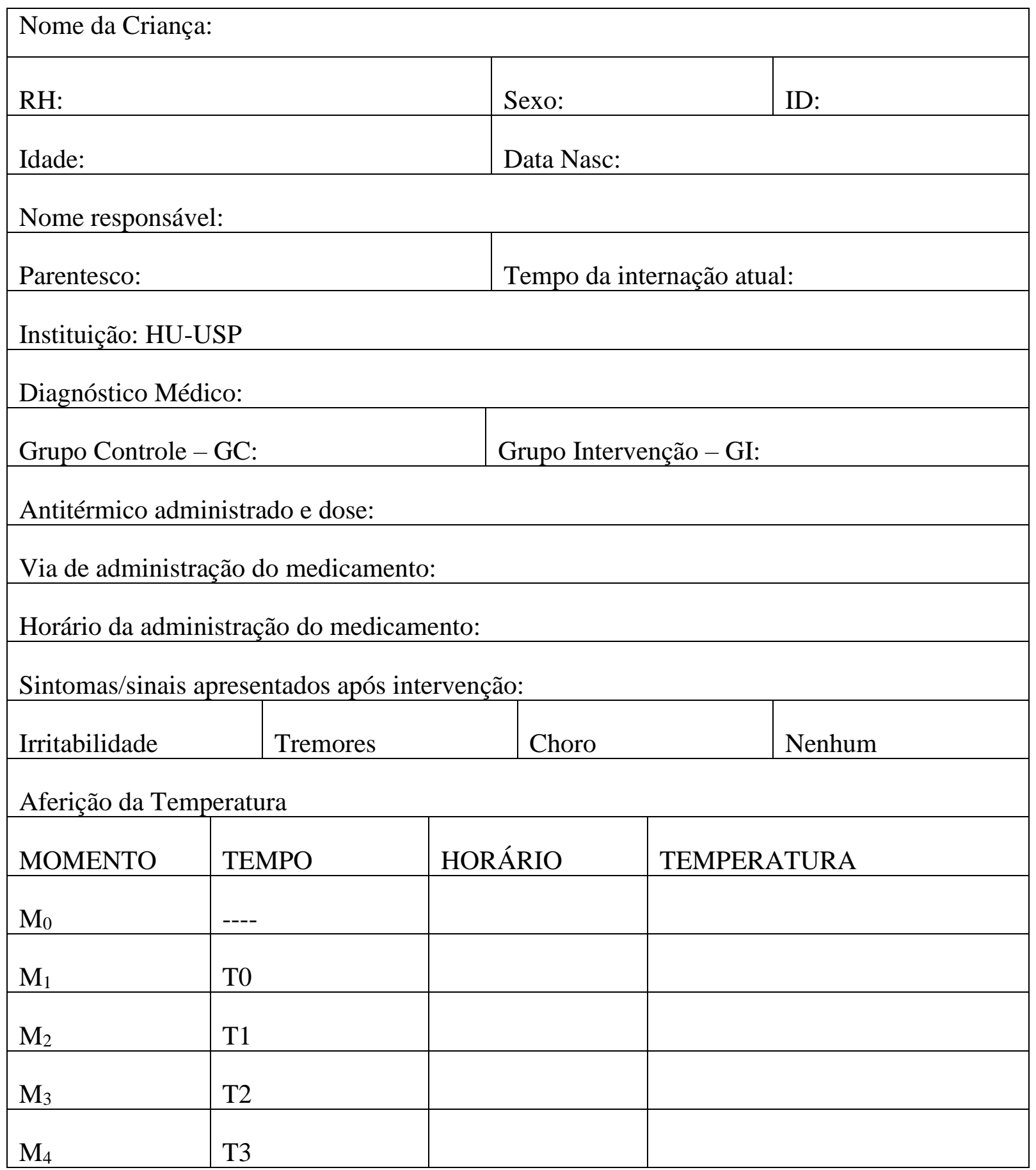

Legenda:

ID: Número de identificação do participante na pesquisa

RG: Registro hospitalar

Medicação: D - Dipirona; P- Paracetamol; I - Ibuprofeno

Via de administração: VO - Via oral; VE: Via enteral; EV: Via endovenosa

Hospital Universitário da USP: HU-USP 


\section{APÊNDICE E}

\section{MANUAL DO COLETADOR}

O estudo será realizado no Hospital Universitário da USP - HU-USP. O HU-USP é um hospital universitário, de atenção secundária, que integra o Sistema Único de Saúde (SUS).

As áreas envolvidas na pesquisa serão o Pronto Socorro Infantil, Unidade de Internação Pediátrica e Unidade de Terapia Intensiva Pediátrica.

\section{CARACTERIZAÇÃO DO ESTUDO}

O objetivo da pesquisa será avaliar o efeito da aplicação da medida não farmacológica "compressa morna", em associação ao antitérmico prescrito, na redução de febre em crianças hospitalizadas. Os participantes serão alocados em dois grupos conforme randomização: Grupo controle: a criança receberá apenas o medicamento antitérmico; Grupo Intervenção: a criança receberá o medicamento antitérmico associado à aplicação das compressas mornas.

\section{CRITÉRIOS DE ELEGIBILIDADE}

Serão incluídas no estudo crianças de 1 mês a 11 anos, 11 meses e 29 dias, que atendam aos seguintes critérios:

- Temperatura axilar $\geq 37,8^{\circ} \mathrm{C}$;

- Intervalo entre a administração do antitérmico e o início da aplicação do tratamento, aplicação de compressas mornas, de até 10 minutos;

- Permissão dos pais ou responsáveis e aceite para participarem do estudo.

Além desses critérios, também será permitida a inclusão do mesmo paciente com intervalo de $12 \mathrm{~h}$ da última inclusão no estudo e não estar sob efeito de antitérmico, sendo necessário ter um intervalo mínimo de 6 horas do último antitérmico. 


\section{CRITÉRIOS DE EXCLUSÃO}

Estabeleceram-se como critérios de exclusão: crianças com o diagnóstico de hipertermia maligna, disfunção neurológica; crianças a serem submetidas a algum procedimento durante o período de até 3 horas após administração do antitérmico.

\section{ETAPAS DA COLETA DE DADOS}

As crianças que apresentarem temperatura axilar igual ou superior a 37,8C, conforme os critérios de inclusão, serão inseridas na pesquisa.

Ao iniciar a coleta de dados, a coletadora irá abrir o envelope correspondente ao número de participação da criança, a numeração estará indicada na parte superior externa do envelope. Após a abertura do mesmo, a coletadora saberá o grupo em que a criança estará alocada, conforme a identificação do termo de consentimento (grupo de intervenção ou grupo controle). Dentro desse envelope, deverá conter duas vias do Termo de Consentimento Livre e Esclarecido (uma via será entregue para o responsável pela criança, a outra ficará guardada junto com os demais dados coletados para posterior entrega à pesquisadora) e o instrumento de coleta de dados.

\section{TERMO DE CONSENTIMENTO LIVRE E ESCLARECIDO}

O termo será aplicado pelo coletador ao responsável pela criança. Antes de inseri-la no estudo, o coletador deverá fazer a leitura de forma clara e objetiva e irá esclarecer possíveis dúvidas do responsável pelo preenchimento.

\section{TERMO DE ASSENTIMENTO}

Será aplicado à criança participante, desde que tenha idade superior a 7 anos, ou que compreenda o conteúdo do termo. 


\section{OPERACIONALIZAÇÃO DA PESQUISA}

A criança e sua mãe ou responsável serão convidados a participar do estudo, conforme a randomização realizada, sendo explicados os procedimentos a serem realizados. Os dados serão coletados por meio da aplicação do instrumento (APÊNDICE D) que se refere aos dados sociodemográficos das crianças do estudo.

A operacionalização do estudo irá ocorrer da seguinte forma:

Grupo Controle (GC): a criança receberá a terapia medicamentosa. A aferição da temperatura ocorrerá nos seguintes momentos: $\mathrm{M}_{0^{-}}$diagnóstico da febre pelo funcionário do hospital. $\mathrm{M}_{1}-$ Confirmação da febre pelo coletador com o termômetro digital padronizado, inserção da criança no estudo segundo os critérios de inclusão e administração do antitérmico prescrito pelo médico, $\mathbf{M}_{2}$ - verificação da temperatura da criança 30 minutos após administração do antitérmico, $\mathrm{M}_{3}$ - verificação da temperatura da criança 60 minutos após antitérmico e $\mathrm{M}_{4}$ - verificação da temperatura da criança 3 h após administração do antitérmico.

Grupo Intervenção (GI): a criança receberá a terapia medicamentosa e em até 10 minutos, após administração do antitérmico, será aplicada a intervenção compressa morna por 15 minutos nas regiões frontal, axilar e inguinal, a seguir terá seu corpo seco. A aferição da temperatura ocorrerá nos seguintes momentos: $\mathrm{M}_{0}$ - diagnóstico da febre pelo funcionário do hospital. $\mathbf{M}_{1}$ - Confirmação da febre pelo coletador com o termômetro digital, inserção da criança no estudo segundo os critérios de inclusão, administração do antitérmico prescrito pelo médico e aplicação de compressas mornas nas regiões frontal, axilar e inguinal por 15 minutos, $\mathbf{M}_{2}$ - verificação da temperatura da criança 30 minutos após administração do antitérmico, $\mathrm{M}_{3}$ - verificação da temperatura da criança 60 minutos após antitérmico e $\mathrm{M}_{4}-$ verificação da temperatura da criança 3 h após administração do antitérmico. 
Quadro explicativo: Tempos de aferição da temperatura corporal e sequência da intervenção.

São Paulo, 2020.

\begin{tabular}{|c|c|c|c|}
\hline$M^{|c|}$ Ações & Ator & Tempo \\
\hline$M_{0}$ & Diagnóstico de febre com termômetro digital & Funcionário & \\
\hline$M_{1}$ & $\begin{array}{l}\text { Confirmação da febre com aferição da } \\
\text { temperatura com termômetro digital padronizado }\end{array}$ & \\
\hline $\begin{array}{l}\text { Administração de antitérmico segundo } \\
\text { prescrição médica } \\
\text { Início das compressas mornas em fronte, axilas e } \\
\text { região inguinal na criança do GI }\end{array}$ & Coletador & Tempo 0 \\
\hline$M_{2}$ & Verificação da temperatura com termômetro & Coletador & $\begin{array}{c}\text { Tempo 1 } \\
30 \text { min após } \\
\text { Tempo 0 }\end{array}$ \\
\hline$M_{3}$ & Verificação da temperatura com termômetro & Coletador & $\begin{array}{c}\text { Tempo 2 } \\
60 \text { min após } \\
\text { Tempo 0 }\end{array}$ \\
\hline$M_{4}$ & Verificação da temperatura com termômetro & Coletador & $\begin{array}{c}\text { Tempo 3 } \\
\text { Temós }\end{array}$ \\
\hline
\end{tabular}

Fonte: Dados do estudo 
INSTRUMENTO DE COLETA DE DADOS

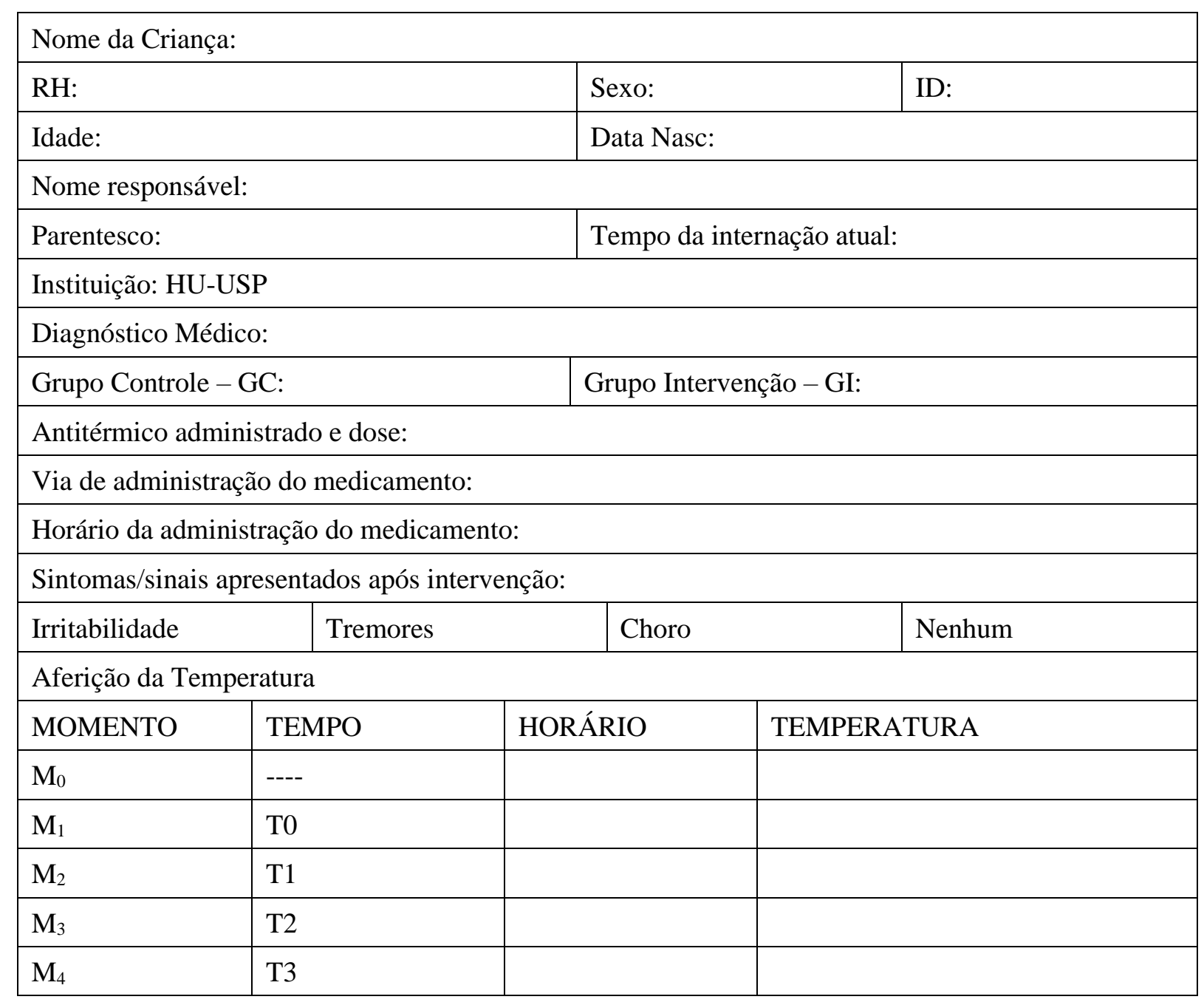

Legenda:

ID: Número de identificação do participante na pesquisa RG: Registro hospitalar

Medicação: D - Dipirona; P- Paracetamol; I - Ibuprofeno

Via de administração: VO - Via oral; VE: Via enteral; EV: Via endovenosa

Hospital Universitário da USP: HU-USP 


\section{APÊNDICE F \\ GUIA RÁPIDO PARA COLETA DE DADOS}

\section{Critérios de inclusão}

- Pacientes com idade de 1 mês a 11 anos, 11 meses e 29 dias

- Temperatura axilar superior a $37,8^{\circ} \mathrm{C}$

- Intervalo entre administração de antitérmico e o início da aplicação das compressas mornas de até 10 minutos

OBS: o mesmo paciente poderá ser reinserido no estudo, conforme os seguintes critérios: após $12 \mathrm{~h}$ da última inclusão no estudo e não estar sob efeito de antitérmico, necessário ter um intervalo mínimo de 6 horas do último antitérmico.

\section{Critérios de exclusão}

- Pacientes com diagnóstico de hipertermia maligna

- Disfunção neurológica

- Pacientes a serem submetidos a algum procedimento durante o período de até 3 horas após administração do antitérmico

Tempos para aferição da temperatura

\begin{tabular}{|l|c|l|l|}
\hline $\mathbf{1}^{\text {a }}$ Temperatura & ---- & $\begin{array}{l}\text { Verificada pelo funcionário do } \\
\text { hospital que está responsável pela } \\
\text { assistência de enfermagem }\end{array}$ & Termômetro digital \\
\hline $\mathbf{2}^{\mathbf{a}}$ Temperatura & T0 & $\begin{array}{l}\text { Aferida antes do antitérmico pelo } \\
\text { coletador }\end{array}$ & Termômetro digital \\
\hline $\mathbf{3}^{\mathbf{a}}$ Temperatura & T1 & $\begin{array}{l}\text { Aferida } 30 \text { minutos após } \\
\text { antitérmico }\end{array}$ & Termômetro digital \\
\hline $\mathbf{4}^{\text {a }}$ Temperatura & T2 & Aferida 1 hora após antitérmico & Termômetro digital \\
\hline $\mathbf{5}^{\text {a }}$ Temperatura & T3 & Aferida 3 horas após antitérmico & Termômetro digital \\
\hline
\end{tabular}

\section{Intervenção}

\begin{tabular}{|l|l|}
\hline Temperatura da água & $34-37^{\circ} \mathrm{C}$ \\
\hline Locais de aplicação da compressa & axilar (2), frontal (1), inguinal (2) \\
\hline Tempo da aplicação da compressa & 15 minutos \\
\hline
\end{tabular}




\section{APÊNDICE G}

Protocolo de febre

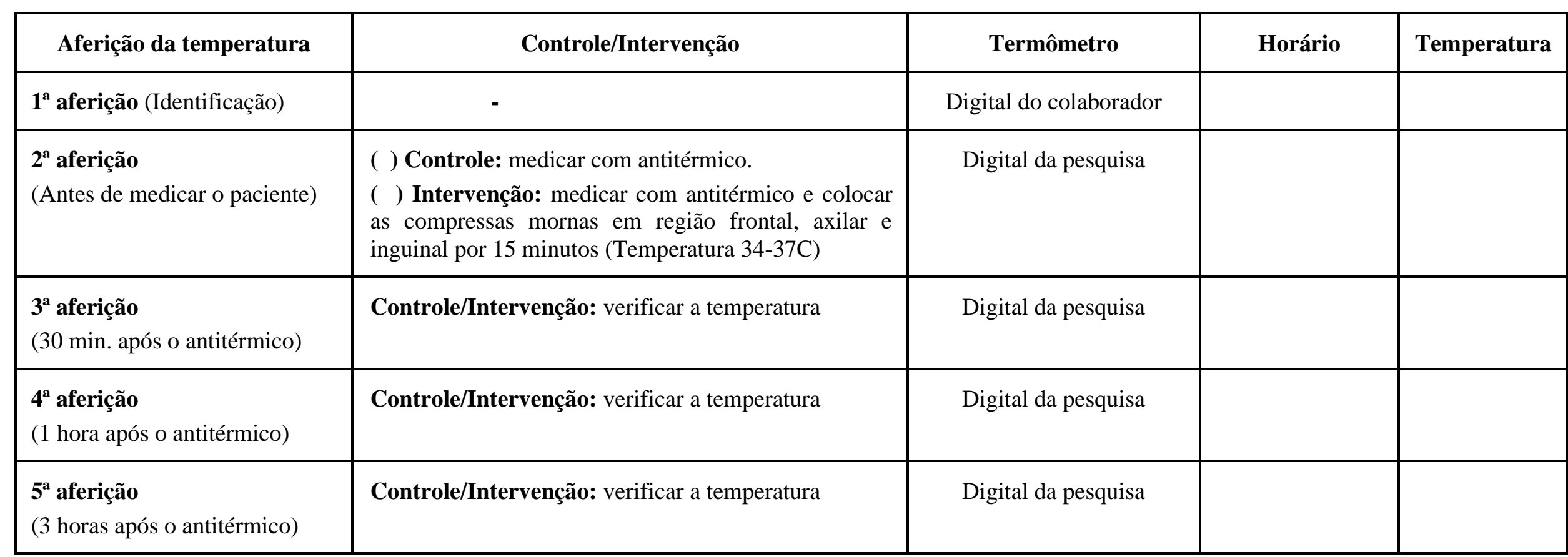



ANEXOS 

ANEXO 1

\section{APROVAÇÃO DO COMITÊ DE ÉTICA DA ESCOLA DE ENFERMAGEM DA UNIVERSIDADE DE SÃO PAULO}

\begin{tabular}{|c|c|c|c|} 
USP - ESCOLA DE \\
ENFERMAGEM DA \\
UNIVERSIDADE DE SÄO
\end{tabular} Ploboformo

\section{DACOI DO PROJETO DE PE BGUILA}

Thtule da Potgusta: O manejo nâs farmacoboke de crancas kbris: Ensab Cinoo Randomzads

Pasquicader: MHRWNA WEIRA DE SOLZA

Ares Tenstios:

Vertace 3

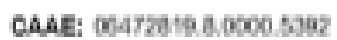

Inctituipgo Propononta: Escola de Erlemagnm da Uninersidade de Sas Paib - EEUSP

Patrooinsdor Prinolost: Financiamento Proprio

\section{DACOS DO PARECER}

\section{Namero de Pareor: 3.301 .460}

\section{Apresentepaso do Projeto:}

Tratase de projoto sotre o manepo nbo tarmacologice de cranças febrs e releve se a um Mestrada. Ensaio

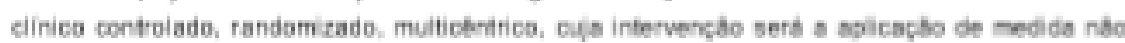
formscolbica, qual seja, compressos momas, associsda s adrinstraçbo de medicamerts anttemico

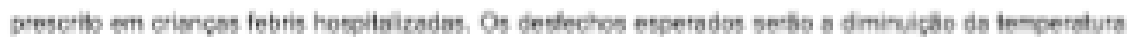

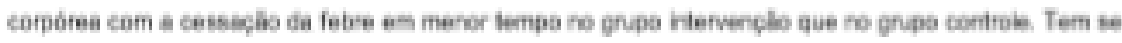
coms hipotese do estudx a medich nas farmecobgice "comeressa mome" em associeça com artilemice

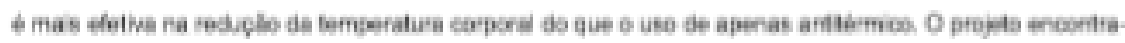

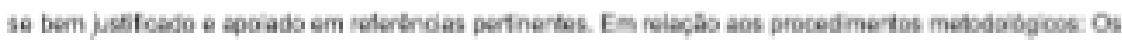
dados serio coletados em unilades pediericas de 2 hosplais em Saso Pais e um hosptal em Tabale. As

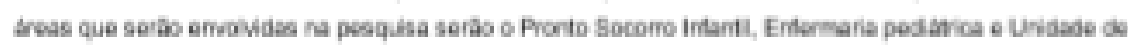
Terapia intensiva Pediatrca. A amostra sera constituda por 28 pacentes, sendo 96 crianças em cada instifuicalo. Serbo incluidas no estudo criancas de 1 mes a 12 anos compietos, que aptesentarem

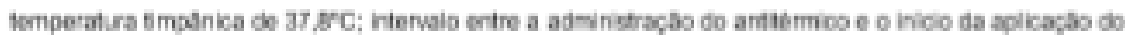
tratsmenta por meio da apicacho de compressas mornas, de ate 10 minitos; e que tretem a sermissbo dos pais ou responsaveis pars a paticipscaso no estudo. Tambe- serb sermida a inclusbo do mesmo

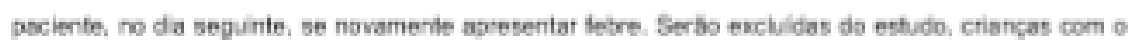
dagnostics de hipertermia maigne: disfunçầ

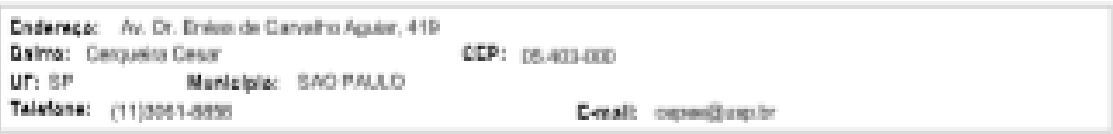




USP - ESCOLA DE
ENFERMAGEM DA
UNIVERSIDADE DE SÃO

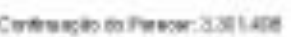

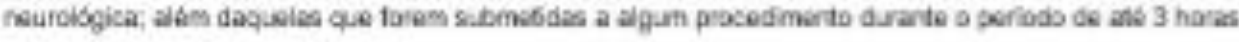
apose administrachio do antiermico.

Os pacientes serfo abatorizadas em 2 grupos: 144 ibo receber a medisements anstérmios (anpo Controle) e 144 ifa receber o medicamento articrmics associado a medida nSo famsoolboica compressa moma (Grupo Imiervercbo). A temperatura bincâvica sera mensurada en quatro monortos durarte 3 haras. O desonho do estudo preve um Grupo Controle [GCF) neste, a crianca reoubera a ferapa modicaserdcsa e

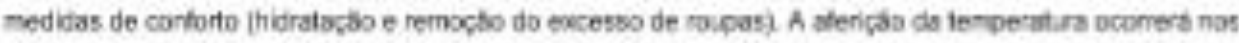

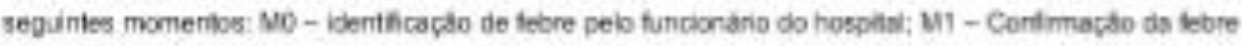
pelo pesquissdior com o fermb-vetro timpanico, inserçäo da criança no estudo segundo os crabcios de

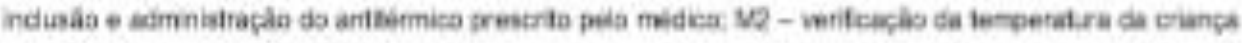

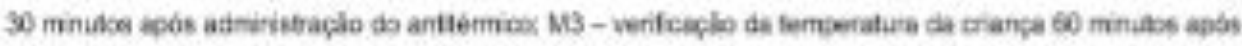

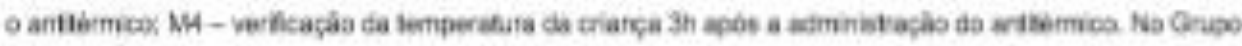

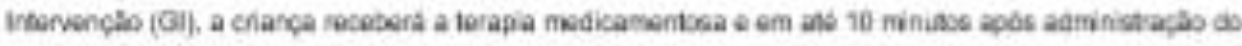

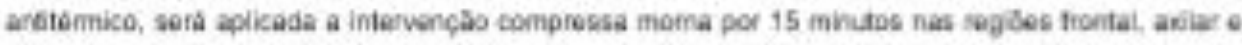

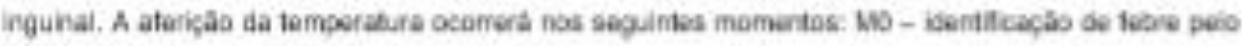

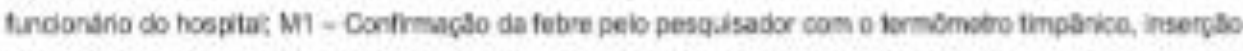

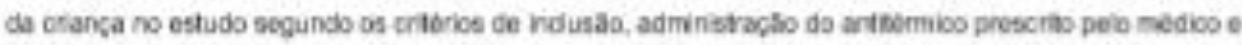

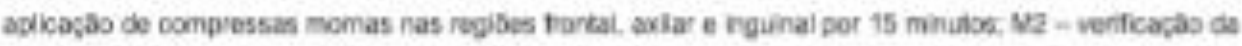

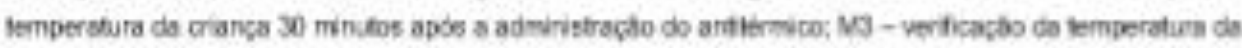

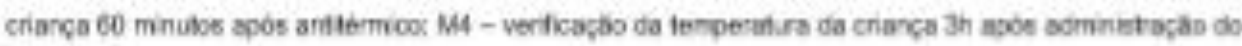
artiliermico.

A randernzacto sera reslesida antes do hido da cokets de dados, por meis do sthe

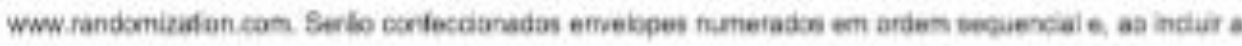

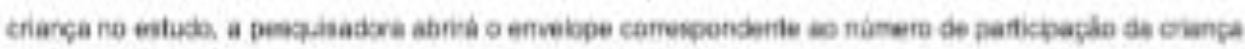

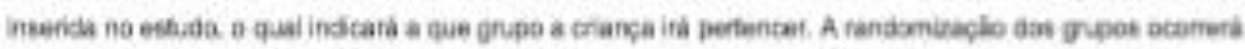

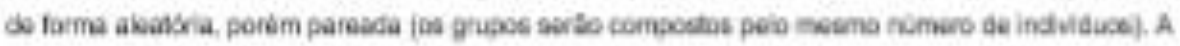

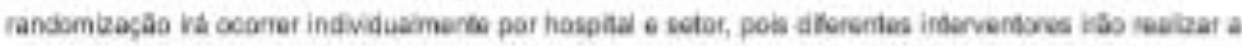

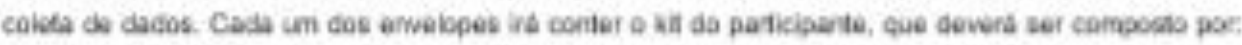
instrumento parscolcta de dados, 1 TCLE em cuas vas e 1 Terno se assentmeras em duas vias. 0 Instrumento condom dados de identifcasalo da crianca e sobre o vaior da

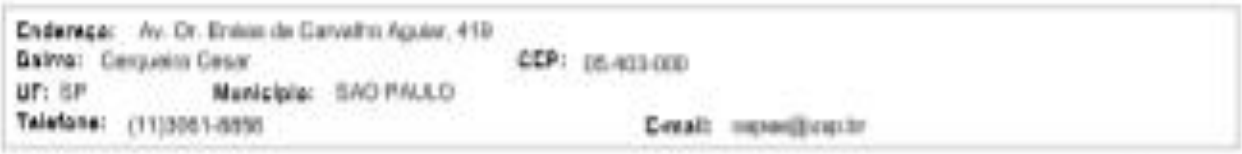




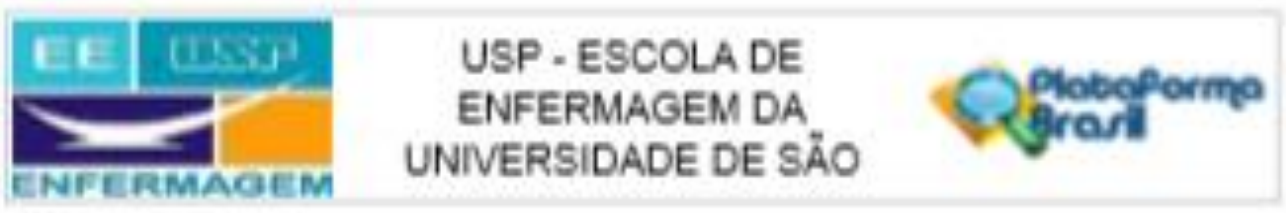

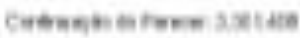

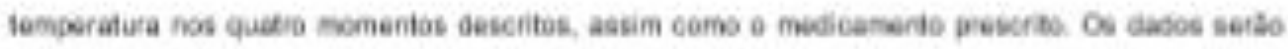

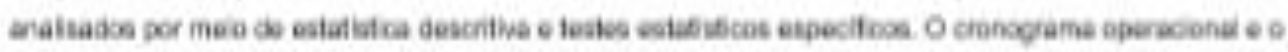

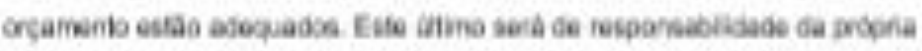

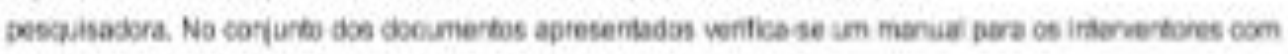
o intais de atbur fiseicade a irtervenças, que parece ascousob.

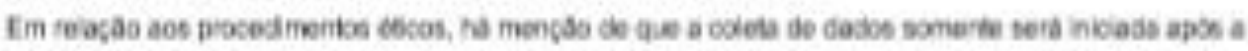

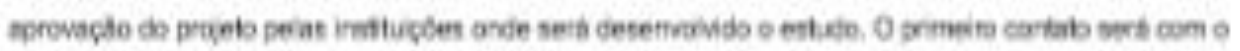

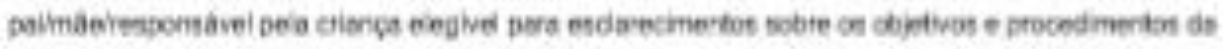

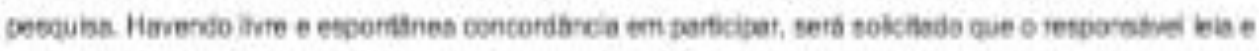

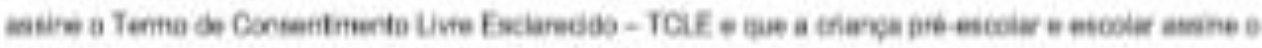
Tamo de Aseritmeris para Partepar de Pesquse Cientifca - TAPPC

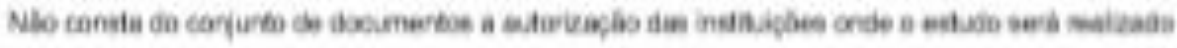

\section{Objettro as Pasquice:}

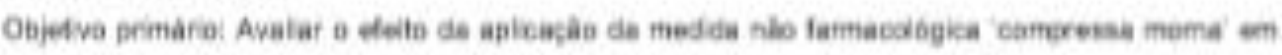

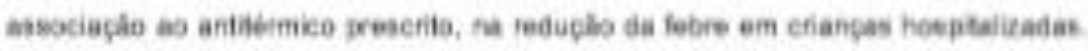

Otentwe secindarios.

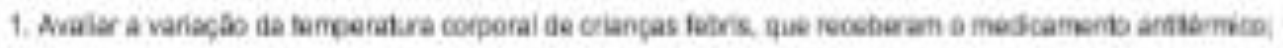

2. Avalar a varlap̧o de femperatua copora de criencas febria, que receberas o medcanenb antiemino

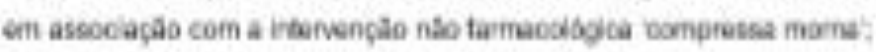

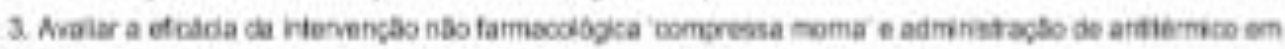
criargas fobre on comparaça com aquelas que recoberam somente o areiterwico.

\section{Avalle;ac doc Fisoot a Bechatoloc:}

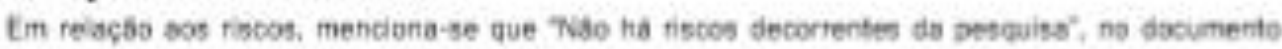

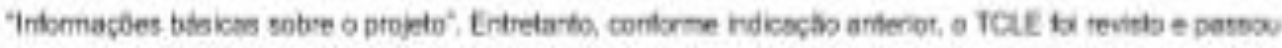

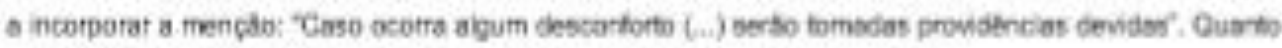

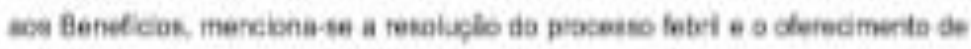

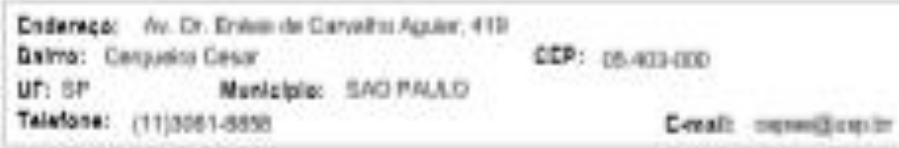




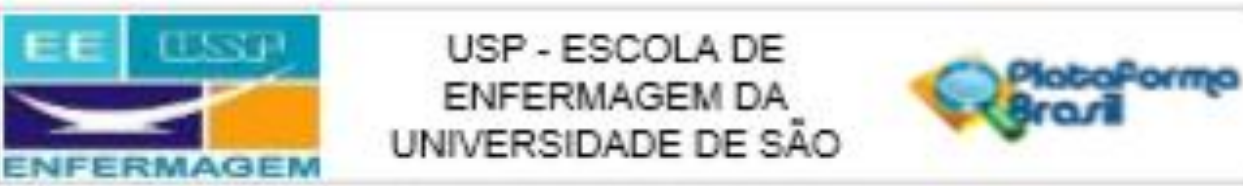

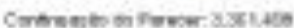

conforto a crianga, alkm da estateiecimento do mehor euidaco a ser cferecias a criences en vigencis de Istire.

\section{Comsnterioc e Concldseragoc cobre a Pecculcs:}

o estudo tem potoncial para coniribur para o culdado do Enflermagem, as avaliar a aplicaslo de una tecnologia simpliticada, qual seja a aplicapa de compvessas momas na presonga de quadros febre.

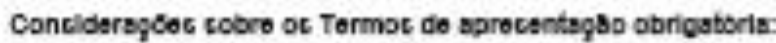

- TCLE; lodas as indicasoes eroilids em parecer anterior foram acatadas, apresentandose, portanto, sobquado. Tambem apresentase na versiso especifca as Gupo Controie $e$ ao Gnupo intenvencalo.

\section{Recomondapose:}

Niso his recomendacbes.

\section{Conolucdec ou Pandbinelac e Licts de inadequepeec.}

MSo aprescrita cbiocs eticos.

\section{Concldarspoec Finaic a oritario do CEP:}

Este CEP informa a necessidade de rogstro dos resultados parciais efrais na Piatulorma Erasl. Enta

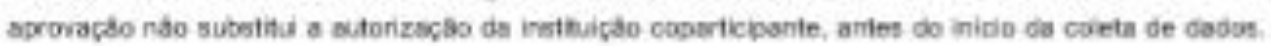

Ecto pareose fol elabcrsdo bscesdo not dooumentog sbeixo roissicnadoe:

\begin{tabular}{|c|c|c|c|c|}
\hline Tpo Documents & Anowno & Potadasm & Aiter & seach \\
\hline 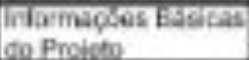 & 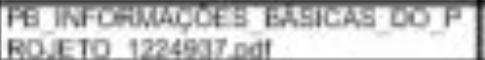 & 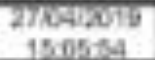 & & RED \\
\hline 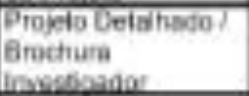 & Projeto Mariena Veite de Soies doct & 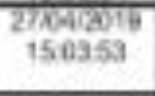 & 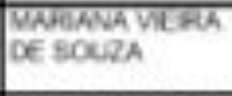 & Rowis \\
\hline Cronagoma & 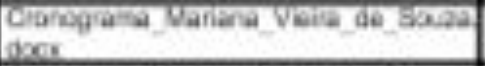 & $\begin{array}{c}2704 \times 2015 \\
1451842\end{array}$ & 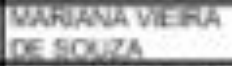 & Ratis \\
\hline Orgamenio & 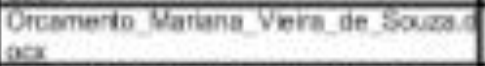 & $\begin{array}{c}27020019 \\
172949\end{array}$ & 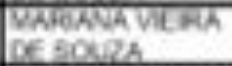 & Rcents \\
\hline $\begin{array}{l}\text { TCLET Temos de } \\
\text { hesenimenthy }\end{array}$ & TCIE Martera Vera de sama doct & $\begin{array}{c}27002019 \\
1730 \mathrm{ces}\end{array}$ & 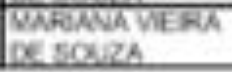 & Acent \\
\hline
\end{tabular}

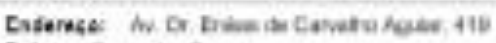

Duima: Cespusu Cespr

CEP: ie tabarn

uri er

Menictales savo puse

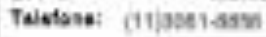

Cesil: asmontawa 


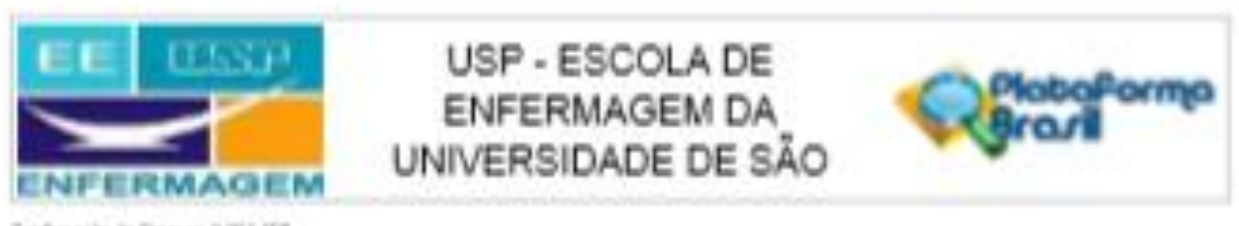

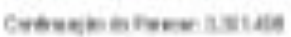

\begin{tabular}{|c|c|c|c|c|}
\hline 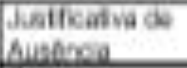 & 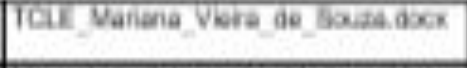 & 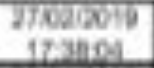 & 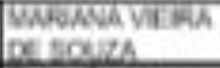 & Nota \\
\hline Othes & 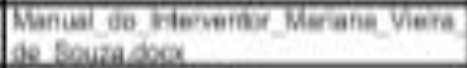 & 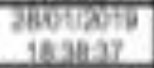 & 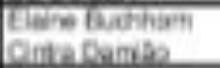 & No6 \\
\hline Toneterosto & fora de Toetoses & $\begin{array}{c}270018019 \\
12.8727\end{array}$ & 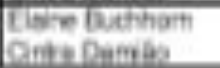 & Actis \\
\hline
\end{tabular}

\section{aituspac de Parsoer:}

Aorovedo

Notascits Apresispas do CONEP:

Nas

BAO PALito, co de Mea en zoto

Astinsde por:

Merols Apsredide Forreira de Olveirs

(Cobramedorial|)

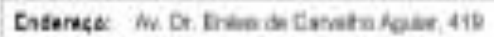

Doimo: Cenueva Cesor

CtP; ts amasin

ur: sr

Maritble: sho ruto

Tainose: c1130s1asso

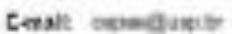




\section{APROVAÇÃO DO COMITÊ DE ÉTICA DO HOSPITAL UNIVERSITÁRIO DA UNIVERSIDADE DE SÃO PAULO}

USP - HOSPITAL
UNIVERSITARIO DA
UNIVERSIDADE DE SÄO
PAULO - HUIUSP

\section{PARECER CON SUBSTANCIADO DO CEP}

Eisberado pels intituipse Copartisipanto

\section{DAOOI DO PAOJETO DE PE BQUIIA}

Thite da Potqusta: O manejo nas farmsodbgico de criances Sebris: Ensaio Cinoo Randomizads

Pasquicador: MARMNA VEIRA DE SOLZA

Ares Tomatios:

Vertse: 1

CAAE: 06478 19.8.3001.0076

Intituipso Proponnta: Hosptal Uneverstario de Uniwersicade de Saso Paulo

Patrooinador Prinolost: Financismerto Probrici

\section{DADOB DO PARECEA}

Namero do Pareoer: 3.604 .872

\section{Apresentspaso do Projeto:}

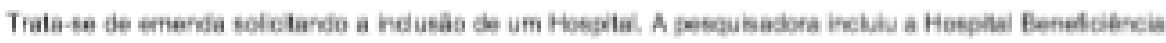
Portuguese

\section{Objettro de Pasquice:}

Stem alkeraço no dosenhe da pescuiba.

Avalispase doc Fisoot o Bensholoc:

NSo howe a toraça nem dos riacos nem do beneficio com a emenda solchlasa.

\section{Comentseloc o Conelderaposes cobre o Petquils:}

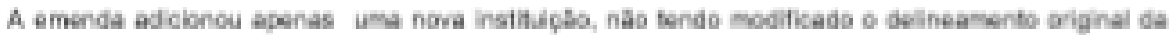
pesquisa.

Coneldarspees tobes ot Termot de sprecentapso obrigatoris:

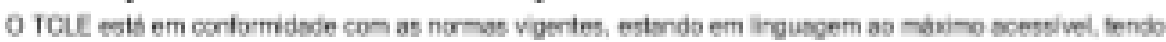
em vista o tersa.

\section{Reocmendapoes:}

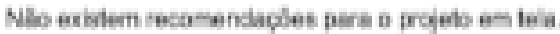

\section{Conolutces ou Pendbnolac o Licta de Inadequspeec:}

Nlo bram encontradas nes pensencias bu inesecuactes necke provets

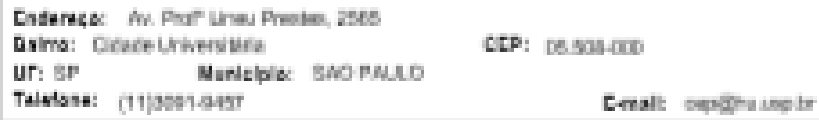




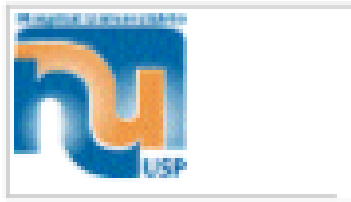

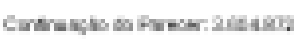

\section{USF - HOSPITAL UNIVERSITARIO DA UNIVERSIDADE DE SĀO PAULO - HUNSP}

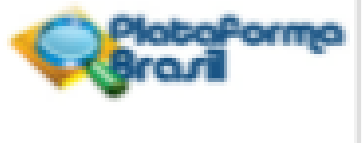

Conchdars,doc Finals a or:Ho do CEF:

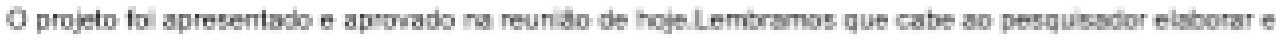

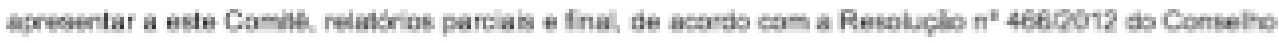

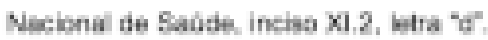

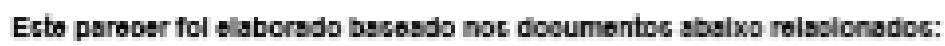

\begin{tabular}{|c|c|c|c|c|}
\hline Tpa Deximata & คำमบั & Fostapurit & Aulur & Entrins \\
\hline Oitros & Toha de rosto_bopatiopante_LPpdi & 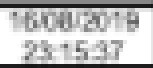 & $\begin{array}{l}\text { WALANA VLAA } \\
\text { CF BOUPA }\end{array}$ & Arets \\
\hline Dinus & Dommantos EP.mi & 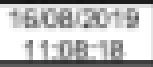 & $\begin{array}{l}\text { MARIAWA VERA } \\
\text { DESTIZS }\end{array}$ & Antils \\
\hline Othes & Tombia_Pandi_GP pal & 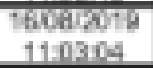 & $\begin{array}{l}\text { WAFAUA VIFA } \\
\text { DE BOMPE }\end{array}$ & Acala \\
\hline 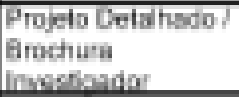 & 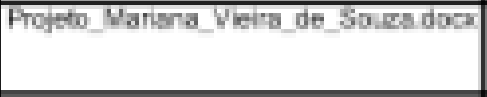 & 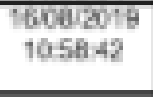 & $\begin{array}{l}\text { WALAWA VLAH } \\
\text { DF SOUPA }\end{array}$ & Anet5 \\
\hline 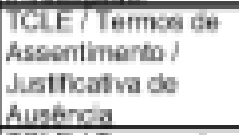 & 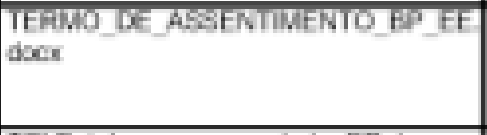 & 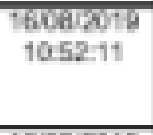 & 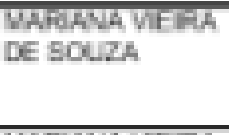 & Aats \\
\hline 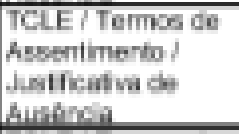 & 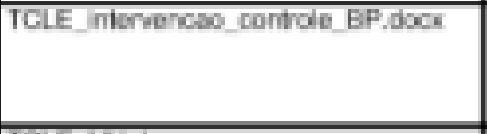 & 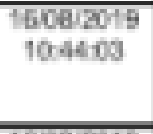 & $\begin{array}{l}\text { WHFIMU WERA } \\
\text { DL SOULA. }\end{array}$ & Motis \\
\hline 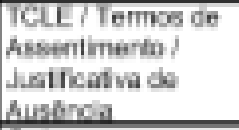 & TELE PAdTER & 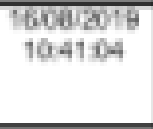 & 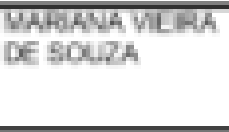 & Acois \\
\hline Othes & 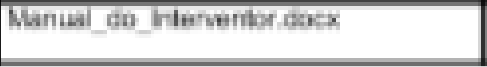 & 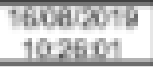 & 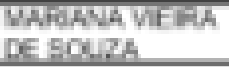 & Anata \\
\hline
\end{tabular}

Bituegdo da Fareasr:

Howein

Hocaget. Apredagdo da CDNEF:

Has

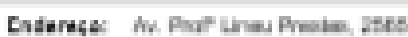

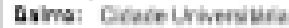

CEF) IS MHAT

UF: Heriple dimoryo

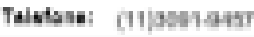

Evalt mancus 


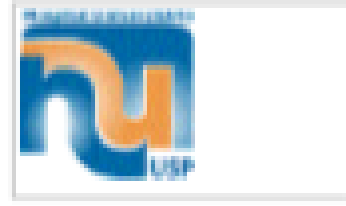

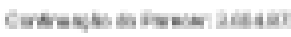

\section{USP - HOSPITAL UNIVERSITARIO DA UNIVERSIDADE DE SÄO PAULO - HU/USP}

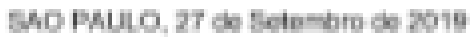

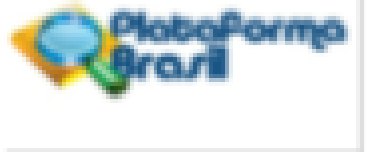

Maurialo Inotin

[Coondnsdoriai|

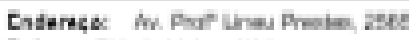

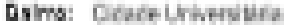

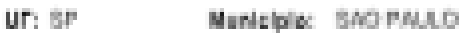

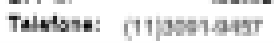

CEF: DEBSHD

Canal: mporiug 